Illinois State University

ISU ReD: Research and eData

Theses and Dissertations

$10-6-2021$

\title{
Factors Associated With Parent Involvement for African American Youth With Intellectual and Developmental Disabilities: Findings From the NLTS-2012
}

LaTonya J. Harris

Illinois State University, tonyaoes@msn.com

Follow this and additional works at: https://ir.library.illinoisstate.edu/etd

\section{Recommended Citation}

Harris, LaTonya J., "Factors Associated With Parent Involvement for African American Youth With Intellectual and Developmental Disabilities: Findings From the NLTS-2012" (2021). Theses and Dissertations. 1489.

https://ir.library.illinoisstate.edu/etd/1489

This Dissertation is brought to you for free and open access by ISU ReD: Research and eData. It has been accepted for inclusion in Theses and Dissertations by an authorized administrator of ISU ReD: Research and eData. For more information, please contact ISUReD@ilstu.edu. 


\section{FACTORS ASSOCIATED WITH PARENT INVOLVEMENT FOR AFRICAN AMERICAN YOUTH WITH INTELLECTUAL AND DEVELOPMENTAL DISABILITIES:}

FINDINGS FROM THE NLTS-2012

\section{LATONYA J. HARRIS}

\section{Pages}

This study used a correlational design to explore the association between parent demographics, parent experiences, parent expectations, and parent involvement for families supporting African American youth with IDD. Chi-square statistical analyses were used to determine the associations between parent involvement and factors related to post-school planning. Associations were found between parent involvement and parent demographics, parent and youth experiences with professionals, and parent expectations for postschool adulthood. The findings of this study provide opportunities for professionals and other stakeholders to intentionally develop actionable goals and objectives aimed at redefining parental involvement through a culturally responsive lens that positions parents as a resource, creates systems built on partnerships, and promotes feelings of inclusiveness for families supporting youths of color with IDD. Recommendations for research and practice are described to assist stakeholders with improving parent involvement.

KEYWORDS: African American, Chi-square, Intellectual and Developmental Disabilities, Parent Involvement, Secondary Transition Planning 
FACTORS ASSOCIATED WITH PARENT INVOLVEMENT FOR AFRICAN AMERICAN YOUTH WITH INTELLECTUAL AND DEVELOPMENTAL DISABILITIES:

FINDINGS FROM THE NLTS-2012

LATONYA J. HARRIS

A Dissertation Submitted in Partial

Fulfillment of the Requirements

for the Degree of

DOCTOR OF EDUCATION

Department of Special Education

ILLINOIS STATE UNIVERSITY

2021 
Copyright 2021 LaTonya J. Harris 
FACTORS ASSOCIATED WITH PARENT INVOLVEMENT FOR AFRICAN AMERICAN YOUTH WITH INTELLECTUAL AND DEVELOPMENTAL DISABILITIES:

FINDINGS FROM THE NLTS-2012

LATONYA J. HARRIS

COMMITTEE MEMBERS:

Debbie Shelden, Chair

Kim W. Fisher

Melinda R. Snodgrass 


\section{ACKNOWLEDGMENTS}

In 2008, I was tasked by my pastor to petition God for what he had purposed from my life. In this assignment, we were to write down the goals that would lead us to our purpose. One of my goals was to become Dr. L. J. Harris. Tucking this away in my bible, a colleague came to me years later with an opportunity to pursue this goal. After many refusals to begin this journey, my colleague finally persuaded me to apply to the doctoral program.

Along the way, I built the required village to complete this mission! First, to my wonderful committee, thank you for your brilliant answers to all my questions, and I had a lot of them. Specifically, to Dr. Debbie Shelden for wiping my tears, both virtually and in-person, over the years. Your constant counsel, patience, and guidance was always present at the right time to keep me headed toward the finish line. Melinda and Kim, thank you for joining my team and loving me through all the changes, updates, and processes to get me to the end. To the professors at Illinois State University, I appreciate each of your deposits through the doctoral program.

A special thanks to my circle, Jennifer, Candice, Nicola, Felicia, Tasha, Paula, Pam, and Stacey for all the phone calls, text messages, and words of encouragement throughout this entire journey. Each of you have prayed over me, cried with me through this journey, and lent me strength to persevere. My Stephen K., thank you friend for showing up EVERYTIME. You, my friend, are one of a kind, and I am truly honored to have you in my life.

To my amazing family, thank you for your sacrifices over the past five years to allow me to complete this mission. My parents and parent-in-loves, thank you for the continued encouragement and support throughout this process. Trinity and Faith, you are mommy's heartbeat and I love you both so much. Sean, my love, thank you for your love and support, 
holding me at night when I cried myself to sleep, loving me when I wanted to quit, loving me when I was grouchy from exhaustion, pushing me to finish what I started, and holding down the family when I needed to focus on this task. You are my hero both on and off the battlefield and I am so blessed to be called your wife.

Finally, I dedicate this dissertation to the memory of my grandmother, Mrs. Ora Lee Washington. Growing up, she deposited the spirit of perseverance, strength, purpose, and repurpose. While she is no longer here with us, I hear her words so clear, "you keep going, and don't you let nobody tell you what you cain't do!"

Momma, this achievement is for you! I love you always. 


\section{CONTENTS}

\section{Page}

ACKNOWLEDGMENTS

TABLES

viii

FIGURES

$\mathrm{X}$

CHAPTER I: INTRODUCTION 1

Background 1

Statement of The Problem $\quad 3$

Overview of Parent Involvement in Secondary Transition 4

Legal Mandates $\quad 5$

$\begin{array}{ll}\text { The Taxonomy for Transition Programming } & 7\end{array}$

Parent Involvement as a Postschool Predictor $\quad 8$

$\begin{array}{ll}\text { Researcher's Positionality } & 10\end{array}$

Frameworks for Parent Involvement $\quad 11$

Epstein's Six Types of Involvement Framework 12

Gerzel-Short's Family Engagement Framework 13

$\begin{array}{ll}\text { Purpose of the Study and Research Questions } & 15\end{array}$

$\begin{array}{ll}\text { Significance of Study } & 16\end{array}$

$\begin{array}{ll}\text { Definition of Terms } & 17\end{array}$

CHAPTER II: LITERATURE REVIEW 19

Parental Perspective on Involvement $\quad 19$

$\begin{array}{ll}\text { Search Procedures } & 19\end{array}$ 
$\begin{array}{ll}\text { Participant Demographics } & 21\end{array}$

$\begin{array}{ll}\text { Parent Perspective Analysis } & 22\end{array}$

$\begin{array}{ll}\text { Parent Actions } & 26\end{array}$

$\begin{array}{ll}\text { Accessing Services } & 26\end{array}$

$\begin{array}{ll}\text { Networking } & 27\end{array}$

$\begin{array}{ll}\text { Advocacy } & 28\end{array}$

$\begin{array}{ll}\text { Student Agency } & 30\end{array}$

Parent Experiences with Professionals $\quad 31$

Professional Engagement: Collaboration 31

$\begin{array}{ll}\text { Professional Knowledge } & 32\end{array}$

$\begin{array}{ll}\text { Training } & 33\end{array}$

$\begin{array}{ll}\text { Discussion } & 34\end{array}$

Parent Involvement in National Longitudinal Transition Studies 37

$\begin{array}{ll}\text { NLTS-2 Overview } & 37\end{array}$

$\begin{array}{ll}\text { NLTS-2 Reports } & 38\end{array}$

NLTS-2 Secondary Analyses $\quad 39$

NLTS 2012 Overview $\quad 40$

NLTS 2012 Secondary Analyses $\quad 41$

$\begin{array}{ll}\text { Summary } & 42\end{array}$

CHAPTER III: METHOD

$\begin{array}{ll}\text { Research Design } & 43\end{array}$ 
$\begin{array}{ll}\text { Data Collection } & 44\end{array}$

$\begin{array}{ll}\text { Data Collection Procedures } & 44\end{array}$

$\begin{array}{ll}\text { Parent Survey } & 44\end{array}$

$\begin{array}{ll}\text { Variables } & 45\end{array}$

Independent Variables $\quad 46$

Parent Supporting Youth with IDD Demographics $\quad 47$

$\begin{array}{ll}\text { Parent Experiences } & 48\end{array}$

Parent Expectations $\quad 49$

Dependent Variables

Parent Involvement at Home

Parent Involvement at School $\quad 52$

$\begin{array}{ll}\text { Population } & 53\end{array}$

$\begin{array}{ll}\text { Data Analysis } & 54\end{array}$

$\begin{array}{ll}\text { Data Preparation } & 56\end{array}$

New Variable $\quad 56$

$\begin{array}{ll}\text { Recoding } & 57\end{array}$

CHAPTER IV: RESULTS

Report on Parent Involvement at Home and School $\quad 62$

Parent Involvement at Home $\quad 62$

Parent Involvement at School 63

$\begin{array}{ll}\text { Chi-Square Analyses } & 64\end{array}$

Parent Demographics and Parent Involvement $\quad 64$ 
Homework Assistance 64

$\begin{array}{ll}\text { School Discussion } & 65\end{array}$

$\begin{array}{ll}\text { Attended IEP Meeting } & 67\end{array}$

$\begin{array}{ll}\text { Attended Transition Planning Meeting } & 68\end{array}$

Association Between Parent Experiences and Parent Involvement 69

Homework Assistance $\quad 69$

$\begin{array}{ll}\text { School Discussion } & 71\end{array}$

$\begin{array}{ll}\text { Attended IEP Meeting } & 73\end{array}$

$\begin{array}{ll}\text { Attended Transition Planning Meeting } & 76\end{array}$

Association Between Parent Expectations and Parent Involvement 78

$\begin{array}{ll}\text { Homework assistance } & 78\end{array}$

$\begin{array}{ll}\text { School Discussion } & 79\end{array}$

$\begin{array}{ll}\text { Attended IEP Meeting } & 80\end{array}$

$\begin{array}{ll}\text { Attended Transition Planning Meeting } & 82\end{array}$

$\begin{array}{ll}\text { Post Hoc Analyses } & 83\end{array}$

Post Hoc Findings between Parent Demographics and Parent Involvement 83

Homework $\quad 83$

School Discussion $\quad 83$

Attended IEP Meeting $\quad 84$

Attended Transition Planning Meeting 84

Post Hoc Findings between Parent Experiences and Parent Involvement 85

Homework Assistance $\quad 85$ 
$\begin{array}{ll}\text { School Discussion } & 85\end{array}$

$\begin{array}{ll}\text { IEP Attendance } & 86\end{array}$

Transition Planning Meeting Attendance $\quad 86$

Post Hoc Findings between Parent Expectations and Parent Involvement $\quad 87$

$\begin{array}{ll}\text { Homework } & 87\end{array}$

$\begin{array}{ll}\text { School Discussion } & 87\end{array}$

$\begin{array}{lr}\text { IEP Attendance } & 88\end{array}$

$\begin{array}{lr}\text { Transition Planning Meeting Attendance } & 88\end{array}$

CHAPTER V: DISCUSSION 92

$\begin{array}{ll}\text { Parent Demographics } & 92\end{array}$

$\begin{array}{ll}\text { Parent Experiences } & 94\end{array}$

$\begin{array}{ll}\text { Parent Expectations } & 95\end{array}$

Implications for Research 996

$\begin{array}{ll}\text { Implications for Practices } & 99\end{array}$

$\begin{array}{ll}\text { Limitations } & 101\end{array}$

$\begin{array}{ll}\text { Conclusion } & 102\end{array}$

$\begin{array}{ll}\text { REFERENCES } & 105\end{array}$

APPENDIX: QUESTIONS SELECTED FROM THE NLTS 2012 PARENT SURVEY 119 


\section{TABLES}

Table

Page

1. Findings from Parent Reports on Involvement in Transition Planning 23

2. Topics Covered in NLTS 2012 Parent Survey 45

3. Frequency of All Parents Supporting Youth with IDD Demographics 47

4. Frequency of All Parents Supporting Youth with IDD Experiences 49

5. Frequency of All Parents Supporting Youth with IDD Expectations 50

6. Frequency of All Parents of Youth with IDD Involvement at Home 52

7. Frequency of All Parents of Youth with IDD Involvement at School 53

8. Study's Research Questions, Variables, and Test 58

$\begin{array}{lll}9 . & \text { Recoded Variables } & 60\end{array}$

10. Parents Involvement at Home for PSAA Youth with IDD 62

11. Parents Involvement at School for PSAA Youth with IDD 63

12. PSAA Youth with IDD Demographics and Homework Assistance 65

13. PSAA Youth with IDD Demographics and School Discussion 66

14. PSAA Youth with IDD Demographics and Attended IEP Meeting 67

15. PSAA Youth with IDD Demographics and Attended Transition Planning Meeting 68

16. PSAA Youth with IDD Experiences and Homework Assistance 70

17. PSAA Youth with IDD Experiences and School Discussion 72

18. PSAA Youth with IDD Experiences and Attended IEP Meeting 74

19. PSAA Youth with IDD Experiences and Attended Transition Planning Meeting 76

20. PSAA Youth with IDD Expectations and Homework Assistance 78 
21. PSAA Youth with IDD Expectations and School Discussion 79

22. $\quad$ PSAA Youth with IDD Expectations and Attended IEP Meeting 81

23. PSAA Youth with IDD Expectations and Attended Transition Planning Meeting 82

24. Post Hoc Findings Between Parent Demographics and Parent Involvement 84

25. Post Hoc Findings Between Parent Experiences and Parent Involvement 89

26. Post Hoc Findings Between Parent Expectations and Parent Involvement 91 


\section{FIGURES}

Figure $\quad$ Page

1. Epstein's Family Involvement Framework 13

2. Gerzel-Short Family Engagement Framework 14 


\section{CHAPTER I: INTRODUCTION}

\section{Background}

Parent involvement is one factor identified as a predictor to improve postschool outcomes for youth with disabilities. While research suggests the importance of parent involvement and special education law mandates parental participation in secondary transition planning, some reports assert parent participation is often limited and superficial when developing the transition plan and Individualized Education Program (IEP; Martinez et al., 2012). Further, Landmark et al. (2012) reported educators believed that parent involvement was important but were unclear on who was responsible for facilitating the engagement. Moreover, local educational agency (LEA) philosophy on parent involvement defined expectations of passive engagement (e.g., IEP attendance) as opposed to more robust engagement (e.g., completing transition assessments, attending meeting.; Landmark et al., 2012).

Parent experiences and perceptions influence involvement in the transition planning process. Hirano, Rowe, Lindstrom, and Chan (2018) examined parent perceptions and experiences with the secondary transition planning process. They identified three themes that influenced involvement: (a) school barriers (e.g., lack of planning, effects of racism and discrimination, failure to align with family values, inaccessible information); (b) family barriers (e.g., lack of resources, limited cultural capital, low self-efficacy); and (c) adult services barriers (e.g., professional staff's limited systems knowledge, professionals' low expectations of student ability, minimal value on parent input). Hence, the activities noted to promote parent 
involvement were often negated or cancelled by barriers created by school, adult services, and family factors.

Families from culturally and linguistically diverse (CLD) backgrounds face additional cultural barriers when navigating the educational and transition planning process. These families were sometimes characterized as uninvolved in the youth's educational planning (Ju et al., 2018; Kim \& Morningstar, 2005). Also, parents from CLD backgrounds were more likely to seek support from resources other than the school due to hidden barriers such as: (a) racism and discrimination (Geenen et al., 2003, 2005; Hirano et al., 2018); (b) lack of alignment with accepted cultural norms (deFur et al., 2001; Geenen et al., 2003, 2005); (c) disrespect and devalue by professionals (deFur et al., 2001; Geenen et al., 2003; Landmark et al., 2007); (d) lack of access to information and resources related to transition (deFur et al., 2001); and (e) complex systemic processes (Geenen et al., 2003; Hirano et al., 2018; Ju et al., 2018). CLD families may develop attitudes and perspectives of their role that were contrary to schoolcentered parent involvement expectations which may in turn have contributed to professionals' negative attitudes (deFur et al., 2001). As a result of these experiences, CLD families' lack of engagement in the educational process promoted reliance on other connections within their social networks (Geenen et al., 2005; Hernandez et al., 2008) and reinforced the non-involvement stereotype held by professionals.

Moreover, researchers found CLD parents valued transition planning and participated at a higher level in non-school based activities (e. g., talking with their child about life after high school, teaching their child how to navigate their disability, teaching their child cultural values of 
family, teaching their child to use transportation) when compared to White parents (Geenen et al., 2001). Researchers also reported CLD family involvement led to positive academic outcomes for the youth (Jeynes, 2007). Williams and Sanchez's (2011) study on parent involvement of inner city African American families found that consideration of family context during the planning of school-based programs and events increased participation. Yet, these findings contradict the narratives purported of limited CLD parents' involvement.

\section{Statement of The Problem}

National longitudinal research found African American young adults with disabilities experienced poorer post-school transitions into adulthood across all areas when compared to their white peers (Newman, 2005). While consisting of $21 \%$ of the respondents in the national survey, African American youth were found to represent $33 \%$ of youth in the mental retardation category and 24\% in the autism category (Newman, 2005). Studies confirmed African American youth were four times more likely to receive the eligibility category label of intellectual disability than other races (Harry \& Klingner, 2006; Jasper \& Bouck, 2013). Additionally, young adults in the category of intellectual disability (ID) are reported to experience fewer successful post-school outcomes (Grigal et al., 2011).

One way to improve the outcome of youth with multiple identities -- race and disability -is to understand factors that progress parent participation in transition planning and activities. In this chapter, I present an overview of parent involvement in secondary transition as defined through legal mandates and research. Next, I describe two models used to frame parent 
involvement in education. Finally, I present the purpose, research questions, and significance of this study.

\section{Overview of Parent Involvement in Secondary Transition}

Parents are an integral part of the IEP and transition team charged with developing a set of coordinating activities to support post-secondary adult life through transition services (IDEA, 2004). Parent participation was found to predict postschool outcomes for youth with disabilities through research of effective practices (Test et al., 2009). Moreover, legislative policies and mandates gave parents a vehicle to participate and engage in the educational process. Predictors, effective practices, and legislative mandates have underscored the importance of the parent as one factor in a youth's achievement of successful post school outcomes.

The contributions and roles of parents are complex and evolving, leading to a myriad of different parental experiences. Engagement of families in transition planning meetings, IEP meetings, and parent-teacher collaboration serve as components to the expectations of parent involvement (IDEA, 2004). Effective participation in transition planning requires parents to understand and navigate complex laws, policies, and legal rights.

To further complicate participation in the transition planning process, families supporting youth with more complex needs must engage many different governmental agency systems designated to support persons with disabilities. Families are typically required to navigate conflicting agency systems' expectations and requirements to learn about and access services. Thus, examining concepts and factors related to parent involvement in the development, decision 
making, and implementation of secondary transition planning and services is a key step to improving the lives of young adults with disabilities.

Parental activities supporting education for youth with disabilities is associated with successful academic and post-school outcomes (Newman, 2005). The foundation of secondary transition services through planning provides a roadmap for all stakeholders toward the development and administration of services that include coordinated activities with a focus on promoting positive post-school outcomes. The following section outlines the legal mandates and research related to parent involvement in secondary transition planning.

\section{Legal Mandates}

Parental legal rights to participate in the educational process for youth with disabilities have continued to evolve over the past 45 years since the enactment of the Education for All Handicapped Children Act of 1975 (EAHCA; Katsiyannis et al., 2001). The importance of parent participation is highlighted throughout the foundational legal mandate addressing special education for youth with disabilities. Reauthorization of EAHCA, renamed the Individuals with Disabilities Education Act (IDEA) in 1990, supported the parent's role in the IEP process, which includes transition planning and services.

The reauthorization of IDEA in 1990 defined transition services addressing many areas to include parent notification of discussions related to activities toward postschool life (Johnson, 2012). Additional parent rights in the IEP/transition process included: (a) access to student records upon request; (b) parent participation in all IEP team meetings regarding identification, placement, and educational decisions; (c) notification in writing if the IEP will be amended prior 
to any changes; (d) written procedural safeguards; (e) translators available to native language; (f) informed consent and agreement prior to any evaluations or services are provided; and $(\mathrm{g})$ the right to request independent educational evaluations at public expense. Several options for dispute resolution were included in the legislative rules to aid parents in participating in the IEP process (i.e., the "Stay Put" rule preventing removal of the student from the current placement until the dispute was resolved, due process, and civil litigation; IDEA, 1990).

In the 1997 reauthorization of IDEA, Congress included a stated objective of the law as "strengthening the role of parents and ensuring that families of such children have meaningful opportunities to participate in the education of their children at school and at home" (IDEA, 1997). As a result, key provisions for parent participation included involvement in evaluation, IEP, placement decision, and progress update requirement commensurate with non-disabled peers (Katsiyannis et al., 2001).

Moreover, IDEA mandates educational agencies to provide opportunities for parents to participate in the IEP and transition planning by providing timely notice in a mutually agreeable time and place. Educational representatives were charged with notifying parents about meeting details (e.g., time, location, purpose) and their rights to invite experts to the meeting. In addition, transition meetings must include post-school goal discussion and the option for agencies servicing persons with disabilities to be invited with parental consent. Districts were required to ensure parents' ability to participate (e.g., interpreter, phone, in-person). Lastly, parents were granted rights to receive a copy of the IEP at no cost (IDEA, 2004). 
The reauthorization of IDEA over the years has provided families with many opportunities to participate and influence the educational process for youth with disabilities in transition planning. The procedural safeguards and due process gave families a legal remedy to address disputes with the school districts (Yell et al., 1998). Later reauthorizations offered parents, through State Educational Agencies (SEA), options for training and technical assistance to navigate the educational system effectively with the goal of ensuring family voice in the IEP and transition planning of youth with disabilities (Wagner et al., 2012).

\section{The Taxonomy for Transition Programming}

Kohler (1996) provided a model for secondary transition programs, The Taxonomy for Transition Programming which included family involvement as a category. The purpose of the taxonomy was to provide a framework connecting research to practice in support of programming for secondary transition activities (Kohler, 1996). The Taxonomy included three subcategories under family involvement: (a) involvement; (b) empowerment; and (c) training.

The taxonomy was recently updated (Kohler et al., 2016) to advance transition education based on recent literature related to effective programs and best practices in transition programming. The category focused on family remained in the updated taxonomy, but the category family involvement changed to family engagement. Emphasis shifted to engagement of families in transition planning by incorporating more tangible practices (Kohler et al., 2016).

In the Taxonomy for Transition Programming 2.0, involvement and empowerment remained subcategories but the third subcategory changed from family training to family preparation. The updated taxonomy included practices to direct support to family involvement 
(e.g., family cultural background and knowledge relevancy, interpreter services). Post-secondary education and linkage to adult service providers were added to family empowerment as needed practices. Another key addition to this subcategory was the provision of transition information to families before their child with an IEP turned 14 years old. The final subcategory, preparation, included more explicit practices to teach all stakeholders specific skills identified to equip the team members with tools to support the youth (e.g., respecting cultural views and values, how to facilitate community experiences). The latter updates to the Taxonomy 2.0 provided a robust set of family-centered strategies and practices which trained, supported, and empowered families and professionals in effective transition planning for successful postschool outcomes.

\section{Parent Involvement as a Postschool Predictor}

In-school predictors of successful postschool outcomes were identified through a systematic literature review. The examination of literature produced 16 evidence-based secondary transition predictors based on correlational studies related to employment, education/training, and independent living (Test et al., 2009). The Institute of Education Sciences (IES) evaluation tool defining the level of evidence was used to establish the "causal inference" of variables. The standards set by the IES for the moderate level of causal inference required a predictor have "two a priori (i.e., planned hypothesis prior to analysis) studies with consistent significant correlations between predictor and outcome variables (exploratory studies were included only when paired with a priori significant correlations), and effect size calculations or data to calculate effect size" (Test et al., 2009, p. 164). Predictors were considered potential if one a priori (i.e., planned hypothesis prior to analysis) study and/or two or more exploratory (no 
specific hypothesis) studies with significant correlations between predictor and outcome variables existed. The review found parent involvement as a potential predictor for the employment domain, with one a priori study (Fourqurean et al., 1991).

A follow-up literature review was conducted to evaluate current research from the National Longitudinal Transition Study-2 (NLTS2) data set to expand Test et al.'s (2009) research and identify any new predictors (Mazzotti et al., 2016). The researchers used Test et al. (2009) to evaluate the levels of evidence with an addendum, emerging, if a predictor had at least an exploratory study. The results indicated no additional relationships in the employment domain, no relationship with independent living, but emerging evidence was noted in the education domain for parent involvement. The most current literature review showed no change in levels for parent involvement in any domains (Mazzotti et al., 2021).

Rowe et al. (2015) expanded research in secondary transition by operationally defining the 16 predictors identified in the initial predictor research (Test et al., 2009) while including program characteristics to assist professionals with implementing and evaluating programming. Parental involvement was defined as “...parent/families/guardians are active and knowledgeable participants in all aspects of transition planning (e.g., decision making, providing support, attending meetings, and advocating for their child)" (Rowe et al., 2015, p. 122). Said another way, research evidenced the value of families' contributions to the transition process beyond attending annual meetings to a more collaborative interaction. Thus, greater emphasis in research of family involvement in the secondary transition process through collaboration, training, and policy was recommended (Rowe et al., 2015). Other findings indicated multiple factors 
associated with parent involvement (e.g., educational demands at home, school interactions, and membership in support groups) were interconnected and influenced parent participation in the secondary transition process (Wagner et al., 2012).

\section{Researcher's Positionality}

I come to this work of examining parent involvement through multiple lenses. Over 20 years ago, I was introduced to the world of special needs resulting from my daughter's diagnosis of developmentally delayed. Prior to her entry into the educational system, my involvement was welcomed in the school because our oldest child was a neurotypical student. During this time, I was actively pursuing career goals. After our first IEP meeting, I realized that I needed to educate myself to fully participate in the process of supporting our daughter in developing into an amazing, contributing member of the community. I began to take classes, attend webinars, read about disabilities so I could partner with the team to ensure our daughter reaches her maximized potential.

The efforts to engage as a parent led to my career change to education. This change came about because I sat in classroom and listened to future educators' positions on family involvement and felt the need to engage the system. The more I experienced the system as a parent, the more invested I became as an educator. The responses and actions from educational professionals to my voice at the table shaped my future self. As a parent of an African American, female youth with a developmental disability, I quickly learned that my voice was critical for creating access to a high-quality education for students with disabilities and participating in changing the narrative of parent involvement for students of color. While we have team members 
who truly supported our vision for our daughter, many experiences with the transition process caused great distress and struggle in navigating the special education system.

Taking the opportunity to become an educator, I began to channel my experiences, both positive and negative, into my workspace to provide the same level of high expectation and collaboration with my assigned families and students. In addition, many times I found myself as the lone voice in the room of colleagues infusing cultural viewpoints, while navigating personal feelings beyond the scope of this study. Questions of how to negotiate my roles as an educator and parent in an evolving system became my conundrum.

To answer this question, I accepted the opportunity to study, at the doctoral level, how our system supports family partnerships to promote student success. Advancing through the doctoral process, working in various secondary settings, and engaging secondary transition planning with my child, I began to appreciate the significant difference in cultural acceptance, integration of family voice, and expectations of students of color.

\section{Frameworks for Parent Involvement}

Frameworks used to examine parent involvement in education have evolved with the passage of legislation and research. Parent involvement is ofttimes predicated on interactions and engagement activities with school district personnel. The frameworks described in this section provide a lens to identify and evaluate specific practices which define and promote family participation in the educational process. 


\section{Epstein's Six Types of Involvement Framework}

One of the more commonly applied frameworks on practices related to families is Epstein's Six Types of Involvement (1995). The Epstein framework primarily focuses on types of parent involvement that promotes academic achievement with families as the "central players." The model was grounded in the examination of shared interactions between family, school, and community which influenced student outcomes within and across each setting (Wagner et al., 2012). Epstein's early frameworks (1992, 1995) included four and six types of practices, respectively. In 2001, the third iteration retained the six types of practices (see Figure $1)$.

The Epstein framework offered many advancements to facilitating home, school, and community interactions (Epstein, 2001, 2005). While Epstein's model is widely used to examine family involvement, it falls short of explicitly addressing the unique needs of families from CLD communities. Cultural and social capital is significant in accessing transition activities in schools (Trainor, 2017). For example, families with strong social networks understand community resources or may use connections to assist with navigating the process. The cultural beliefs of families may influence the types of involvement families' access. As such, families from CLD backgrounds may require additional considerations when promoting involvement. 


\section{Figure 1.}

Epstein's Family Involvement Framework

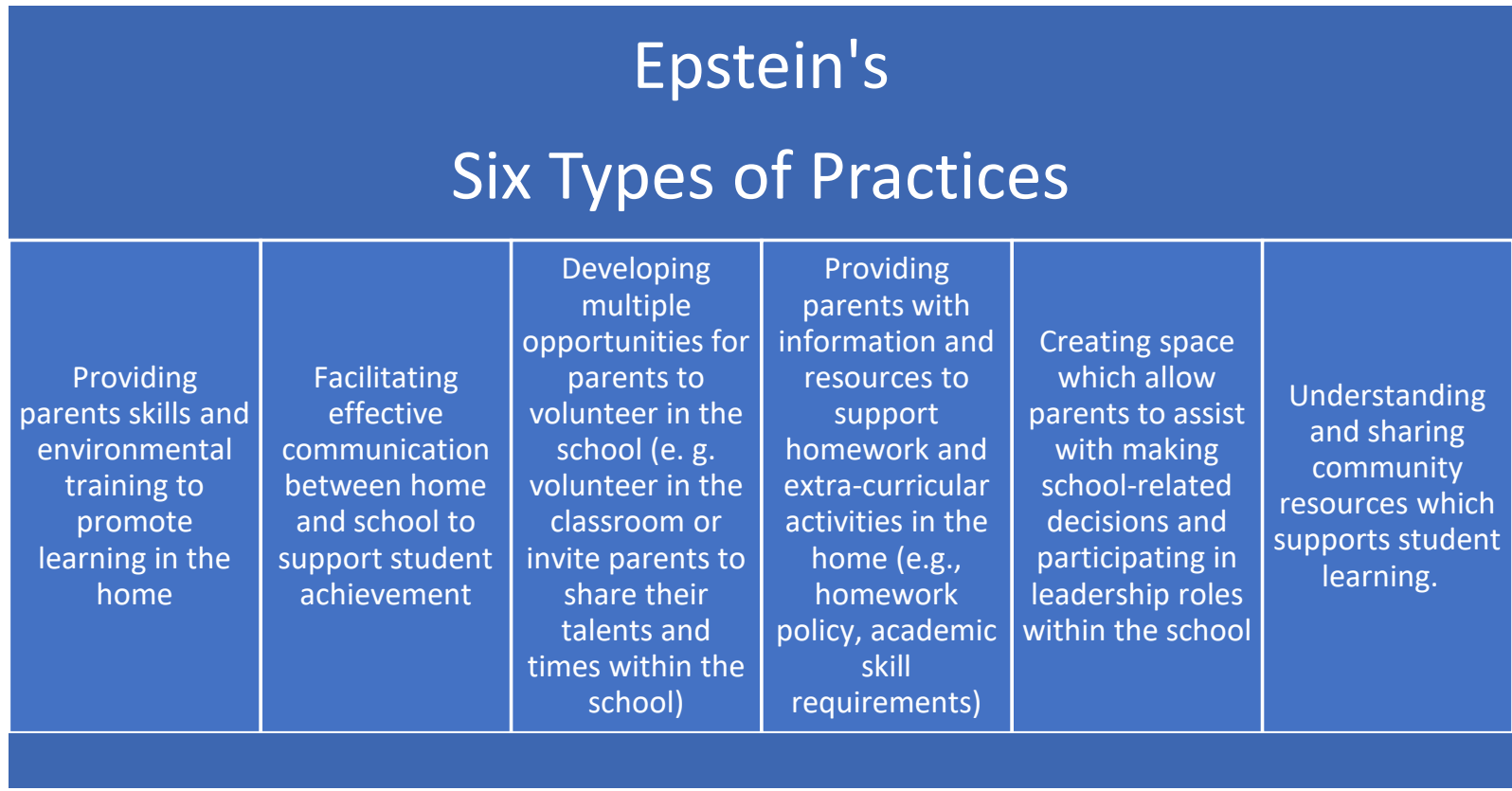

\section{Gerzel-Short's Family Engagement Framework}

Gerzel-Short and colleagues (2019) presented a parent engagement model which narrowed the focus to address strategies specific to involving CLD families (see Figure 2). The researchers identified strategies geared toward developing relationships with CLD families through: (a) creating an embracing school setting; (b) facilitating academic partnerships in the home; and (c) providing behavioral supports respecting cultural views and beliefs.

Schools were encouraged to create an environment which developed a space representative of the demographics served in the setting. The authors offered four approaches to creating an embracing setting for families. The first approach, entitled interpretation, promoted schools integrating signage and language interpreters into the buildings. The next approach 
called invitation encouraged school personnel to invite the family to share important cultural beliefs and ideals related to their child's academic abilities with the goal of developing the school and classroom community. The third strategy, interaction, advocated for the inclusion of family voice in important educational decision making through surveys and interviews to understand family needs to connect with community resources. The final strategy, intention, endorsed school officials and staff seeking and listening to understand what families valued as important to their child.

The overall approach presented in the model posits partnerships between professionals and CLD families. Notably, promoting two-way communication, integrating family input, and understanding expectations informed by cultural views into system development was vital to family participation (Gerzel-Short et al., 2019).

\section{Figure 2.}

Gerzel-Short Family Engagement Framework

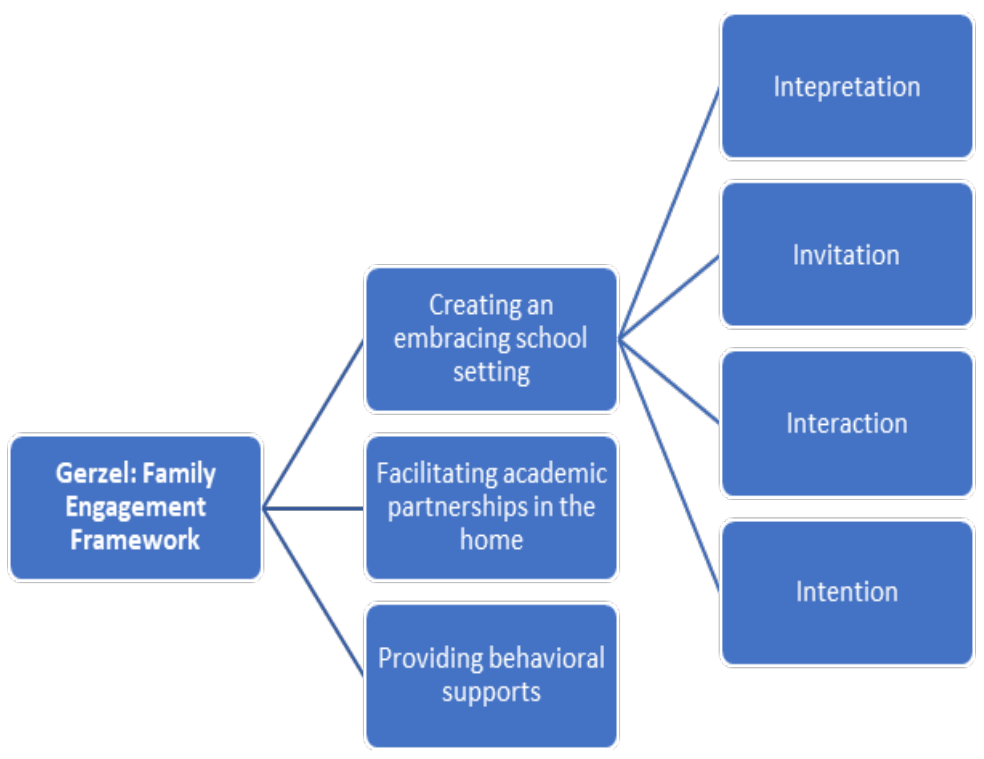


The frameworks outlined above provide a lens for this research to explore parent involvement related to CLD families. In addition, the use of these approaches, along with current research on parent involvement, informed the selection of factors related to school-family relationship that influence examining family participation. Further, characteristics gleaned from these models were used to inform the data analysis in this study. Based on research, areas of interest for this study included: (a) ensuring parent expectations are considered in context (Gerzel-Short et al., 2019); (b) using effective and regular communication (Epstein, 2001; Gerzel-Short et al., 2019); (c) positioning parents as a resource for learning about students in the home and community (Gerzel-Short et al., 2019); (d) providing families with resources needed outside of school; and (e) creating a space for parents to inform participation in decision making related to post school planning (Epstein, 2001).

\section{Purpose of the Study and Research Questions}

As explained above, research and legislative advancements are present to support parent involvement in transition planning to improve outcomes, and research supports those parents of African American families are interested in supporting their child's educational experiences but feel unwelcomed and disrespected by professionals in the educational system overall (Zionts et al., 2003). Further, research confirms many youths with IDD and those who identify as African American are at a higher risk of poorer postschool outcomes (Lipscomb et al., 2017). I found no studies investigating parent involvement focusing on the intersection between African American youth with IDD in transition planning. Thus, the purpose of this study will be the first, to my knowledge, to examine a national data set to understand factors associated with parent 
involvement, as defined by the National Longitudinal Transition Study 2012 (NLTS 2012), of families supporting African American youth with IDD in the transition planning at home and in school. Tenets presented by Epstein (2002) and Gerzel-Short et al. (2019) will be used to frame this study addressing the following research questions:

1. To what extent do families report supporting African American youth with IDD through parent involvement in transition planning as defined by the NLTS 2012 data set?

2. What is the association between socioeconomic status (SES), marital status, educational level, or employment status and parent involvement in transition planning of families supporting African American youth with IDD as defined by the NLTS 2012 study?

3. What is the association between family experiences with the school and parent involvement in transition planning of families supporting African American youth with IDD as defined by the NLTS 2012 study?

4. What is the association between post school family expectations and parent involvement in transition planning of families supporting African American youth with IDD as defined by the NLTS 2012 study?

\section{Significance of Study}

This study will contribute to the extant literature in many ways. First, no studies were found specifically examining factors associated with parent involvement of families supporting African American youth with IDD in transition planning. The importance of studying this 
population is critical due to the post-outcomes experienced by this population. Second, using a national longitudinal study will allow for consideration of a larger population across settings. Finally, information gleaned from this research can inform family involvement approaches in secondary transition programming to identify positive factors associated with positive parent involvement of African American families and promote transition services and supports.

In the next chapter, I will review literature related to parent narratives on involvement in transition planning for youth with disabilities using current qualitative literature and studies evaluating parent involvement using the NLTS-2 and NLTS 2012.

\section{Definition of Terms}

Intellectual and Developmental Disability (IDD) - disorders that are usually present at birth and that negatively affect the trajectory of the individual's physical, intellectual, and/or emotional development (Carter et al., 2011; National Institutes of Health, 2016)

Parent involvement - active and knowledgeable participation in all facets of planning for postschool transition (Rowe et al., 2015)

Post-school Transition Predictors - identified in-school activities which are positively correlated with post-school success in education, employment, and independent living (Mazzotti et al., 2021)

Social capital - resources, both tangible and symbolic, that are derived from a person's connectedness to society via social networks (Trainor, 2008)

Transition Planning - evaluating needs, strengths, and skills required for a youth to move from high school to postsecondary life (Mazzotti et al., 2009) 
Transition Services - coordinated experiences and skill development purposed to facilitate successful postschool education, employment, and community inclusion for youth with disabilities (IDEA, 1997) 


\section{CHAPTER II: LITERATURE REVIEW}

The frameworks in Chapter 1 identified strategies to promote family involvement in the educational process. The purpose of this literature review was to explore school and home parent involvement in transition planning. First, I present peer reviewed literature using qualitative and mixed methods research methods to explore parent perspective on involvement. Then, I provide a general overview of findings on parent involvement in transition planning from extant research using the National Longitudinal Transition Study 2 (NLTS-2) and NLTS 2012.

\section{Parental Perspective on Involvement}

The review of literature investigating parent perspectives on involvement included peerreviewed journal articles using qualitative or mixed methods methodology since 2010. The research focus of the articles was on parent reports related to experiences with secondary transition planning for youth with disabilities. The selected studies were reported in English and conducted in the United States. Finally, only studies using parents' and families' narratives for analyses were considered. Studies missing any of the inclusionary criteria were excluded from this review.

\section{Search Procedures}

I accessed multiple databases during my initial search including Academic Search Complete, CINAHL Plus, Education Full Text, ERIC, PsycArticles, PsycINFO, and SocIndex with Full Text. The combination of keywords used in the search were parent involvement OR parent engagement $\mathrm{OR}$ parent participation $\mathrm{OR}$ parent partnership $\mathrm{OR}$ family participation AND secondary transition planning OR collaboration which yielded 84 articles. After reading 
the titles and abstracts, two articles were retained as meeting the inclusionary requirements. Eighty-two articles were rejected during this process as they did not focus on parent involvement in secondary transition planning.

Next, I conducted a hand search of eight relevant journals. The journals were selected if they met the following criteria: (a) focused on special education topics; (b) peer-reviewed; (c) published in English; and (d) conducted in the United States. The following journals met the criteria: Exceptional Children, Career Development and Transition for Exceptional Individuals, Focus on Autism and other Developmental Disabilities, Education and Training Autism and Developmental Disabilities, Journal of Vocational Rehabilitation, Journal of Special Education, Multiple Voices, and Remedial and Special Education. Using the established inclusionary criteria for participants, topic, and methodology with the date parameter of 2010 to 2020,20 articles were identified as focusing on parent involvement with secondary transition planning based on the title and abstract review. Articles were rejected if they did not meet the participant criteria. Upon completing a full review of the participant section of each article, four articles met the inclusionary requirements of parents as the sample population.

Finally, I conducted an ancestral search of the selected articles to identify additional resources which met the inclusionary criteria. The search yielded one additional article which met the inclusion requirement for this literature review bringing the total number of articles identified to seven.

The seven selected articles met the inclusionary criteria included: (a) a focus on parent involvement in transition planning; (b) parents of youth with disabilities were identified as the 
participants; (c) used qualitative or mixed methods methodology, (d) published in a scholarly; peer-reviewed journal; (e) published between 2010-2020; (f) published in English; and (g) conducted in the United States.

\section{Data Collection}

The articles were examined for parent narratives on secondary transition planning. Galvan and Galvan (2017) suggest summarizing methods and findings in a table format to provide an overview of the literature. The articles used in the literature review are summarized in Table 1. The summary includes: (a) participant demographics; (b) the research objectives; and (c) findings of each of the included articles (Galvan \& Galvan, 2017).

\section{Participant Demographics}

A total of 182 parents participated across the seven studies. The reported demographics were inconsistent across the included studies. Participant information in one article included married couples reporting on the same student. Each participant was the parent supporting a youth or young adult with disability during secondary transition planning. Across all studies, race and ethnicity were reported for $95 \%(n=172)$ of participants; of these $58.7 \%$ identified as White/Caucasian, 21.5\% Asian, 11.0\% African American/Black, 5.8\% Hispanic/Latino, and $2.9 \%$ identified as multiple race/ethnicities. Four studies reported the role of the participant, with mothers representing $81.9 \%(n=68)$ of the sample. Four of the studies reported parent educational level. Over half of the participants (52.8\%) in these studies were college graduates, with four (4\%) earning a degree in their native country outside the United States. Participates reported income level in four studies. Two of the four studies reported annual income of the 
participants with most participants $(55 \%)$ earning over $\$ 65,000$ per year, while the other two studies relayed family earnings as low- to mid-income. Family members reported their experiences with transition planning for 171 youth and young adults. Only one study reported binary gender of youth which included $76.9 \%(n=10)$ females. All seven studies identified the disability type. Of these, six out of seven studies included families supporting youth with autism or intellectual disability. Other disabilities identified in these studies were: (a) specific learning disability; (b) developmental disability (c) other disabilities (spina bifida, hydrocephalus, quadriparesis, cerebral palsy, Turner syndrome, Cri du chat syndrome, hard of hearing, and visual impairment); and (d) multiple disabilities.

\section{Parent Perspective Analysis}

Coding the articles entailed closely reading each article looking at themes identified through analysis of the interview or focus group data by the author(s). I recorded themes from each article in an Excel spreadsheet. Next, I reviewed the recorded themes for patterns to find broader themes. In reviewing the themes, I used focused coding techniques (Saldaña, 2016) to identify which themes appeared most often and were significant for parent involvement as defined in Chapter 1. From this, two categories emerged: parent actions and parent experiences.

I defined parent actions as overt parent activities used to promote transition planning. Examples of these activities included: (a) engaging social networks; (b) independently contacting community resources; (c) accessing adult services; or (d) enlisting professionals outside of school systems. Conversely, I defined parent experiences as actions by professionals or system 


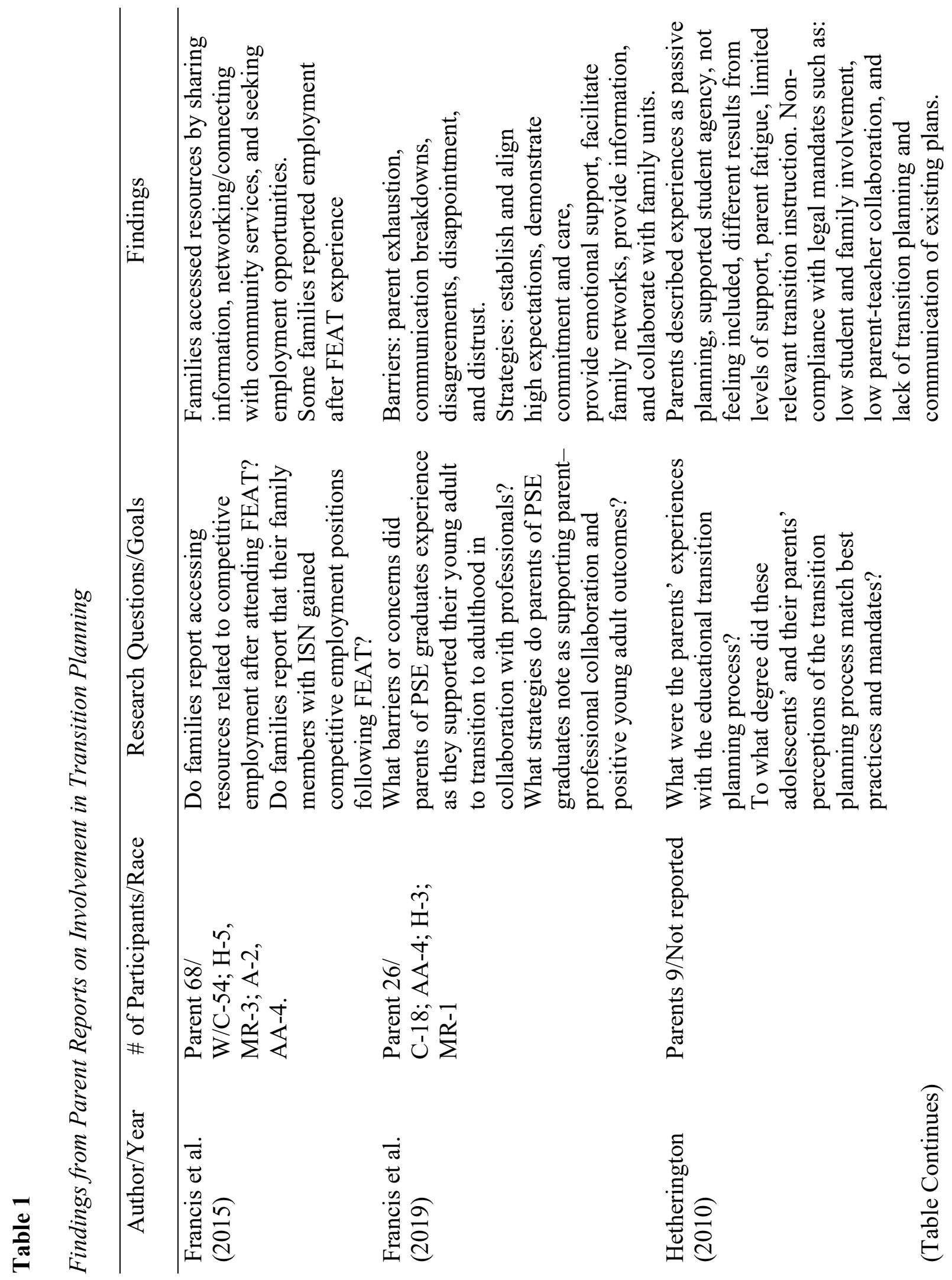




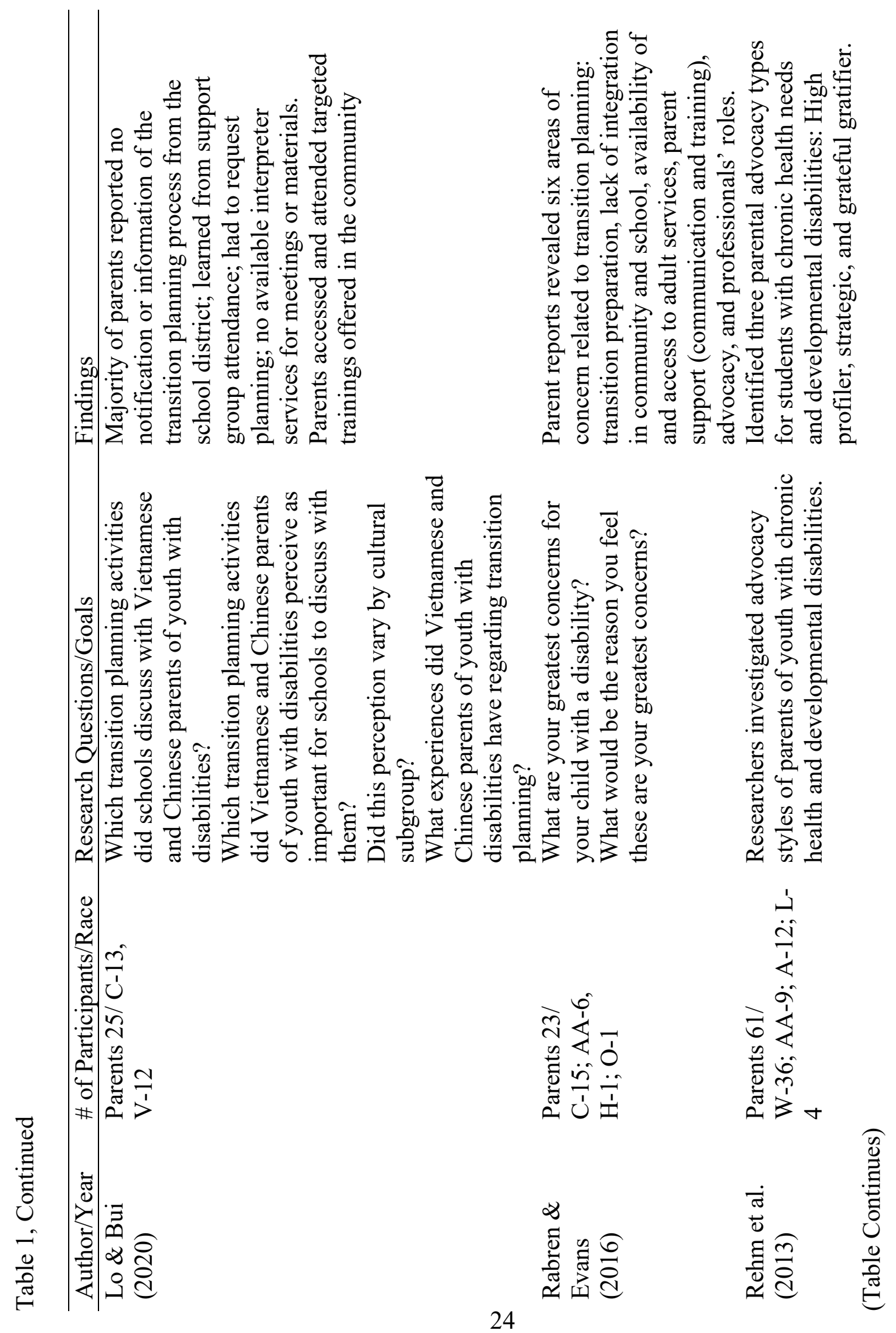




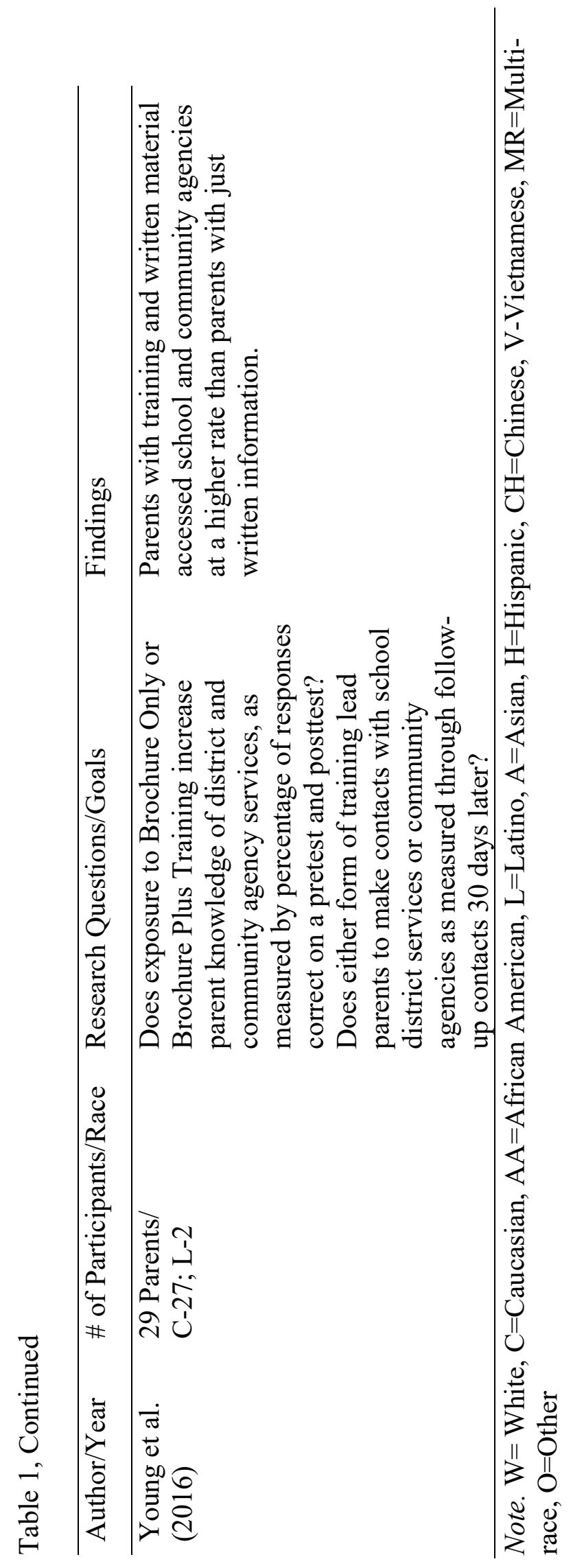


practices related to transition planning which either promoted or diminished involvement in the process. Some examples of these experiences are: (a) parent perception of professional treatment; (b) professionals/staff expectations for the youth; or (c) professional knowledge on available community services and resources.

Next, I sorted the themes from the included articles into two categories of actions and experiences based on the definitions described above. Once the themes were assigned to the respective category, I merged the related themes into broader themes to synthesize the findings. The following sections on parent actions and experiences describe themes found in the literature.

\section{Parent Actions}

Parent actions, engagement, or disengagement with transition planning and implementation were evident across all seven articles. Major themes on parent actions in transition planning included: (a) accessing services; (b) networking; (c) advocating; and (d) student agency.

\section{Accessing Services}

In three of the seven articles, participants indicated accessing services to support their children with disabilities was a necessary action. Participants in these studies reported accessing employment supports, programs offering financial assistance, and other social service agencies supporting persons with disabilities after leaving the educational system (Francis et al., 2015; Rabren \& Evans, 2016; Young et al., 2016).

Outside agency support was accessed when parents had specific knowledge of available services and contact information. For example, Francis et al. (2015) found that families who 
participated in the Family Employment Awareness Training (FEAT) reported contacting at least five employment-related services resulting from information shared during the sessions. Accessing outside agencies was positively influenced by receiving training and written information (Francis et al., 2015). Other findings showed that parents who participated in the training accessed services and support at a higher rate than parents who did not participate in training (Young et al., 2016). The services include: (a) case management; (b) state services for persons with developmental disabilities; (c) waiver programs for home-based supports; (d) federal programs (e.g., vocational rehabilitation); and (e) direct supports (e.g., job coaching, assistive technology).

Parent reports on accessing services also yielded concerns and strategies about understanding and navigating adult services (Rabren \& Evans, 2016). Parents participating in the focus groups suggested that understanding the availability and types of services offered by adult service agencies was critical for increasing engagement in the planning process (Young et al., 2016). To increase parent access and understanding, parents recommended the school district develop a communication platform for families that included agency and service listings (Young et al., 2016).

\section{Networking}

Networking between families, professionals, and community members was evidenced in two studies (Francis et al., 2015; Lo \& Bui, 2020). Parents reported employing networking activities by engaging in sharing learned information to improve transition planning across stakeholders. The flow of information allowed families and professionals to learn from one 
another, thus increasing access to services based on the knowledge gained during these interactions.

Other networking parent actions included participants engaging in community connections. Francis et al. (2015) found families reported using networking to gain employment and volunteer opportunities for their youth. For example, one family member made direct contact with employers to understand expectations and priorities for potential applicants which led to the acquisition of new knowledge to promote work experience for the student (Francis et al., 2015). In addition, community systems were established through support groups, parent training and conferences to create connections between families (Francis et al., 2015; Lo \& Bui, 2020).

Lo and Bui (2020) further expanded research on parent activities using community connections with a study of Chinese and Vietnamese families navigating transition. Findings showed that linguistic barriers with school personnel led families to seek support in transition planning and advocacy from support groups within the community. Parents expressed frustration that these services were not offered by the school district, with one parent sharing that information learned through the community group should have been available through the district (Lo \& Bui, 2020).

\section{Advocacy}

Advocacy activities were found across all seven studies. Advocacy emerged as two types: independently seeking training to learn about secondary transition and leveraging their knowledge to access services and supports. The level and intensity of advocacy demonstrated by parents varied depending on several factors: (a) available cultural and social resources (Lo \& 
Bui, 2020; Rabren \& Evans, 2016); (b) knowledge of rights and responsibilities (Rehm et al., 2013); and (c) the relationship with the professional staff (Francis et al., 2015, 2019; Lo \& Bui, 2020; Rabren \& Evans, 2016; Rehm et al., 2013).

Rehm and Evans (2013) reported advocacy styles were related to the type of relationship the parent desired to have or maintain with the professionals supporting the student. Parents of students with more individualized needs were defined as either high profile, strategic, or gratifier. Each style was connected to a specific parental approach which in turn impacted the collaborative or lack of relationship with professionals on the transition planning team. For example, high profile parents were effective negotiators, usually highly educated, connected with the educational system, and leveraged their knowledge of systems to gain services, whereas strategic parents tended to research services and target specific goals with care to maintain collaborative relations. Gratifier parents' behaviors tended to focus on supporting the professionals in their efforts to provide services and support. Thus, strategic and gratifier parents tended to use a more collaborative approach to transition planning and implementation, while high profile parents' approach led to an adversarial relationship with professionals (Rehm et al., 2013).

Similarly, participants demonstrated advocacy through accessing social and cultural capital in varied ways (Francis et al., 2015, 2019; Lo \& Bui, 2020; Rabren \& Evans 2016; Rehm et al., 2013). Three of the articles found parent use of information garnered from networks increased their knowledge, thus leading to effective advocacy for supports and services (Francis et al., 2015; Lo \& Bui, 2020; Rehm et al., 2013). Lo and Bui (2020) evidenced the use of 
cultural connections with a local support group assisting parents with understanding and navigating the system which addressed the language and cultural barriers. Accessing and leveraging the capital allowed parents to develop an understanding of transition planning and effectively advocate for their student's needs.

\section{Student Agency}

Student agency is defined as an individual's intentional influence on their functional and life's circumstances (Anderson et al., 2019). Student agency emerged as a factor in the level of parent involvement in the transition planning process. Three articles found student agency influenced parent involvement in transition planning (Francis et al., 2019; Hetherington et al., 2010; Rabren \& Evans, 2016). Hetherington and colleagues (2010) noted student participation increased in transition planning when they experienced a circle of support facilitated by the parent. One student reported, "I have a circle of support which helps me figure out what I really want to do so we are going to different places to see what is available for me for a career" (Hetherington et al., 2010, p. 166). Three families reported using the circle of support approach, with two sharing successful experiences leading to more student involvement. Using this support was facilitated by the parents to ensure the student had multiple layers of support outside of school.

Parents stressed the importance of involvement in transition planning for youths perceived as having low self-advocacy skills (Francis et al., 2019; Rabren \& Evans, 2016). These parents believed the youth lacked the skills necessary to effectively communicate their interests or needs to others without support. One parent stated, “There's no way he could ever advocate 
for himself" (Rabren \& Evans, 2016, p. 316). Therefore, perceived student agency was higher and parent participation lower when parents felt their child demonstrated self-advocacy skills. Conversely, parents felt an increased need to be actively involved in transition planning for students with greater support needs.

\section{Parent Experiences with Professionals}

During transition planning, parents reported many different experiences with professionals that influenced involvement. The experiences shared were both positive and negative. The themes generated from the reports from families included: (a) professional engagement-collaboration; (b) professional knowledge; and (c) training.

\section{Professional Engagement: Collaboration}

Three articles reported parent insights on collaboration with school professionals. Parents reported a disconnect with school personnel leading to frustration due to: (a) staff's unwillingness to update their current practices in planning and service delivery (Francis et al., 2019); (b) the school's failure to notify families about transition planning (Lo \& Bui, 2020); (c) staff's availability to meet with families (Lo \& Bui, 2020); and (d) lack of reciprocal communication (Lo \& Bui, 2020; Rabren \& Evans, 2016). Moreover, parents reported their collaborative efforts being unsupported and unappreciated by professionals (Francis et al., 2019; Hetherington et al., 2010; Rabren \& Evans, 2016). These experiences led to some parents communicating with professionals using less assertive approaches to avoid being labeled by professionals as "pushy," "overbearing," or “demanding" (Francis et al., 2019, p. 239). Other 
parents reported disengaged or adversarial relationships with school professionals (Rabren \& Evans, 2016).

A significant factor that potentially influenced parent involvement was professionals' low expectations of the youth's abilities to achieve. Francis et al. (2019) reported participants discontentment with professionals who deemed transition planning or rigorous instruction as unimportant as evidenced by their lack of engagement. One parent reported feeling ignored by the professionals when requests were made for full inclusion or other transition activities. Another parent described involvement as the "fight" to prevent professional perceptions of the student's abilities based on standardized assessment to limit expectations and access to rigorous instruction (Hetherington et al., 2010). The sentiments expressed by these parents increased advocacy to improve professional expectations and transition activities to provide opportunities for the students (Francis et al., 2019).

\section{Professional Knowledge}

Professionals' knowledge of available resources and effective transition planning is critical to the process. In three studies, participants reported professionals assigned to support students and families in the transition process demonstrated a lack of knowledge and understanding of transition planning and available community resources (Hetherington et al., 2010; Lo \& Bui, 2020; Rabren \& Evans, 2016). Parents stated that professionals were unaware of effective transition planning practices or were not certified staff members in special education (Hetherington et al., 2010; Rabren \& Evans, 2016). 
Professional staff's inability to communicate with parents due to a lack of linguistic capacity was another factor identified by participates (Lo \& Bui, 2020). Parent narratives revealed reports of being denied involvement in the transition planning, both in meetings and written materials, due to the language barrier between the professionals and families. As a result, parents conveyed experiences of limited involvement in planning, decision-making, and collaboration related to transition (Lo \& Bui, 2020).

\section{Training}

Offerings of training by school districts was reported in three studies by parents as important to involvement in transition planning (Francis et al., 2015; Lo \& Bui, 2020; Young et al., 2016). The concerns and use of training to support families varied in the studies. One study found that $64 \%$ of parents who received training on transition services and supports attempted to access the agencies and school transition services, whereas parents without direct training reported not completing follow-up with any services or agencies (Young et al., 2016). Further, parents without training reported feeling overwhelmed with the breadth of information provided. Parents with training reported feeling overwhelmed but accessed the supports which further promotes the key role training provides in increasing family involvement (Francis et al., 2015; Young et al., 2016).

Parents reported concern with the lack of parent training as required by the legal mandate through IDEA (2004) in one article (Lo \& Bui, 2020). The participants indicated that the school districts' failure to share information or provide training on transition planning compelled parents to access other sources for information and training. However, some families reported 
limited knowledge or access to community resources due to language barrier and minimal connections with school professionals resulting in no access to transition planning activities (Lo $\&$ Bui, 2020). The report of knowledge and access highlighted the importance, influence, and disparity of social and cultural capital within the educational system.

\section{Discussion}

The narratives of parents in transition planning for students with disabilities exposed many opportunities and limitations to improve post-school outcomes. The findings and implications between family actions and their experiences with professionals in transition planning are highly valuable to improving student post-school outcomes. The parent reports illuminated the interactions between parent actions and parent experiences resulting in increased or decreased parent involvement. Parent actions described activities families engaged related to collaboration with school personnel and outside of school to promote positive post-school outcomes.

Themes relative to actions highlighted by parents were activities such as: (a) accessing services; (b) networking; (c) advocating for their child; and (d) engaging staff when student agency was perceived as limited. The participants' actions, or lack of action, were initiated because of frustration with the system, understanding and using social capital, or engaging through legally mandated training. Parents were more apt to seek services, network, and advocate for their youth when they understood the process or held social connections which supported the navigation through established systems. Equally important to the previous themes 
were the perceptions held by parent of the youth's self-advocacy level. Parents reported a higher level of involvement when the student was perceived to have low self-advocacy.

Moreover, parent experiences with school personnel and other professionals appeared to have some influence on the parent's level of involvement and response to transition planning. Some participants reported professional interactions and training as impactful during the transition process. Specifically, (a) professional knowledge of transition planning and implementation; (b) collaboration with the transition team; and (c) perception of student and family involvement affected parent participation. Professionals' invitation to collaborate and their knowledge of the resources promoted increased family involvement during transition planning. Further, the professional's expectation of student success was deemed a critical component to home-school interactions. However, parent reports of low expectations by professionals, lack of willingness to explore new practices outside of current employed strategies, and limited awareness of available community resources led to a disconnect members of the transition team.

Although actions and experiences were expressed separately, the interactions between the two influenced parental engagement or disengagement. For example, parents who experienced language barriers were forced to seek and access community services. Therefore, experiences with limited services through the school district in participants' native language resulted in families taking action to seek other sources of support. On the other hand, the language barrier between professionals and parents and lack of navigational skills of parents in locating 
community resources prevented some families from accessing transition services needed to promote post-school success in both school and community.

Other interactions noted between parent actions and experiences were participants' advocacy approach and access to social capital. The approach and level of social capital shaped experiences with some professionals and activities engaged by the parents. Families with high advocacy and understanding of the legal requirements for transition planning more often reported adversarial relationships with school personnel, while those with low advocacy or limited knowledge either passively participated or totally disengaged. The latter is especially true for families of color (Kim \& Morningstar, 2005). The availability of high social capital increased involvement in the planning as these families had knowledge and networks to achieve positive outcomes for adult life (Rehm et al., 2013).

The narratives of parents supporting youth with greater support needs are indispensable in developing more inclusive and engaging policies within the school district and creating sustainable stakeholder collaboration. Even more, family engagement framework with a focus on improving involvement for parents from culturally diverse backgrounds indicates the importance of these strategies in supporting success for youth (Gerzel-Short et al., 2019). These adjustments are especially critical for individuals experiencing multiple identities such as the intersection of youth with more intensive needs and youth of color (YOC; Connor et al., 2016), who tend to experience significantly lower postschool outcomes when compared to their peers across all transition domains (Newman, et al., 2010). 
However, school districts' implementation of effective transition planning for YOC continue to fall short of research-based practices, nor does it rise to fidelity with the law. Gothberg and colleagues' (2019) survey and interviews of district personnel revealed: (a) limited to no implementation of transition planning; (b) low cultural competence among staff; (c) limited access to resources for CLD youth; and (d) few opportunities to develop self-determination skills based on the 11 researched indicators for CLD youth and parent involvement. Consideration of equal importance was the use of standardized practices for all youth and families versus a customized approach (e.g., specialized training, CLD peer mentors) to address the unique needs specific to CLD families. These findings were significant as the participants were the interdisciplinary transition team with the role of facilitating transition planning for youth with disabilities in their respective districts (Gothberg et al., 2019).

\section{Parent Involvement in National Longitudinal Transition Studies}

The Office of Special Education Program (OSEP) of the U. S. Department of Education has funded a total of three longitudinal studies over the past 30 years. The following section will provide an overview and research findings of the last two studies in the series.

\section{NLTS-2 Overview}

In 1997, OSEP funded the NLTS-2 as a continued examination of post-school outcomes for youth with disabilities receiving services under IDEA. The NLTS-2 study reported on the experiences and outcomes of youth with disabilities during and after high school over a 10-year timespan, between 2000-2010 in five waves of data collection. 


\section{NLTS-2 Reports}

The No Child Left Behind Act of 2001 (NCLB) addressed the importance of parent involvement and operationally defined the role parents have in assisting in their children's education. In response to NCLB, a special report detailing findings from NLTS-2 on family involvement of youth with disabilities was released by OSEP (Newman, 2005). The report generated a national picture of family participation in developing educational plans for youth with disabilities at the secondary level based on the following: (a) home involvement; (b) school activities involvement; (c) IEP participation; and (d) family expectations. Findings revealed youth with disabilities were more likely to receive assistance with homework from parents at a rate of $21 \%$ compared to $4 \%$ of the general population. Further, parents of youth with disabilities engaged in more school activities than the general population parent except for a slight difference of $2 \%$ shown in the category of volunteering. Parents reported attending IEP the meeting at a rate of $88 \%$, school personnel developing the IEP goals $45 \%$ of the time, and feeling their contribution was the "right amount" at a rate of $65 \%$ through the parent interview (Newman, 2005).

The NLTS-2 report on support and services for youth with disabilities surveyed parents in many areas related to involvement. One finding by Levine et al. (2004) indicated parents responded "some" and "great deal" respectively to their level of effort to access additional related services for their youth for post-school planning supporting youth with autism $(27.7 \% / 32.5 \%$,$) , mental retardation (20.8 \% / 25.7 \%)$, and multiple disabilities $(22.2 \%, 27.3 \%)$. Additionally, parents of youth with autism reported their efforts to access services revealed 
limited availability or their child did not qualify for the related services. Further, these authors found when considering race that parents supporting African American youth with disabilities were twice as likely to use a "great deal of effort" to access services for their child with a disability when compared to White and Hispanic youth.

\section{NLTS-2 Secondary Analyses}

Secondary analyses were conducted using the NLTS-2 data on the role of parent involvement in facilitating post-school outcomes for youth with disabilities. The topics include: (a) the effects of socio-economic status of parents on parent involvement and expectations (Wagner et al., 2014); (b) the effects of parent involvement on actual outcomes (i.e., graduating from high school with a standard diploma, postschool employment, and enrollment/completion of postsecondary education; Doren et al., 2012); and (c) parent involvement by specific disability category (Cawthon et al., 2015). Interestingly, the Cawthon and colleagues (2015) investigation on behaviors and expectation of parents on transition related outcomes (general life, employment, and academic) for individuals who are Deaf or hard of hearing found that none of the parent involvement variables using behavior as a measure were a predictor. Conversely, parent expectations were a predictor on expected outcomes related to living independently, employment, and education 10 years after high school for this population.

While Cawthon and colleagues (2015) focused on parent behaviors and expectations, Doren et al. (2012) investigated the predictive nature of parent expectation on postschool outcomes. Findings showed parent expectations as a significant predictor of outcomes for youth 
upon graduating from high school, achieving paid employment, and enrolling in postsecondary education programs.

Using the NLTS-2 data, Wagner et al. (2012) examined parent involvement through meeting attendance, satisfaction with their decision-making involvement, and factors associated with parent attendance and satisfaction with their involvement using the Epstein framework on parent involvement. Results showed factors such as high involvement at school and home, and support group membership increased parent attendance and satisfaction. Notably, parents with high at home involvement were found to report a negative satisfaction rating.

Other secondary analyses using the NLTS2 data covered topics on employment and postsecondary education and in-school experiences for students with IDD (Carter et al., 2011; Grigal et al., 2011). A strong predictor of student success after high school with employment and postsecondary education was indicated when parent expected the youth to attain positive postschool outcomes (Carter et al., 2011; Papay \& Bambara, 2014). Thus, understanding parent expectations and in-school experiences using the NLTS-2 has shown the influence of families with transition planning and outcomes for students with disabilities.

\section{NLTS 2012 Overview}

The National Longitudinal Transition Study 2012 (NLTS 2012) is the third in a series of

longitudinal studies sponsored by the U. S. Department of Education to examine the experiences of youth with disabilities receiving services under IDEA and their families (Burghardt et al., 2017). A detailed report is available on the NLTS 2012 website (https://ies.ed.gov/ncee/pubs/20174016/pdf/20174021.pdf) which includes an executive 
summary, sampling details, data collection, analysis procedures, and analyses reports. The study used a nationally stratified probability sample of 572 school districts, charter schools, and special schools (serving deaf and/or blind youth) serving youth in the transition age range (13-22).

The final reports were presented in three volumes. Volume 1 focused on comparisons between youth with disabilities serviced under IDEA, youth serviced by Section 504 of the Rehabilitation Act of 1973, and youth without an IEP or 504 plans (Lipscomb.et al., 2017). Volume 2 reported findings on youth with disabilities across 12 disability categories defined in IDEA (Lipscomb.et al., 2017). The final report, Volume 3, examined youth with disabilities across the three longitudinal studies on transition (Liu et al., 2018).

\section{NLTS 2012 Secondary Analyses}

Studies conducted using the NLTS 2012 data for secondary analyses have examined a myriad of topics related to transition planning for students with disabilities. The topics include: (a) parents' post-secondary education expectations for students with IDD (Qian et al., 2020); (b) parent involvement at home and school as defined by the NLTS 2012 survey predicting bullying of students with autism spectrum disorder (ASD; Matthias et al., 2021); and (c) parent reports on student experiences with participating in the IEP/transition planning meeting (Johnson et al., 2020). One finding called for schools to develop systems to support training for parents on transition planning and building navigational skills to access post-school options (Qian et al., 2020). Qian and colleagues (2020) acknowledged the importance of understanding and building post-school expectation with parents supporting students with disabilities. Finally, research on 
students with IDD participation in the IEP and transition planning process revealed limited involvement when compared with other youth (Johnson et al., 2020).

\section{Summary}

In this chapter, I conducted a review of current literature examining qualitative studies focused on parental reports on involvement in transition planning. Results from parent reports revealed two categories, experiences, and actions, which influenced parent involvement. The interaction between the themed experiences and actions was cyclical and appeared to influence parent involvement in the transition planning process, and the level of involvement by the family.

In addition to current literature on parental reports through qualitative studies, current literature and reports based on NLTS-2 and NLTS 2012 data were reviewed. Findings confirmed that African American youth and youth with IDD continue to struggle with achieving postschool outcomes. This is especially concerning when youth are African American and serviced through IDEA under the category of IDD as both identities present with dismal post-school outcomes. Yet, no study has been conducted to identify factors specifically influencing parent involvement in transition planning focusing on the intersection of disability and race. Hence, this study serves to examine associations between transition factors and parent involvement using the intersection of race and specific disabilities to determine opportunities to improve post-school outcomes. 


\section{CHAPTER III: METHOD}

There currently exists a gap in the research examining parent involvement of families supporting African American youth with IDD with transition planning. While research on family involvement exists, there are no studies specifically focused on examining factors associated with family involvement for this population. Thus, this study used the NLTS 2012 data to identify factors linked to promoting parent involvement of families supporting transition-age African American youth with IDD. The research questions used to guide this inquiry were:

1. To what extent do families report supporting African American youth with IDD through parent involvement in transition planning as defined by the NLTS 2012 data set?

2. What is the association between SES, marital status, educational level, or employment status and parent involvement in transition planning of families supporting African American youth with IDD as defined by the NLTS 2012 study?

3. What is the association between family experiences with the school and parent involvement in transition planning of families supporting African American youth with IDD as defined by the NLTS 2012 study?

4. What is the association between post-school family expectations and parent involvement in transition planning of families supporting African American youth with IDD as defined by the NLTS 2012 study?

\section{Research Design}

This study used a correlational design to explore the association between parent demographics, parent experiences, and parent expectations of school-based and home-based 
parent involvement for families supporting African American youth with IDD. Results from a review of the literature and legislative mandate definitions were used to identify the factors selected from the NLTS 2012 data as variables for the study.

\section{Data Collection}

\section{Data Collection Procedures}

The NLTS 2012 study, funded by the U.S. Department of Education, included data collected with a parent survey developed by the NLTS research team. The participating school districts provided administrative data comprised of the sampled youth contact information and background characteristics. Surveys were administered to parents and youth in two phases: February through October 2012 and January through August 2013. Phase 1 used computerassisted telephone interviewing to conduct interviews with parents. Phase 2 data collection protocol was revised to add a web-based survey option and field interviews to increase response rates. For this study, I focused on the responses collected from surveys completed by parents supporting African American students with IDD.

\section{Parent Survey}

NLTS 2012 data were collected using a parent survey which consisted of five sections: (a) youth experiences at school; (b) parent involvement at school; (c) abilities, disabilities; and services; (d) experiences with the IEP, 504, and school support; and (e) youth plans. The items included in the survey were constructs adopted from previous longitudinal studies on transition, along with new constructs developed to address current relevant policy issues in the field (see Appendix A). Table 2 outlines the topics and definitions covered in the parent survey. 


\section{Table 2}

Topics Covered in NLTS 2012 Parent Survey

\begin{tabular}{|c|c|}
\hline Topic & Definition \\
\hline Disabilities and abilities & $\begin{array}{l}\text { If youth had a disability or not; If so, were services rendered } \\
\text { under an IEP or 504; Level of student functional ability }\end{array}$ \\
\hline $\begin{array}{l}\text { School enrollment and } \\
\text { service receipt }\end{array}$ & $\begin{array}{l}\text { Youth enrollment and graduation status; Whether student was } \\
\text { ever suspended or expelled; Receipt of special education } \\
\text { and related services; Other supports received through } \\
\text { the school }\end{array}$ \\
\hline $\begin{array}{l}\text { Parent's involvement in } \\
\text { their children's } \\
\text { education }\end{array}$ & $\begin{array}{l}\text { Whether parents attend school events, met with teachers, helped } \\
\text { with homework, participated in the IEP and transition } \\
\text { meetings }\end{array}$ \\
\hline $\begin{array}{l}\text { Parent expectations for } \\
\text { their children's } \\
\text { futures }\end{array}$ & $\begin{array}{l}\text { The education level parents expect the youth will attain; } \\
\text { Challenges in furthering education and employment; } \\
\text { Expected living arrangements and financial } \\
\text { independence }\end{array}$ \\
\hline $\begin{array}{l}\text { Background characteristics } \\
\text { and socioeconomic } \\
\text { status } \\
\end{array}$ & $\begin{array}{c}\text { Household size; Primary language used at home; Youths' race } \\
\text { and ethnicity; Parents' income, education, and marital } \\
\text { status; Household receipt of federal financial assistance }\end{array}$ \\
\hline \multicolumn{2}{|c|}{ Source: National Longitudinal Transition Study 2012 restricted-use data file: Sampling and } \\
\hline \multicolumn{2}{|c|}{ 2012-2013 survey data (RUF), "Parent Baseline Questionnaire”, U.S. Department of } \\
\hline \multicolumn{2}{|c|}{ Education, Institute for Education Sciences, National Center for Education Statistics. } \\
\hline \multicolumn{2}{|r|}{ Variables } \\
\hline \multicolumn{2}{|c|}{ The variables presented in the following sections were selected from the NLTS 2012} \\
\hline \multicolumn{2}{|c|}{ parent survey focused on parent demographics, experiences, expectations, and types of parent } \\
\hline \multicolumn{2}{|c|}{ involvement from all respondents to the survey. The section will outline the independent and } \\
\hline
\end{tabular}




\section{Independent Variables}

The independent variables used in this study were selected from items included in the parent survey of the NLTS 2012. The items selected were categorized into three themes: (a) family demographics (4 variables); (b) parent experiences (7 variables); and (c) parent expectations (3 variables). I selected parent experience items based on the finding from the literature review exploring parent narratives on transition planning experiences (Francis et al., 2015; Francis et al., 2019; Hetherington et al., 2010; Lo \& Bui, 2020; Rabren \& Evans, 2016; Rehm et al., 2013; Young et al., 2016) and existing studies addressing secondary analyses of NLTS-2 and NLTS 2012.

Parent expectations are predictors of successful postschool outcomes for persons with disabilities (Mazzotti et al., 2016). Based on a prior research, I defined parent expectation domains as: (a) paid employment (Carter et al., 2012; Doren et al., 2012; Papay \& Bambara, 2014); (b) post-secondary education (Chiang et al., 2012; Doren et al., 2012; Papay \& Bambara, 2014); and (c) independent living (Carter et al., 2012, 2018).

The following describes the variables used in each section for analyses. Further, variable tables with variable names found in the NLTS 2012 codebook are included in each section, including variable names found in the NLTS 2112 codebook (Bloomenthal et al., 2017), descriptions of the variables, and frequency for each response to items from all parents supporting students with IDD. 


\section{Parent Supporting Youth with IDD Demographics}

Four family demographic variables of all parents supporting youth with IDD were selected for this study. Table 3 outlines each demographic variable with the frequency and percentage for each category. The household income measure used a four-point scale. Parents reported marital status using a six-point scale. Educational level was reported by parents using a six-point scale. Lastly, parent employment status was reported using a dichotomous scale.

\section{Table 3}

Frequency of All Parents Supporting Youth with IDD Demographics

\begin{tabular}{cccc}
\hline Variable & \multicolumn{1}{c}{ Family Demographics } & $n$ & $(\%)$ \\
\hline p_h_income & Household income & & 28.76 \\
& $\$ 0-\$ 40,000$ & 6,320 & 13.87 \\
& $\$ 40,001-\$ 80,000$ & 3,050 & 6.60 \\
& $\$ 80,001-120,000$ & 1,450 & 5.32 \\
H1 & More than $\$ 120,000$ & 1,170 & \\
& Marital status & & 33.49 \\
& Married & 7,360 & 3.72 \\
& In a marriage-like relationship & 820 & 8.75 \\
& Divorced & 1,920 & 3.24 \\
p_h_ed & Separated & 710 & 2.04 \\
& Widowed & 450 & 7.07 \\
& Single, never married & 1,550 & 8.04 \\
& Highest Education & & 21.07 \\
& Less than high school & 1,770 & 3.51 \\
& High School diploma or GED & 4,630 & 7.96 \\
& Technical or trade school degree & 770 & 10.80 \\
2-year college degree & 1,750 & 6.51 \\
& 4-year college degree & 2,370 & 11.69 \\
& Graduate degree & 1,430 & 46.61 \\
\hline
\end{tabular}


Note. $n$ = unweighted frequency was rounded to the nearest 10, per the IES data-reporting requirement.

Source: U.S. Department of Education, National Center for Education Statistics, National Longitudinal Transition Study 2012.

\section{Parent Experiences}

Seven variables from the parent survey of all parents supporting youth with IDD related to their experiences were used to establish the school personnel and school-based activities. These included four variables specifically related to parent experiences. Three variables on youth participation were included to address reports of increased involvement in the transition planning process when parents perceived their youth lacked the capacity to, or were unwilling to, participate due to factors related to their disability. Findings noted in Chapter 2 showed the level of parent involvement was influenced by experiences and actions of their youth in the transition planning process (Francis et al., 2019; Hetherington et al., 2010; Rabren \& Evans, 2016). Therefore, variables specifically identified through parent reports were considered in this study. Parents responded to dichotomous scale for all survey items in this section. Table 4 shows the frequency of the responses of all parents supporting youth with IDD to the items related to experiences with school activities. 
Table 4

Frequency of All Parents Supporting Youth with IDD Experiences

\begin{tabular}{|c|c|c|c|}
\hline Variable & Parent Experiences & $n$ & $(\%)$ \\
\hline \multirow[t]{3}{*}{ D33 } & Training on rights and responsibilities & & \\
\hline & Yes & 3,300 & 15.03 \\
\hline & No & 6,620 & 30.15 \\
\hline \multirow[t]{3}{*}{$\mathrm{F} 4$} & Met w/school counselor PS options & & \\
\hline & Yes & 4,380 & 19.94 \\
\hline & No & 4,130 & 18.81 \\
\hline \multirow[t]{3}{*}{ p_y_transagency } & $\begin{array}{l}\text { Community service agency staff } \\
\text { attended TPM }\end{array}$ & & \\
\hline & Yes & 1,190 & 5.44 \\
\hline & No & 1,600 & 7.28 \\
\hline \multirow[t]{3}{*}{ p_p_tpinvite } & Parents invited to TPM & & \\
\hline & Yes & 2,630 & 11.99 \\
\hline & No & 250 & 1.14 \\
\hline \multirow[t]{3}{*}{ p_y_tpinfo } & Youth received info at TPM & & \\
\hline & Yes & 1,190 & 5.44 \\
\hline & No & 1,600 & 7.28 \\
\hline \multirow[t]{3}{*}{ p_y_goalsomeinput } & Youth provided input IEP/TPM & & \\
\hline & Yes & 1,920 & 8.76 \\
\hline & No & 1,730 & 7.86 \\
\hline \multirow[t]{3}{*}{ p_y_goals } & Youth part of developing IEP/TPM goals & & \\
\hline & Yes & 1,390 & 6.34 \\
\hline & No & 2,210 & 10.07 \\
\hline
\end{tabular}

Note. $n=$ unweighted frequency was rounded to the nearest 10, per the IES data-reporting requirement. $\mathrm{TPM}=$ Transition planning meeting, $\mathrm{IEP}=$ Individualized Education Program.

Source: U.S. Department of Education, National Center for Education Statistics, National Longitudinal Transition Study 2012.

\section{Parent Expectations}

The survey on parent expectations included three variables on postschool outcomes: (a) employment; (b) education; and (c) independent living. Using a four-point rating scale for the 
employment outcome, parents were asked if the youth will be financially independent without reliance on governmental or family support by age 30 . The educational expectation outcome for youth was measured using a five-point rating scale. The last variable in this section surveyed parents' expectation for independent living options for their youth by age 30 . The frequency and percentage of parent expectations from all parents supporting youth with IDD responses are reported in Table 5.

Table 5

Frequency of All Parents Supporting Youth with IDD Expectations

\begin{tabular}{clcc}
\hline Variable & \multicolumn{1}{c}{ Parent Expectation } & $n$ & $(\%)$ \\
\hline p_y_finanexp & Employment & & \\
& Definitely will & 3,870 & 17.64 \\
& Probably will & 3,870 & 17.64 \\
& Probably won't & 1,700 & 7.75 \\
& Definitely won't & 1,480 & 6.62 \\
p_y_edexpect & & \\
& Educational & 130 & 0.61 \\
& Less than high school & 1,860 & 8.49 \\
& High School diploma or GED & 620 & 2.84 \\
& Technical or trade school degree & 1,450 & 6.61 \\
& 2-year college degree & 3,100 & 14.10 \\
& 4-year college degree & 1,860 & 8.46 \\
p_y_livingexp & Graduate degree & & \\
& Live independently & 9,180 & 41.81 \\
& Yes & 3,370 & 15.36 \\
\hline
\end{tabular}

Note. $n=$ unweighted frequency was rounded to the nearest 10, per the IES data-reporting requirement.

Source: U.S. Department of Education, National Center for Education Statistics, National Longitudinal Transition Study 2012. 


\section{Dependent Variables}

Parent involvement in their youth's education was explored in the NLTS 2012 parent survey through items related to parents' attending school events, volunteering, meeting with teachers, helping with homework, having post-school discussions with their youth, attending in the IEP meeting, and attending the transition planning meetings (Burghardt et al., 2017).

Also noted in Chapter 2, parent involvement in support of secondary transition planning was reported outside of the school experiences. Therefore, the variable reporting parent response to school discussion with their youth was included to represent an aspect of family involvement outside of school. The focus of this study was to identify relationships between factors related to experiences and expectations with involvement connected with parent actions. Thus, four out of the seven parent involvement variables were selected for this study which aligned with the previous literature measuring conducting secondary analyses on national longitudinal data (Wagner et al., 2012).

The dependent variables were divided into two themes, parent involvement at home and parent involvement at school. The following sections describe each variable and theme related to parent involvement.

\section{Parent Involvement at Home}

Two variables from the parent survey were included as parent involvement at home: parent assistance with homework and parent discussion with youth about post-school plans. The first parent involvement variable focused on homework assistance measured by five response options related to how often the youth received help with homework. Parent discussion with 
youth about post-school plans was measured using a four-point scale to rate how often they discussed school plans with the youth. Table 6 shows the frequency of all parents supporting youth with IDD responses for both home involvement variables.

\section{Table 6}

Frequency of All Parents of Youth with IDD Involvement at Home

\begin{tabular}{clcc}
\hline \multicolumn{1}{c}{ Variable } & \multicolumn{1}{c}{ PI at home } & $n$ & (\%) \\
\hline p___helphomework & $\begin{array}{l}\text { Parent or another adult assisted } \\
\text { with homework }\end{array}$ & \\
& 5 or more times a week & 1,730 & 7.87 \\
& 3 to 4 times a week & 1,890 & 8.62 \\
& 1 to 2 times a week & 3,510 & 15.96 \\
& Less than once a week & 2,410 & 10.96 \\
p_p_talksch & Never & 3,330 & 15.16 \\
& Discussed school & 10,560 & 48.08 \\
& Regularly & 1,620 & 7.38 \\
& Occasionally & 320 & 1.45 \\
& Rarely & 430 & 1.97 \\
\hline
\end{tabular}

Note. $n=$ unweighted frequency was rounded to the nearest 10 , per the IES data-reporting requirement. PI = Parent involvement.

Source: U.S. Department of Education, National Center for Education Statistics, National Longitudinal Transition Study 2012.

\section{Parent Involvement at School}

Attending the IEP and attending transition meetings were the two school-based involvement measures included in the analysis for this study. All parents supporting youth with IDD responded to items which inquired if they attended the IEP meeting and a transition 
planning meeting (when offered at their school) in the past two years using a two-point scale (see Table 7).

Table 7

Frequency of All Parents of Youth with IDD Involvement at School

\begin{tabular}{llcc}
\hline Variable & \multicolumn{1}{c}{ PI at school } & $n$ & $(\%)$ \\
\hline p_p_iepmeet & Attended IEP meeting & & 37.99 \\
& Yes & 8,340 & 5.93 \\
& No & 1,300 & \\
p_p_tpmeet & Attended TPM & & 11.69 \\
& Yes & 2,570 & 6.52 \\
\hline
\end{tabular}

Note. $n=$ unweighted frequency was rounded to the nearest 10, per the IES data-reporting requirement.

Source: U.S. Department of Education, National Center for Education Statistics, National Longitudinal Transition Study 2012.

\section{Population}

The NLTS 2012 participating sample included 432 districts, with 12,990 parent and 11,130 youth completed surveys. Youth and parents responded to items related to their background and experiences with topics related to secondary transition planning for youth with and without disabilities. The youth with disabilities were served under 12 categories established in IDEA or a 504 plan, while other participants did not receive services under IDEA or 504.

The identified disabilities being analyzed in this study are autism, ID, and multiple disabilities listed as d_y_disability $=1,5$, and 6 in the NLTS 2012 data set. Overall, parents supporting all youth within the targeted categories totaled 5,350 (autism, $n=1,650$; intellectual 
disabilities, $n=2,090$; multiple disabilities, $n=1,610)$. The identified sample $(n=610)$ from the overall population were parents supporting African American students with IDD.

\section{Data Analysis}

All tests were run in Stata 16 because this software allows for complex survey design analysis. To obtain a representative sample of adolescents with disabilities from across the United States, the NLTS 2012 used a stratified sampling stratum determined by district and disability status. Due to this sampling design, I used the svyset c_apsu [ pweight $=$ $<y \_w e i g h t$ _enrolledyouth $>$ ] analytic weighting within the c_astratum strata command for all analyses. This ensured the sampling design was considered and that estimates, and standard errors were correct. As shown in Table 8, data analyses were conducted using descriptive statistics for Research Question 1, and chi-square, Fisher's exact, and Pearson residual statistical testing for Research Questions 2, 3, and 4.

Chi-square statistical testing was used to determine the association between variables. Fisher's exact testing was conducted on all models to address expected frequencies less than 5 (Crowson, 2020; Howell, 2011). The statistical significance level was declared as $\alpha=.05$. Post hoc testing, Pearson residual was conducted on models determined to be statistically significant to identify which cells were contributing to the overall discrepancy between the observed and expected frequency counts (Crowson, 2020). The absolute value $>1.96$ was used to determine if a statistically significant difference was found in the residual analysis.

To answer Research Question 1, I ran frequencies on all parent involvement outcome variables. There was no missingness as all missing data were due to skip logic where parents 
were not respondents to the question based on previous questions. Frequency counts for assisting with homework and discussing postschool plans were determined based on parent responses on how often they reported engaging in the task. Frequencies were also calculated for a number of participants who reported attending the IEP meeting and attending the transition planning meeting.

To answer Research Question 2, I ran chi-square, Fisher's exact testing and post hoc statistical testing between the parent involvement variables and family demographics to explore differences in dependent variables by family characteristics. For family demographics, I ran four models. All models used the following as dependent variables: (a) assisting with homework; (b) discussing postschool plans; (c) attending the IEP meeting; and (d) attending the transition planning meeting. The first model used parental income level as the independent variable. The second model used parent marital status as the independent variables. The third model used parent educational level as the independent variable. The final model used parent employment status as the independent variable.

To answer Research Question 3, I ran chi-square, Fisher's exact testing and post hoc statistical testing between the dependent variables and family experiences variables to explore differences in dependent variables by family experiences. Using family experience variables, I ran seven models. All models used: (a) assisting with homework; (b) discussing postschool plans; (c) attended the IEP meeting; and (d) attended the transition planning meeting as the dependent variables. 
The following variables were used as independent variables for experiences: (a) the parent received training on disability rights and responsibilities; (b) the parent met with school counselor; (c) the community service agency staff attended the transition planning meeting; (d) the parent were invited to the transition planning meeting; (e) the youth received post-school information at the transition planning meeting; (f) the youth provided some input in IEP and transition plan; and $(\mathrm{g})$ the youth shared an equal part of developing IEP and transition goals.

To answer Research Question 4, I ran chi-square, Fisher's Exact test and post-hoc statistical testing between the parent involvement variables and family expectations to explore differences in dependent variables by family expectations. Expectations were measured in three domains, meaning three models were used to analyze the data. All models used: (a) assisting with homework; (b) discussing postschool plans; (c) attended the IEP meeting; and (d) attended the transition planning meeting as the dependent variables. The three variables used for parent expectations, or independent variables, were (a) employment; (b) education; and (c) independent living.

\section{Data Preparation}

\section{New Variable}

To prepare the data for analysis, I created a new variable called d_y_disabilityIDD combining data for youth in the categories of autism, intellectual disability, and multiple disabilities. The three categories included in the new variables align with previous research analyses of youth with IDD (Carter et al., 2012; Griffin et al., 2010). 


\section{Recoding}

In the initial run of the data, all categories were entered in Stata 16. chi-square, Fisher's exact, and Pearson residual testing were performed using assigned coded independent and dependent variables from the NLTS 2012. However, errors occurred related to Fisher's exact test results due to the number of expected frequencies being less than five in some categories. To address the errors, categories collapsed to allow for statistical runs of all variables (Knapp, 2018).

The recoded categories were generated based on the research questions focus and the use of similar variables in existing research. As shown in Table 9, six variable categories required recoding for analyses. 


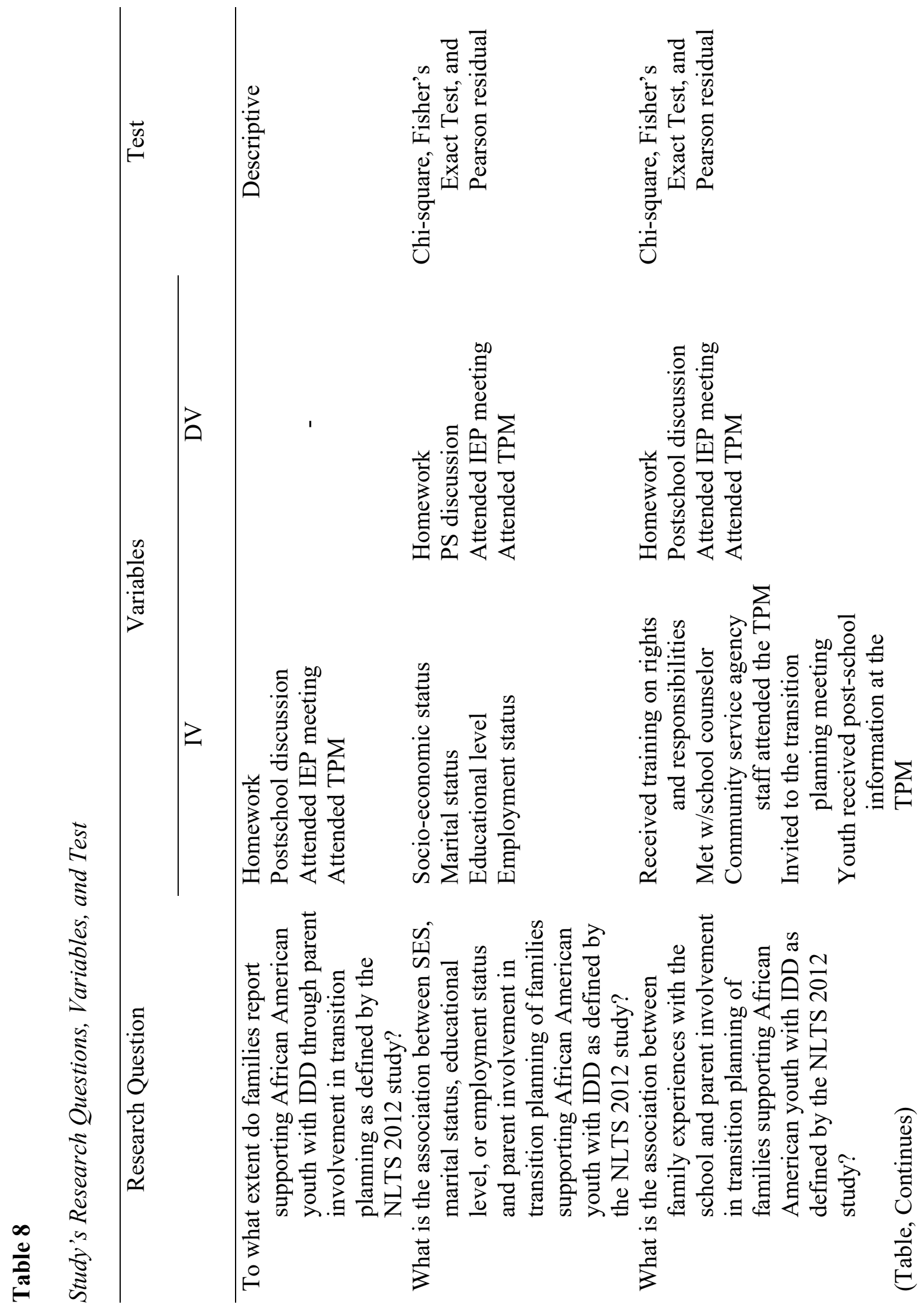




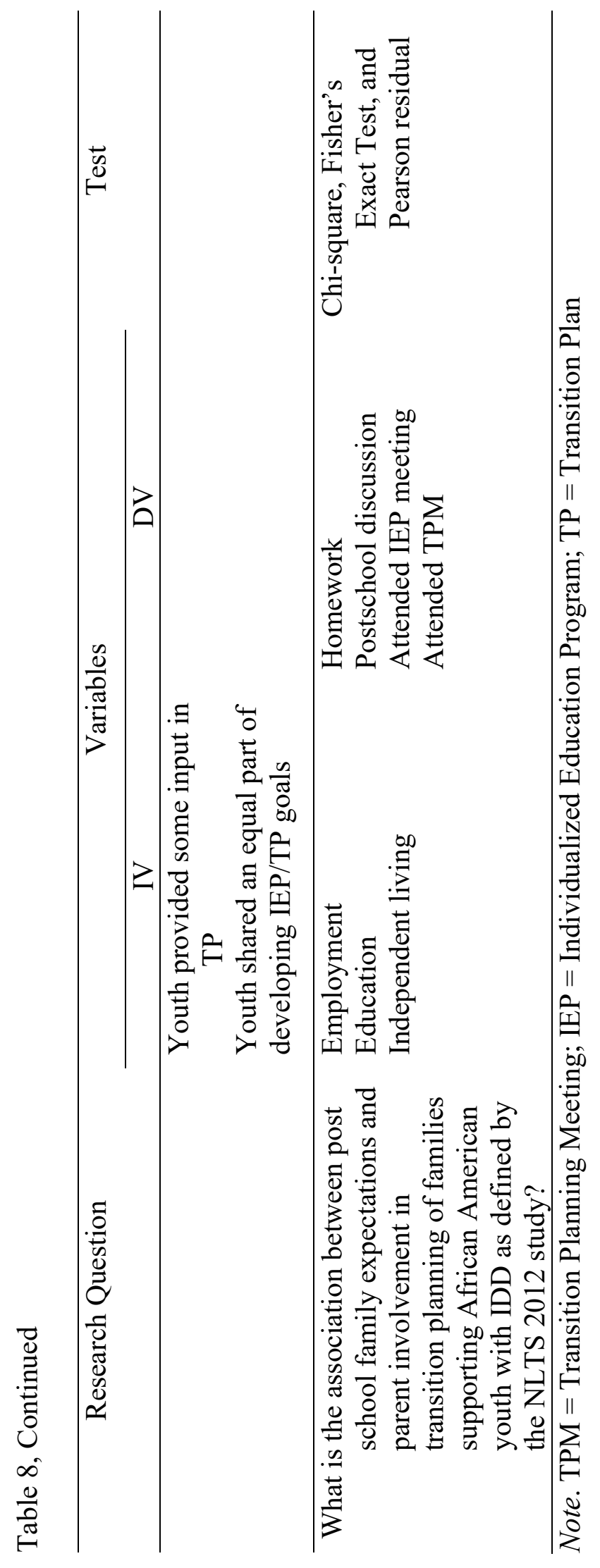


Table 9

Recoded Variables

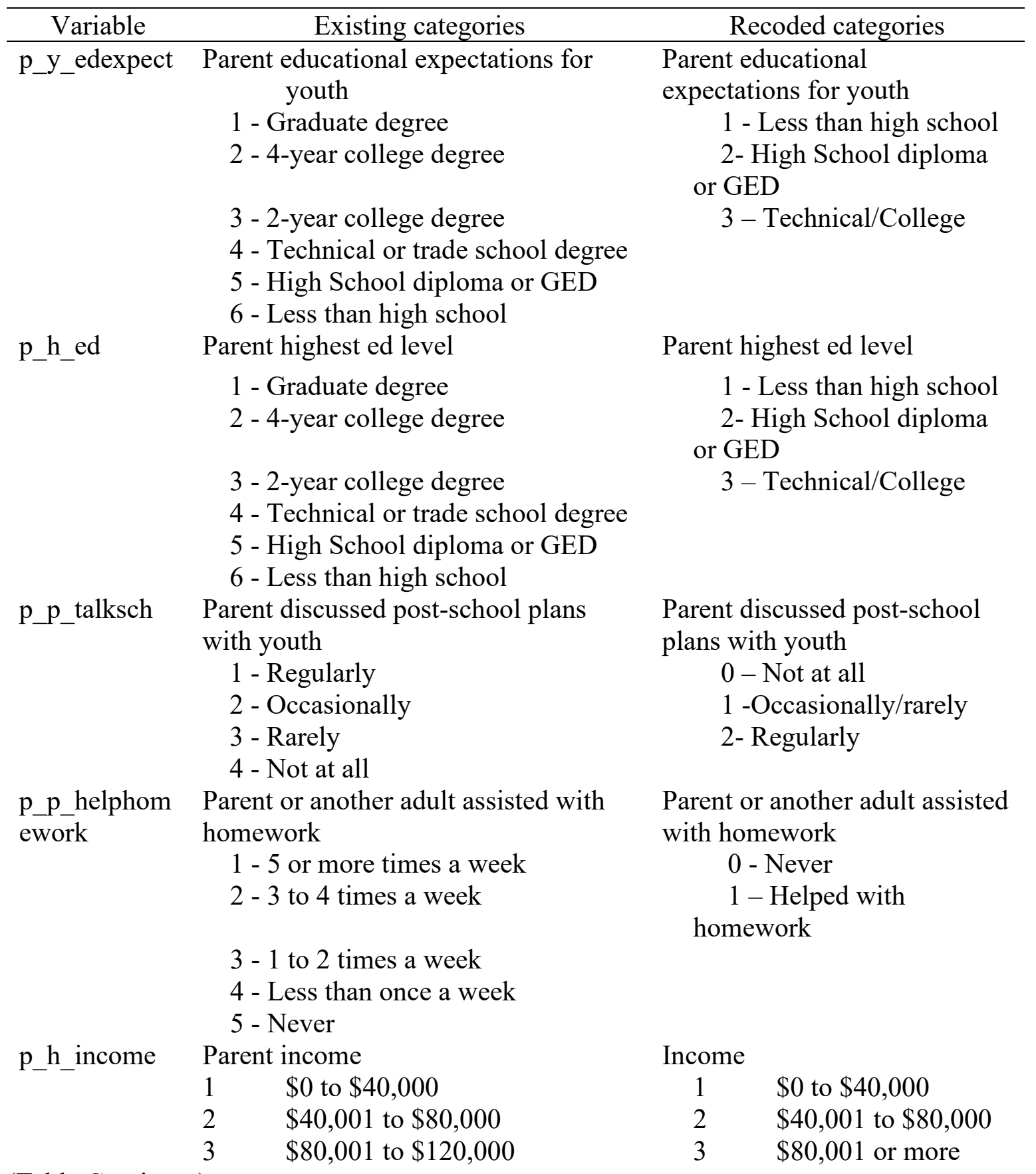

(Table Continues) 
Table 9, Continued

\begin{tabular}{|c|c|c|c|}
\hline Variable & \multicolumn{2}{|c|}{ Existing categories } & Recoded categories \\
\hline & 4 & More than $\$ 120,000$ & \\
\hline \multirow[t]{7}{*}{ H14 } & & marital status & Marital Status \\
\hline & 1 & Engaged & $0 \quad$ Not married \\
\hline & 2 & Single, never married & Married \\
\hline & 3 & Married & \\
\hline & 4 & In a married-type relationship & \\
\hline & 5 & Divorced & \\
\hline & 6 & Widowed & \\
\hline
\end{tabular}

Source: National Longitudinal Transition Study 2012 restricted-use data file: Sampling and 2012-2013 survey data (RUF), "Parent Baseline Questionnaire”, U.S. Department of Education, Institute for Education Sciences, National Center for Education Statistics. 


\section{CHAPTER IV: RESULTS}

The results included in this chapter address the research questions guiding this study. The following sections outline parent reported frequency of involvement at home and school. In addition, results from chi-square, Fisher's exact, and Pearson residual testing identified factors associated with parent involvement.

\section{Report on Parent Involvement at Home and School}

\section{Parent Involvement at Home}

Parents reported supporting their youth through parent involvement home factors related to successful post-school transition were identified using descriptive statistics. Table 10 presents the two variables used to measure parent involvement at home - assisting with homework and discussing post-school plans for parents supporting African American (PSAA) students. Seventy-three percent of parents supporting African American students with IDD reported providing homework assistance at least once per week. Over 95\% of parents reported having school plan discussions with their youth, with the majority $(75 \%)$ speaking to their child regularly.

\section{Table 10}

Parents Involvement at Home for PSAA Youth with IDD

\begin{tabular}{lccc}
\hline Variable & Variable description & $n$ & $(\%)$ \\
\hline $\mathrm{p} \_$_ _helphomework & Parent or another adult assisted & & \\
& with homework & 120 & 19.51 \\
& 5 or more times a week & 110 & 17.21 \\
& 3 to 4 times a week & 140 & 22.79 \\
& 1 to 2 times a week & 80 & 13.30 \\
(Table Continues) & Less than once a week & &
\end{tabular}


Table 10, Continued

\begin{tabular}{llcc}
\hline Variable & Variable description & $n$ & $(\%)$ \\
\hline & Never & 160 & 26.39 \\
P_p_talksch & Parent discussed post-school & & \\
& plans with youth & & \\
& Regularly & 460 & 75.41 \\
& Occasionally & 100 & 16.56 \\
& Rarely & 20 & 2.95 \\
& Not at all & 30 & 5.08 \\
\hline
\end{tabular}

Note. $n=$ unweighted frequency was rounded to the nearest 10, per the IES data-reporting requirement. PSAA $=$ Parents Supporting African American Students with IDD.

Source: National Longitudinal Transition Study 2012 restricted-use data file: Sampling and 2012-2013 survey data (RUF), “Parent Baseline Questionnaire”, U.S. Department of Education, Institute for Education Sciences, National Center for Education Statistics.

\section{Parent Involvement at School}

Parent reported involvement in school-based meetings are displayed in Table 11. Eightyfour percent of parents reported attending an IEP meeting within the last 2 years, while only $30 \%$ attended a transition planning meeting.

Table 11

Parents Involvement at School for PSAA Youth with IDD

\begin{tabular}{llcc}
\hline Variable & Variable description & $n$ & $(\%)$ \\
\hline p_p_iepmeet & Attended IEP meeting & & \\
& Yes & 510 & 84.10 \\
& No & 80 & 13.44 \\
p_p_tpmeet & Attended TPM & & \\
& Yes & 180 & 30.49 \\
& No & 80 & 13.77 \\
\hline
\end{tabular}


Note. $n=$ unweighted frequency was rounded to the nearest 10, per the IES data-reporting requirement. PSAA = Parents Supporting African American Students with IDD. TPM = Transition Planning Meeting Source: National Longitudinal Transition Study 2012 restricted-use data file: Sampling and 2012-2013 survey data (RUF), “Parent Baseline Questionnaire”, U.S. Department of Education, Institute for Education Sciences, National Center for Education Statistics.

\section{Chi-Square Analyses}

A series of chi-square statistical testing was conducted to explore the association between involvement at home and school for the targeted population and family demographics, school experiences, and parent expectations. Fifty-six models were run in these analyses. The percentages in the tables below represent the frequency parents reported their participation (or not) in home and school activities when the independent variable was present.

\section{Parent Demographics and Parent Involvement}

\section{Homework Assistance}

As shown in Table $12,68 \%$ of parents earning less than $\$ 40,000$, and $86 \%$ of unmarried parents reported assisting their youth with homework. Most parents assisting with homework held at least a high school diploma (79\%) and were employed full-time (65\%). The chi-square value was significant for marital status, parental education level, and employment status. Income levels of parents were not found to be associated with participation in homework assistance. 
Table 12

PSAA Youth with IDD Demographics and Homework Assistance

\begin{tabular}{|c|c|c|c|c|c|}
\hline \multirow[t]{3}{*}{ Parent Demographics } & \multicolumn{4}{|c|}{ Homework Assistance } & \multirow[t]{3}{*}{$\chi^{2}$} \\
\hline & \multicolumn{2}{|c|}{ Helped w/Homework } & \multicolumn{2}{|c|}{ Never } & \\
\hline & $n$ & $\%$ & $n$ & $\%$ & \\
\hline Income & & & & & 7.2453 \\
\hline$\$ 0-\$ 40,000$ & 390 & 67.54 & 140 & 68.81 & \\
\hline$\$ 40,000-\$ 80,000$ & 100 & 17.54 & 30 & 13.86 & \\
\hline$\$ 80,001$ or more & 40 & 6.49 & 10 & 4.46 & \\
\hline Marital status & & & & & $22.0315 * * *$ \\
\hline Not married & 490 & 85.96 & 160 & 76.73 & \\
\hline Married & 80 & 13.16 & 40 & 17.33 & \\
\hline Education level & & & & & $15.7693 * *$ \\
\hline$<$ than HS & 110 & 19.47 & 50 & 25.74 & \\
\hline HS Grad/GED & 250 & 43.68 & 80 & 37.13 & \\
\hline Tech/Coll & 200 & 34.74 & 60 & 30.69 & \\
\hline Employment status & & & & & $81.1372 * * *$ \\
\hline Yes & 370 & 64.91 & 100 & 51.98 & \\
\hline No & 200 & 34.74 & 80 & 41.58 & \\
\hline
\end{tabular}

Note. $n=$ unweighted frequency was rounded to the nearest 10, per the IES data-reporting requirement. $\%=$ percentage of parents reporting participation (or not) when the independent variable was present. PSAA = Parents Supporting African American Youth with IDD.

Source: National Longitudinal Transition Study 2012 restricted-use data file: Sampling and 2012-2013 survey data (RUF), "Parent Baseline Questionnaire”, U.S. Department of Education, Institute for Education Sciences, National Center for Education Statistics. $* p<.05 . * * p<.01 . * * * p<.001$.

\section{School Discussion}

There was a statistically significant relation between parents discussing school with their child and parent income, marital status, education level, and employment (see Table 13). Most parents who earned less than $\$ 40,000(65 \%)$, were unmarried (84\%), had at least a high school 
diploma (42\%), and worked full-time (63\%) reported discussing school with their child regularly.

Table 13

PSAA Youth with IDD Demographics and School Discussion

\begin{tabular}{|c|c|c|c|c|c|c|c|}
\hline \multirow[t]{3}{*}{ Parent Demographics } & \multicolumn{6}{|c|}{ Parent Discussed School } & \multirow[t]{3}{*}{$\chi^{2}$} \\
\hline & \multicolumn{2}{|c|}{ Regularly } & \multicolumn{2}{|c|}{ Occ/Rarely } & \multicolumn{2}{|c|}{ Not at all } & \\
\hline & $n$ & $\%$ & $n$ & $\%$ & $n$ & $\%$ & \\
\hline Income & & & & & & & $20.23 * *$ \\
\hline$\$ 0-\$ 40,000$ & 370 & 64.98 & 120 & 77.99 & 30 & 71.11 & \\
\hline$\$ 40,000-\$ 80,000$ & 110 & 18.82 & 20 & 10.69 & $<10$ & 6.67 & \\
\hline$>\$ 80,000$ & 40 & 7.14 & $<10$ & 1.89 & & & \\
\hline Marital status & & & & & & & $11.46^{*}$ \\
\hline Not married & 480 & 83.80 & 140 & 86.16 & 30 & 73.33 & \\
\hline Married & 90 & 14.81 & 20 & 10.06 & 10 & 20.00 & \\
\hline Education level & & & & & & & $12.36^{*}$ \\
\hline$<$ than HS & 110 & 18.99 & 40 & 27.67 & 10 & 22.22 & \\
\hline HS Grad/GED & 240 & 41.99 & 70 & 44.03 & 20 & 35.56 & \\
\hline Tech/Coll & 200 & 36.24 & 40 & 24.53 & 20 & 35.56 & \\
\hline Emp. status & & & & & & & $16.63 *$ \\
\hline Yes & 360 & 63.07 & 90 & 59.12 & 20 & 44.44 & \\
\hline No & 200 & 35.54 & 60 & 37.74 & 20 & 48.89 & \\
\hline
\end{tabular}

Note. $n=$ unweighted frequency was rounded to the nearest 10, per the IES data-reporting

requirement. $\%=$ percentage of parents reporting participation (or not) when the independent variable was present. \# Rounds to zero. PSAA = PSAA = Parents Supporting African American Youth with IDD.

Source: National Longitudinal Transition Study 2012 restricted-use data file: Sampling and 2012-2013 survey data (RUF), “Parent Baseline Questionnaire”, U.S. Department of Education, Institute for Education Sciences, National Center for Education Statistics. $* p<.05 . * * p<.01 . * * * p<.001$. 


\section{Attended IEP Meeting}

Table 14 shows that, of all categories, most parents who reported attending the IEP meeting earned less than $\$ 40,000(67 \%)$, were unmarried (85\%), earned at least a high school diploma (78\%), and were employed full-time (61\%). Statistical significance was associated with parent income and educational level only when related to IEP attendance.

\section{Table 14}

PSAA Youth with IDD Demographics and Attended IEP Meeting

\begin{tabular}{|c|c|c|c|c|c|}
\hline \multirow[t]{3}{*}{ Parent Demographics } & \multicolumn{4}{|c|}{ Parent Attended IEP Meeting } & \multirow[t]{3}{*}{$\chi^{2}$} \\
\hline & \multicolumn{2}{|c|}{ Yes } & \multicolumn{2}{|c|}{ No } & \\
\hline & $n$ & $\%$ & $n$ & $\%$ & \\
\hline Income & & & & & $24.46^{* *}$ \\
\hline$\$ 0-\$ 40,000$ & 430 & 66.77 & 90 & 77.12 & \\
\hline$\$ 40,000-\$ 80,000$ & 110 & 17.55 & 10 & 11.02 & \\
\hline$>\$ 80,000$ & 40 & 6.43 & 10 & 4.24 & \\
\hline Marital status & & & & & 0.83 \\
\hline Not married & 530 & 84.91 & 100 & 88.14 & \\
\hline Married & 90 & 15.09 & 10 & 11.86 & \\
\hline Education level & & & & & $25.71 * *$ \\
\hline$<$ than HS & 120 & 18.34 & 40 & 33.90 & \\
\hline HS Grad/GED & 270 & 41.85 & 50 & 44.07 & \\
\hline Tech/Coll & 230 & 36.36 & 30 & 21.19 & \\
\hline Emp. status & & & & & 5.33 \\
\hline Yes & 400 & 61.44 & 70 & 61.02 & \\
\hline No & 230 & 36.21 & 50 & 38.98 & \\
\hline
\end{tabular}

Note. $n=$ unweighted frequency was rounded to the nearest 10 , per the IES data-reporting requirement. $\%=$ percentage of parents reporting participation (or not) when the independent variable was present. $\mathrm{PSAA}=$ Parents Supporting African American Youth with IDD; IEP= Individual Education Program; TPM = Transition Planning Meeting 
Source: National Longitudinal Transition Study 2012 restricted-use data file: Sampling and 2012-2013 survey data (RUF), “Parent Baseline Questionnaire”, U.S. Department of Education, Institute for Education Sciences, National Center for Education Statistics. $* p<.05 . * * p<.01 . * * * p<.001$.

\section{Attended Transition Planning Meeting}

Displayed in Table 15 are associations of parent attendance at the transition planning meeting when demographics were examined in the model. Most parents reporting attending the meeting earned less than $\$ 40,000(68 \%)$, were unmarried (84\%), had a high school diploma (79\%), and employed (59\%).

No statistically significance was evident between parent demographics and parents attending the transition planning meeting.

\section{Table 15}

PSAA Youth with IDD Demographics and Attended Transition Planning Meeting

\begin{tabular}{|c|c|c|c|c|c|}
\hline \multirow[t]{3}{*}{ Parent Demographics } & \multicolumn{4}{|c|}{ Parent Attended Transition Planning Meeting } & \multirow[t]{3}{*}{$\chi^{2}$} \\
\hline & \multicolumn{2}{|c|}{ Yes } & \multicolumn{2}{|c|}{ No } & \\
\hline & $n$ & $\%$ & $n$ & $\%$ & \\
\hline Income & & & & & 4.41 \\
\hline$\$ 0-\$ 40,000$ & 160 & 66.81 & 70 & 66.67 & \\
\hline$\$ 40,000-\$ 80,000$ & 40 & 17.67 & 20 & 14.71 & \\
\hline$\$ 80,001$ or more & 10 & 4.31 & 10 & 8.82 & \\
\hline Marital status & & & & & 1.10 \\
\hline Not married & 200 & 84.05 & 80 & 82.35 & \\
\hline Married & 30 & 13.36 & 20 & 14.71 & \\
\hline Education level & & & & & 6.17 \\
\hline$<$ than High School & 40 & 18.53 & 20 & 20.59 & \\
\hline High School & 100 & 44.83 & 50 & 45.10 & \\
\hline Graduate/GED & & & & & \\
\hline Tech/Coll & 80 & 33.62 & 30 & 31.37 & \\
\hline
\end{tabular}


Table 15, Continued

\begin{tabular}{lccccc}
\hline Parent Demographics & \multicolumn{3}{c}{$\begin{array}{c}\text { Parent Attended Transition Planning Meeting } \\
\text { Yes }\end{array}$} & \multirow{2}{*}{$\chi^{2}$} \\
\cline { 2 - 5 } & $n$ & $\%$ & $n$ & $\%$ & \\
\hline Employment status & 140 & 59.48 & 60 & 62.75 & \\
$\quad$ Yes & 90 & 37.93 & 40 & 34.31 & \\
No & & & & \\
\hline
\end{tabular}

Note. $n=$ unweighted frequency was rounded to the nearest 10, per the IES data-reporting requirement. $\%=$ percentage of parents reporting participation (or not) when the independent variable was present. PSAA = Parents Supporting African American Youth with IDD.

Source: National Longitudinal Transition Study 2012 restricted-use data file: Sampling and 2012-2013 survey data (RUF), “Parent Baseline Questionnaire”, U.S. Department of Education, Institute for Education Sciences, National Center for Education Statistics. $* p<.05 . * * p<.01 . * * * p<.001$.

\section{Association Between Parent Experiences and Parent Involvement}

\section{Homework Assistance}

Parent involvement through homework assistance, experiences with school activities, and personnel factors are represented in Table 16. Sixty percent of parents reported not receiving training on their rights and responsibilities but assisted their child with homework. However, there was no relationship noted between homework assistance and parents receiving training related to their rights and responsibilities. Parents reported assisting their students with homework at a higher rate when they had interactions with the school counselor or other staff members $(40 \%)$, community service agencies attending the meeting $(16 \%)$, and parents being invited to the transition planning meeting (28\%). Reports of involvement with homework assistance were also reported when the youth received information about post-school options 
(20\%), the youth provided some input at the IEP and transition planning meeting $(24 \%)$, and youth's participation in the IEP/transition meeting with goal development (11\%).

It should be noted that parents reported helping students with homework at a higher rate even when the youth did not provide input (48\%) or assist with developing goals at the IEP/transition meeting (24\%). A statistical relationship was noted with parent involvement when associated with all experiences except parent training on their rights and responsibilities.

\section{Table 16}

PSAA Youth with IDD Experiences and Homework Assistance

\begin{tabular}{|c|c|c|c|c|c|}
\hline \multirow[t]{3}{*}{ Parent Experiences } & \multicolumn{4}{|c|}{ Homework Assistance } & \multirow[t]{3}{*}{$\chi^{2}$} \\
\hline & \multicolumn{2}{|c|}{ Helped w/ homework } & \multicolumn{2}{|c|}{ Never } & \\
\hline & $n$ & $\%$ & $n$ & $\%$ & \\
\hline Parent Training & & & & & 7.91 \\
\hline Yes & 220 & 37.89 & 70 & 32.67 & \\
\hline No & 340 & 59.65 & 130 & 64.36 & \\
\hline Met w/school counselor & & & & & $25.25 * *$ \\
\hline Yes & 230 & 39.65 & 60 & 29.21 & \\
\hline No & 180 & 32.28 & 110 & 51.98 & \\
\hline $\begin{array}{l}\text { Community service } \\
\text { agency staff attend TPM }\end{array}$ & & & & & $23.58 * * *$ \\
\hline Yes & 90 & 15.79 & 40 & 18.32 & \\
\hline No & 80 & 13.86 & 40 & 21.29 & \\
\hline Invited to TPM & & & & & $77.48 * * *$ \\
\hline Yes & 160 & 28.42 & 70 & 35.15 & \\
\hline No & 10 & 2.11 & 10 & 4.95 & \\
\hline $\begin{array}{l}\text { Youth received PS info at } \\
\text { TPM }\end{array}$ & & & & & $24.82 * * *$ \\
\hline Yes & 120 & 20.35 & 40 & 21.29 & \\
\hline No & 50 & 9.30 & 40 & 17.82 & \\
\hline $\begin{array}{l}\text { Youth provided some } \\
\text { input in IEP \& TP }\end{array}$ & & & & & $17.13^{*}$ \\
\hline Yes & 70 & 24.26 & 30 & 12.87 & \\
\hline $\begin{array}{l}\text { No } \\
\text { (Table Continues) }\end{array}$ & 140 & 47.59 & 70 & 36.14 & \\
\hline
\end{tabular}


Table 16, Continued

\begin{tabular}{lccccc}
\hline Parent Experiences & \multicolumn{3}{c}{ Homework Assistance } & \multirow{2}{*}{$\chi^{2}$} \\
& Helped w/ homework & Never & \\
\cline { 2 - 5 } & $n$ & $\%$ & $n$ & $\%$ & $12.86^{*}$ \\
Youth equal part of & & & & \\
developing IEP/TP goals & & & & \\
$\quad$ Yes & 60 & 11.23 & 30 & 12.38 \\
$\quad$ No & 140 & 24.74 & 70 & 36.63 \\
\hline
\end{tabular}

Note. $n=$ unweighted frequency was rounded to the nearest 10, per the IES data-reporting requirement. $\%=$ percentage of parents reporting participation (or not) when the independent variable was present. $\mathrm{PS}=$ Postschool; $\mathrm{TPM}=$ Transition Planning Meeting; $\mathrm{IEP}=$ Individual Education Program; TP $=$ Transition Plan. PSAA = Parents Supporting African American Youth with IDD.

Source: National Longitudinal Transition Study 2012 restricted-use data file: Sampling and 2012-2013 survey data (RUF), “Parent Baseline Questionnaire”, U.S. Department of Education, Institute for Education Sciences, National Center for Education Statistics. $* p<.05 . * * p<.01 . * * * p<.001$.

\section{School Discussion}

Table 17 shows the association between school discussion and experiences with the school district. Discussion about school was held regularly less than $40 \%$ of the time across all experiences. A statistical difference was noted with parents' discussions about school when a meeting occurred with the school counselor or staff member, the youth had received information on postschool options, and the youth was an equal partner in developing IEP and transition plan goals. Agency staff attendance, invitation to the transition planning meeting, youth participation 
in the meeting, and goal development residual analysis were not found statistically significant to parent homework assistance.

There was no statistical significance indicated between parents discussing school-related topics with their child when receiving training on disability rights and responsibilities, community service agency staff members attending, and parents receiving an invitation to the transition meeting. Moreover, a youth's input in the IEP and transition plan was not significant to parental discussions about the school.

Table 17

PSAA Youth with IDD Experiences and School Discussion

\begin{tabular}{|c|c|c|c|c|c|c|c|}
\hline \multirow[t]{3}{*}{ Parent Experiences } & \multicolumn{6}{|c|}{ Parent Discussed School } & \multirow[t]{3}{*}{$\chi^{2}$} \\
\hline & \multicolumn{2}{|c|}{ Regularly } & \multicolumn{2}{|c|}{ Occ/Rarely } & \multicolumn{2}{|c|}{ Not at all } & \\
\hline & $n$ & $\%$ & $n$ & $\%$ & $n$ & $\%$ & \\
\hline $\begin{array}{l}\text { Training/rights and } \\
\text { responsibilities }\end{array}$ & & & & & & & 7.08 \\
\hline Yes & 220 & 37.98 & 100 & 37.78 & 20 & 37.78 & \\
\hline No & 340 & 59.23 & 50 & 32.70 & 30 & 62.22 & \\
\hline $\begin{array}{l}\text { Met } w / \text { school } \\
\text { counselor }\end{array}$ & & & & & & & $17.17 * *$ \\
\hline Yes & 230 & 40.42 & 50 & 29.56 & 10 & 17.78 & \\
\hline No & 200 & 35.02 & 70 & 42.14 & 20 & 51.11 & \\
\hline $\begin{array}{l}\text { Community service } \\
\text { agency staff attend } \\
\text { TPM }\end{array}$ & & & & & & & 7.82 \\
\hline Yes & 100 & 17.42 & 20 & 11.32 & 10 & 20.00 & \\
\hline No & 80 & 14.29 & 30 & 21.38 & 10 & 15.56 & \\
\hline Invited to TPM & & & & & & & 77.48 \\
\hline Yes & 170 & 29.44 & 50 & 32.08 & 10 & 28.89 & \\
\hline No & 20 & 2.96 & $<10$ & 1.89 & $<10$ & 6.67 & \\
\hline $\begin{array}{l}\text { Youth received PS } \\
\text { info at TPM }\end{array}$ & & & & & & & $14.61^{*}$ \\
\hline Yes & 120 & 20.91 & 40 & 22.64 & $<10$ & 8.89 & \\
\hline $\begin{array}{l}\text { No } \\
\text { (Table Continues) }\end{array}$ & 60 & 10.80 & 20 & 9.43 & 10 & 26.67 & \\
\hline
\end{tabular}


Table 17, Continued

\begin{tabular}{|c|c|c|c|c|c|c|c|}
\hline \multirow[t]{3}{*}{ Parent Experiences } & \multicolumn{6}{|c|}{ Parent Discussed School } & \multirow[t]{3}{*}{$\chi^{2}$} \\
\hline & \multicolumn{2}{|c|}{ Regularly } & \multicolumn{2}{|c|}{ Occ/Rarely } & \multicolumn{2}{|c|}{ Not at all } & \\
\hline & $n$ & $\%$ & $n$ & $\%$ & $n$ & $\%$ & \\
\hline $\begin{array}{l}\text { Youth provided some } \\
\text { input in IEP \& TP }\end{array}$ & & & & & & & 11.97 \\
\hline Yes & 80 & 13.76 & 20 & 10.69 & 0 & 0.0 & \\
\hline No & 140 & 24.74 & 50 & 31.45 & 20 & 37.78 & \\
\hline $\begin{array}{l}\text { Youth equal part of } \\
\text { developing IEP/TP } \\
\text { goals }\end{array}$ & & & & & & & $22.14 * *$ \\
\hline Yes & 70 & 12.20 & 20 & 12.58 & 0 & 0.00 & \\
\hline No & 160 & 27.18 & 40 & 27.04 & 20 & 37.80 & \\
\hline
\end{tabular}

Note. $n=$ unweighted frequency was rounded to the nearest 10, per the IES data-reporting requirement. $\%=$ percentage of parents reporting participation (or not) when the independent variable was present. \# Rounds to zero. PS = Postschool, TPM = Transition Planning Meeting, $\mathrm{IEP}=$ Individual Education Program, $\mathrm{TP}=$ Transition Plan. PSAA = Parents Supporting African American Youth with IDD.

Source: National Longitudinal Transition Study 2012 restricted-use data file: Sampling and 2012-2013 survey data (RUF), “Parent Baseline Questionnaire”, U.S. Department of Education, Institute for Education Sciences, National Center for Education Statistics. $* p<.05 . * * p<.01 . * * * p<.001$.

\section{Attended IEP Meeting}

Table 18 displays the relationship between parent attendance at the IEP meeting and experiences with school personnel and activities. Over $57 \%$ of parents who attended the IEP responded that they did not receive training on their rights and responsibilities. Moreover, parents who attended the IEP meeting conveyed having a meeting with the counselor (40\%) and 
being invited to the transition planning meeting (32\%). Only $18 \%$ of parents reported attending the IEP meeting and having the community service agency in attendance at the IEP meeting.

Statistical significance between parent attendance at the IEP meeting were evidenced when parents received training on their rights and responsibilities, parents met with the school counselor or other staff, community service agency staff attended the transition planning meeting, and parents were invited to the transition planning meeting. A statistically significance was also noted when youth received information at the transition planning meeting, youth provided input in the development of the IEP and transition plan, and the youth was reported contributing to the goals developed in the IEP and transition plan, with parent attendance at the IEP.

\section{Table 18}

PSAA Youth with IDD Experiences and Attended IEP Meeting

\begin{tabular}{lccccc}
\hline Parent Experiences & \multicolumn{3}{c}{ Parent Attended IEP Meeting } & \multirow{2}{*}{$\chi^{2}$} \\
& \multicolumn{2}{c}{ Yes } & No & \\
\cline { 2 - 5 } & $n$ & $\%$ & & & \\
\hline Training/rights and responsibilities & & & & & $737.66^{* * *}$ \\
$\quad$ Yes & 270 & 42.16 & 20 & 14.41 & \\
$\quad$ No & 370 & 57.68 & 100 & 85.59 & \\
Metw/school counselor & & & & & $22.49 * *$ \\
$\quad$ Yes & 250 & 39.66 & 30 & 22.03 & \\
$\quad$ No & 220 & 34.17 & 70 & 55.08 &
\end{tabular}

(Table Continues) 
Table 18, Continued

\begin{tabular}{|c|c|c|c|c|c|}
\hline \multirow[t]{3}{*}{ Parent Experiences } & \multicolumn{4}{|c|}{ Parent Attended IEP Meeting } & \multirow[t]{3}{*}{$\chi^{2}$} \\
\hline & \multicolumn{2}{|c|}{ Yes } & \multicolumn{2}{|c|}{ No } & \\
\hline & $n$ & $\%$ & $n$ & $\%$ & \\
\hline $\begin{array}{l}\text { Community service agency staff } \\
\text { attend TPM }\end{array}$ & & & & & $20.94 *$ \\
\hline Yes & 110 & 17.55 & 10 & 11.86 & \\
\hline No & 100 & 16.14 & 20 & 16.95 & \\
\hline Parents invited to TPM & & & & & $30.32 * * *$ \\
\hline Yes & 200 & 32.13 & 30 & 22.88 & \\
\hline No & 10 & 2.04 & 10 & 8.47 & \\
\hline Youth got received info at TPM & & & & & $17.66^{*}$ \\
\hline Yes & 140 & 21.63 & 20 & 17.80 & \\
\hline No & 80 & 11.91 & 10 & 11.02 & \\
\hline Youth provided input in IEP \& TP & & & & & $36.11 * * *$ \\
\hline Yes & 90 & 13.32 & 10 & 8.47 & \\
\hline No & 190 & 29.78 & 20 & 16.10 & \\
\hline Youth equal part of developing & & & & & $32.42 * * *$ \\
\hline IEP/TP goals & & & & & \\
\hline Yes & 80 & 13.17 & 10 & 5.08 & \\
\hline No & 190 & 30.09 & 20 & 19.49 & \\
\hline
\end{tabular}

Note. $n=$ unweighted frequency was rounded to the nearest 10, per the IES data-reporting requirement. $\%=$ percentage of parents reporting participation (or not) when the independent variable was present. $\mathrm{PS}=$ Postschool, $\mathrm{TPM}=$ Transition Planning Meeting, $\mathrm{IEP}=$ Individual Education Program, TP $=$ Transition Plan. PSAA $=$ Parents Supporting African American Youth with IDD.

Source: National Longitudinal Transition Study 2012 restricted-use data file: Sampling and 2012-2013 survey data (RUF), “Parent Baseline Questionnaire”, U.S. Department of Education, Institute for Education Sciences, National Center for Education Statistics. $* p<.05 . * * p<.01 . * * * p<.001$. 


\section{Attended Transition Planning Meeting}

As shown in Table 19, parent attendance at the transition planning meeting was compared to experiences with school personnel and activities. Although parents reported no training on responsibilities and rights, 55\% still reported attending the transition planning meeting. Sixtyfive percent of parents that met with school personnel also attended the transition planning meeting. A statistical relationship was found with parents receiving training on their rights and responsibilities, meeting with the school counselor, community service agency staff attendance, being invited to the transition planning meeting, youth receiving information on postschool options at the transition planning meeting, youth providing input in IEP and transition plan, and the youth participating in the developing of the IEP and transition plan goals.

\section{Table 19}

PSAA Youth with IDD Experiences and Attended Transition Planning Meeting

\begin{tabular}{|c|c|c|c|c|c|}
\hline \multirow[t]{3}{*}{ Parent Experiences } & \multicolumn{4}{|c|}{ Parent Attended Transition Planning Meeting } & \multirow[t]{3}{*}{$\chi^{2}$} \\
\hline & \multicolumn{2}{|c|}{ Yes } & \multicolumn{2}{|c|}{ No } & \\
\hline & $n$ & $\%$ & $n$ & $\%$ & \\
\hline $\begin{array}{c}\text { Training/rights and } \\
\text { responsibilities }\end{array}$ & & & & & $30.85 * * *$ \\
\hline Yes & 110 & 45.26 & 30 & 24.51 & \\
\hline No & 130 & 54.74 & 80 & 75.49 & \\
\hline Met w/school counselor & & & & & $274.80 * * *$ \\
\hline Yes & 150 & 65.52 & 20 & 20.59 & \\
\hline No & 80 & 33.62 & 80 & 78.43 & \\
\hline $\begin{array}{l}\text { Community service } \\
\text { agency staff attend } \\
\text { TPM }\end{array}$ & & & & & $692.89 * * *$ \\
\hline Yes & 110 & 47.84 & 20 & 15.69 & \\
\hline $\begin{array}{l}\text { No } \\
\text { (Table Continues) }\end{array}$ & 110 & 48.71 & 10 & 9.80 & \\
\hline
\end{tabular}


Table 19, Continued

\begin{tabular}{|c|c|c|c|c|c|}
\hline \multirow[t]{3}{*}{ Parent Experiences } & \multicolumn{4}{|c|}{ Parent Attended Transition Planning Meeting } & \multirow[t]{3}{*}{$\chi^{2}$} \\
\hline & \multicolumn{2}{|c|}{ Yes } & \multicolumn{2}{|c|}{ No } & \\
\hline & $n$ & $\%$ & $n$ & $\%$ & \\
\hline Parents invited to TPM & & & & & $692.28 * * *$ \\
\hline Yes & 210 & 90.95 & 20 & 21.57 & \\
\hline No & 20 & 8.19 & $<10$ & 3.92 & \\
\hline $\begin{array}{c}\text { Youth got received info at } \\
\text { TPM }\end{array}$ & & & & & $695.89 * * *$ \\
\hline Yes & 150 & 63.78 & 10 & 11.76 & \\
\hline No & 80 & 32.33 & 10 & 13.73 & \\
\hline $\begin{array}{c}\text { Youth provided input in } \\
\text { IEP \& TP }\end{array}$ & & & & & $724.21 * * *$ \\
\hline Yes & 80 & 35.34 & 10 & 13.73 & \\
\hline No & 150 & 62.93 & 60 & 60.78 & \\
\hline $\begin{array}{l}\text { Youth equal part of } \\
\text { IEP/TP goals }\end{array}$ & & & & & $722.87 * * *$ \\
\hline Yes & 70 & 31.90 & 20 & 14.71 & \\
\hline No & 160 & 66.81 & 60 & 59.80 & \\
\hline
\end{tabular}

Note. $n=$ unweighted frequency was rounded to the nearest 10, per the IES data-reporting requirement. $\%=$ percentage of parents reporting participation (or not) when the independent variable was present. \# Rounds to zero. PS = Postschool, TPM = Transition Planning Meeting, $\mathrm{IEP}=$ Individual Education Program, $\mathrm{TP}=$ Transition Plan. PSAA = Parents Supporting African American Youth with IDD.

Source: National Longitudinal Transition Study 2012 restricted-use data file: Sampling and 2012-2013 survey data (RUF), “Parent Baseline Questionnaire”, U.S. Department of Education, Institute for Education Sciences, National Center for Education Statistics. $* p<.05 . * * p<.01 . * * * p<.001$. 


\section{Association Between Parent Expectations and Parent Involvement}

\section{Homework assistance}

Parents shared their expectations for their youth's post-school adult life. Table 20 presents the association between parent assistance with homework and their expectations after high school. Fifty-five percent of parents reported assisting with homework when the youth was expected to earn a wage that would allow self-sufficiency. Homework assistance was statistically significance when the parent held the belief that the youth's post-educational attainment was beyond high school (43\%) and would live independently found parent involvement (47\%). A statistical significance was found with parent involvement with homework and employment, education, and independent living.

\section{Table 20}

PSAA Youth with IDD Expectations and Homework Assistance

\begin{tabular}{|c|c|c|c|c|c|}
\hline \multirow{3}{*}{ Parent Expectations } & \multicolumn{4}{|c|}{ Homework Assistance } & \multirow{3}{*}{$\chi^{2}$} \\
\hline & \multicolumn{2}{|c|}{ Helped with homework } & \multicolumn{2}{|c|}{ Never } & \\
\hline & $n$ & $\%$ & $n$ & $\%$ & \\
\hline Employment & & & & & $34.05 * * *$ \\
\hline Yes & 320 & 55.79 & 70 & 33.31 & \\
\hline No & 220 & 38.60 & 120 & 61.39 & \\
\hline Education & & & & & $36.95 * * *$ \\
\hline$<$ than High School & 20 & 2.98 & 20 & 8.91 & \\
\hline $\begin{array}{l}\text { High School } \\
\text { Graduate/GED }\end{array}$ & 280 & 48.60 & 130 & 62.38 & \\
\hline $\begin{array}{l}\text { Technical } \\
\text { School/College }\end{array}$ & 250 & 42.98 & 50 & 22.77 & \\
\hline Independent Living & & & & & $20.61 * * *$ \\
\hline Yes & 270 & 47.19 & 60 & 31.19 & \\
\hline No & 280 & 49.30 & 130 & 62.87 & \\
\hline
\end{tabular}


Note. $n=$ unweighted frequency was rounded to the nearest 10, per the IES data-reporting requirement. $\%=$ percentage of parents reporting participation (or not) when the independent variable was present. PSAA $=$ Parents Supporting African American Youth with IDD.

Source: National Longitudinal Transition Study 2012 restricted-use data file: Sampling and 2012-2013 survey data (RUF), "Parent Baseline Questionnaire”, U.S. Department of Education, Institute for Education Sciences, National Center for Education Statistics. ${ }^{*} p<.05 .{ }^{* *} p<.01 .{ }^{* * *} p<.001$.

\section{School Discussion}

Table 21 displays the results of the association between the parents' report of communicating with the youth about school with their expectations for post-school. Fifty-two percent of parents who expected their child to gain employment by age 30 reported discussing school with their youth. Over $90 \%$ of parents who regularly discussed school believed their child would achieve at least a high school diploma. Forty-seven percent of parents who discussed school regularly anticipated that their child would live independently by age 30 . All categories were statistically significant.

\section{Table 21}

PSAA Youth with IDD Expectations and School Discussion

\begin{tabular}{lccccccc}
\hline Parent Expectations & \multicolumn{6}{c}{ Parent Discussed School } & \multirow{2}{*}{$\chi^{2}$} \\
& \multicolumn{2}{c}{ Regularly } & \multicolumn{2}{c}{ Occ/Rarely } & Not at all & \\
\cline { 2 - 6 } & $n$ & $\%$ & $n$ & $\%$ & $n$ & $\%$ & \\
\hline Employment & & & & & & & $21.95^{* *}$ \\
$\quad$ Yes & 300 & 52.26 & 80 & 48.43 & 10 & 22.22 & \\
$\quad$ No & 250 & 43.03 & 70 & 43.40 & 30 & 71.11 & \\
(Table Continues) & & & & & & &
\end{tabular}


Table 21, Continued

\begin{tabular}{|c|c|c|c|c|c|c|c|}
\hline \multirow[t]{3}{*}{ Parent Expectations } & \multicolumn{6}{|c|}{ Parent Discussed School } & \multirow[t]{3}{*}{$\chi^{2}$} \\
\hline & \multicolumn{2}{|c|}{ Regularly } & \multicolumn{2}{|c|}{ Occ/Rarely } & \multicolumn{2}{|c|}{ Not at all } & \\
\hline & $n$ & $\%$ & $n$ & $\%$ & $n$ & $\%$ & \\
\hline Education & & & & & & & $45.99 * * *$ \\
\hline$<$ than High School & 20 & 3.31 & 10 & 5.03 & 10 & 20.00 & \\
\hline $\begin{array}{l}\text { High School Grad/ } \\
\text { GED }\end{array}$ & 290 & 50.70 & 90 & 54.09 & 30 & 64.44 & \\
\hline Tech School/College & 240 & 41.46 & 50 & 31.45 & $<10$ & 8.89 & \\
\hline Independent Living & & & & & & & $36.99 * * *$ \\
\hline Yes & 270 & 47.74 & 60 & 35.22 & 10 & 13.33 & \\
\hline No & 280 & 48.95 & 90 & 55.97 & 40 & 86.67 & \\
\hline
\end{tabular}

Note. $n=$ unweighted frequency was rounded to the nearest 10, per the IES data-reporting requirement. $\%=$ percentage of parents reporting participation (or not) when the independent variable was present. PSAA = Parents Supporting African American Youth with IDD.

Source: National Longitudinal Transition Study 2012 restricted-use data file: Sampling and 2012-2013 survey data (RUF), “Parent Baseline Questionnaire”, U.S. Department of Education, Institute for Education Sciences, National Center for Education Statistics. $* p<.05 . * * p<.01 . * * * p<.001$.

\section{Attended IEP Meeting}

Table 22 presents $48 \%$ of parents who reported attending the IEP meeting also reported expecting their child to gain employment by age 30 . The same percentage of parents who attended the IEP meeting did not expect their child to be gainfully employed by the same age. Parents who attended the IEP meeting reported their youth will attain a high school diploma (53\%) compared to those that did not expect their child to attain a high school diploma or GED (5\%). Fifty-five percent of parents who attended the IEP meeting did not expect their youth to 
live independently by age 30 . Employment and independent living were found to be statistically significant.

Table 22

PSAA Youth with IDD Expectations and Attended IEP Meeting

\begin{tabular}{|c|c|c|c|c|c|}
\hline \multirow{3}{*}{ Parent Expectations } & \multicolumn{4}{|c|}{ Parent Attended IEP Meeting } & \multirow{3}{*}{$\chi^{2}$} \\
\hline & \multicolumn{2}{|c|}{ Yes } & \multicolumn{2}{|c|}{ No } & \\
\hline & $n$ & $\%$ & $n$ & $\%$ & \\
\hline Employment & & & & & $341.90 * * *$ \\
\hline Yes & 310 & 47.96 & 70 & 58.47 & \\
\hline No & 310 & 47.96 & 40 & 34.75 & \\
\hline Education & & & & & 45.99 \\
\hline$<$ than High School & 30 & 5.33 & & & \\
\hline $\begin{array}{l}\text { High School } \\
\text { Graduate/GED }\end{array}$ & 340 & 52.66 & 60 & 54.24 & \\
\hline $\begin{array}{l}\text { Technical } \\
\text { School/College }\end{array}$ & 230 & 36.52 & 50 & 38.14 & \\
\hline Independent Living & & & & & $26.79 * * *$ \\
\hline Yes & 260 & 41.07 & 60 & 46.61 & \\
\hline No & 350 & 55.49 & 50 & 44.92 & \\
\hline
\end{tabular}

Note. $n=$ unweighted frequency was rounded to the nearest 10, per the IES data-reporting requirement. $\%=$ percentage of parents reporting participation (or not) when the independent variable was present. \# Rounds to zero. PSAA = Parents Supporting African American Youth with IDD.

Source: National Longitudinal Transition Study 2012 restricted-use data file: Sampling and 2012-2013 survey data (RUF), "Parent Baseline Questionnaire”, U.S. Department of Education, Institute for Education Sciences, National Center for Education Statistics. ${ }^{*} p<.05 .{ }^{* *} p<.01 .{ }^{* * *} p<.001$. 


\section{Attended Transition Planning Meeting}

As shown in Table 23, 45\% of parents who attended the transition planning meeting also expected their youth to attain employment. Most parents who attended the planning meeting (51\%) expected their youth to earn a high school diploma. Only $40 \%$ of parents expected their youth to live independently and attended the transition planning meeting. Employment was found statistically significant with parents attending the transition planning meeting.

\section{Table 23}

PSAA Youth with IDD Expectations and Attended Transition Planning Meeting

\begin{tabular}{|c|c|c|c|c|c|}
\hline \multirow{3}{*}{ Parent Expectations } & \multicolumn{4}{|c|}{ Parent Attended Transition Planning Meeting } & \multirow[t]{3}{*}{$\chi^{2}$} \\
\hline & \multicolumn{2}{|c|}{ Yes } & \multicolumn{2}{|c|}{ No } & \\
\hline & $n$ & $\%$ & $n$ & $\%$ & \\
\hline Employment & & & & & $26.5180^{* *}$ \\
\hline Yes & 110 & 45.26 & 40 & 37.25 & \\
\hline No & 120 & 51.72 & 60 & 55.88 & \\
\hline \multicolumn{6}{|l|}{ Education } \\
\hline$<$ than High School & 20 & 6.90 & 10 & 5.88 & 13.7707 \\
\hline $\begin{array}{l}\text { High School } \\
\text { Graduate/GED }\end{array}$ & 120 & 51.29 & 60 & 56.86 & \\
\hline $\begin{array}{l}\text { Technical } \\
\text { School/College }\end{array}$ & 90 & 36.64 & 30 & 27.45 & \\
\hline Independent Living & & & & & 6.3667 \\
\hline Yes & 90 & 39.66 & 40 & 36.27 & \\
\hline No & 130 & 56.03 & 60 & 58.82 & \\
\hline
\end{tabular}

Note. $n=$ unweighted frequency was rounded to the nearest 10 , per the IES data-reporting requirement. $\%=$ percentage of parents reporting participation (or not) when the independent variable was present. PSAA = Parents Supporting African American Youth with IDD. Source: National Longitudinal Transition Study 2012 restricted-use data file: Sampling and 2012-2013 survey data (RUF), “Parent Baseline Questionnaire”, U.S. Department of Education, Institute for Education Sciences, National Center for Education Statistics. 
$* p<.05 . * * p<.01 . * * * p<.001$.

\section{Post Hoc Analyses}

Post analyses were performed on all models identified as statistically significant in the chi square testing. The following sections will describe the findings of these analyses for each research question.

\section{Post Hoc Findings between Parent Demographics and Parent Involvement}

The association between parent demographics and involvement were examined in the next sections using post hoc analyses. Table 24 summarizes the results of each model with and without statistical significance between the two variables.

\section{Homework}

Post hoc analyses showed a statistical significance between homework assistance and parent employment status, $\chi^{2}(1, N=780)=5.57, p=0.01$. However, the residual did not meet the 1.96 significance. Marital status, $\chi^{2}(1, N=780)=3.03, p=0.08$ and parent education, $\chi^{2}(1, N=780)=6.52, p=0.16$ were not statistically significant.

\section{School Discussion}

Post hoc testing between parent demographics and school discussion revealed the statistical significance with parents earning more $\$ 80,000$ or more, $\chi^{2}(4, N=780)=16.77, p=$ 0.00 and discussing post school with their youth. Parents with income over $\$ 80,000$ reported occasionally or rarely speaking with their youth about school showed a statistically significance. Parent education level, $\chi^{2}(4, N=780)=10.19, p=0.04$, showed a statistical significance with only parents reporting college level attainment and occasionally talking to their youth meeting 
the 1.96 residual threshold. No statistical residual significance was noted for marital status, $\chi^{2}(1, N=780)=0.11, p=0.73$, and employment status, $\chi^{2}(2, N=780)=4.62, p=0.10$.

\section{Attended IEP Meeting}

Post hoc analysis was conducted on income and education level when considering parent attendance at the IEP meeting. The residual threshold was not met with parents reporting not attending the IEP meeting who held a high school diploma and those with a technical/college education, $\chi^{2}(2, N=780)=18.07, p=0.00$. The income residuals did not show a significance, $\chi^{2}(2, N=780)=4.83, p=0.08$.

\section{Attended Transition Planning Meeting}

No statistical significance associations were noted between parent attendance at the transition planning meeting and parent characteristic. Thus, post hoc analyses were not performed on any models in this section

\section{Table 24}

Post Hoc Findings Between Parent Demographics and Parent Involvement

\begin{tabular}{|c|c|c|c|c|}
\hline Demographics & Homework & $\begin{array}{c}\text { School } \\
\text { discussion }\end{array}$ & Attended IEP & $\begin{array}{c}\text { aPearson Residual } \\
\text { Significance }\end{array}$ \\
\hline Income & - & Significant $^{\mathrm{a}}$ & Not Significant & $\begin{array}{c}\text { Parents } 80 \mathrm{k}+\text { occ/rarely } \\
\text { spoke with youth } \\
\text { about PS }\end{array}$ \\
\hline Employment & Significant & $\begin{array}{c}\text { Not } \\
\text { Significant }\end{array}$ & - & None \\
\hline Marital Status & $\begin{array}{c}\text { Not } \\
\text { Significant }\end{array}$ & $\begin{array}{c}\text { Not } \\
\text { Significant }\end{array}$ & - & None \\
\hline
\end{tabular}

(Table Continues) 
Table 24, Continued

\begin{tabular}{|c|c|c|c|c|}
\hline Demographics & Homework & $\begin{array}{c}\text { School } \\
\text { discussion }\end{array}$ & Attended IEP & $\begin{array}{l}\text { apearson Residual } \\
\text { Significance }\end{array}$ \\
\hline Education & $\begin{array}{c}\text { Not } \\
\text { Significant }\end{array}$ & Significant $^{\mathrm{a}}$ & Significant & $\begin{array}{l}\text { Parents w/college } \\
\text { reported } \\
\text { occasionally/rarely } \\
\text { speaking to their } \\
\text { youth about post } \\
\text { school options }\end{array}$ \\
\hline
\end{tabular}

Note. "- " indicates no significance in the chi square analysis. Models with p-value $<.05$ are

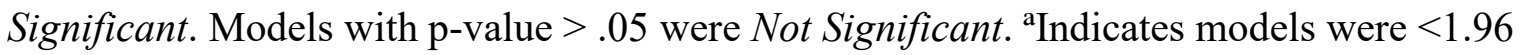

threshold to determine contribution to chi square significance.

Post Hoc Findings between Parent Experiences and Parent Involvement

As shown in Table 25, seven involvement/experiences models were statistically significant in the post hoc analysis. The following sections delineate the findings per parent involvement variable.

\section{Homework Assistance}

Post hoc analysis identified two statistically significant relationships between homework assistance and parent experiences. The first difference related to parents reporting never assisting their youth with homework and meeting with the counselor. The association showed a relationship in both categories, if parents met with the school staff or not, $\chi^{2}(1, N=780)=$ $17.18, p=0.00$. Homework assistance and youth receiving information about post-school were statistically related as well, but the residual did not meet the 1.96 significant threshold, $\chi^{2}(1, N=$ 780) $=4.72, p=0.03$.

\section{School Discussion}

Post hoc analysis showed parents discussing post school plans was significant when meeting with the counselor, $\chi^{2}(2, N=780)=12.96, p=0.00$, but the residual did not meet the 
1.96 threshold. Conversely, youth receiving information during the transition planning meeting, $\chi^{2}(2, N=780)=11.85, p=0.00$, youth was involved in developing goals, $\chi^{2}(2, N=780)=$ $7.51, p=0.02$, or youth participating in the IEP and transition meetings, $\chi^{2}(2, N=780)=$ $7.51, p=0.02$ were determined to be significant. Residual significance was noted in both categories related to the information the youth received and parents not discussing school at all with the student. The greatest contribution was parents reported not discussing school with the student and no information was shared with the youth about life after high school.

\section{IEP Attendance}

Post hoc analyses revealed a statistical significance between parent attended the IEP and parents receiving training on their rights and responsibilities, $\chi^{2}(1, N=780)=32.75, p=0.00$, speaking with the counselor or other staff about career options, $\chi^{2}(1, N=780)=19.28, p=0.00$, were invited to the transition planning meeting, $\chi^{2}(1, N=780)=19.28, p=0.00$, and the youth provided some input in the IEP and transition meeting, $\chi^{2}(1, N=780)=8.11, p=0.00$. The residual analyses identified significance when parents received training but did not attend the meeting; parents met with the counselor but did not attend the meeting; and parents were not invited to the transition planning meeting and did not attend the IEP meeting. The youth providing input did not yield a residual significance.

\section{Transition Planning Meeting Attendance}

Post hoc analyses revealed a statistical significance between parents receiving training on rights and responsibilities but reporting not attending the transition planning meeting, $\chi^{2}(1, N=$ $780)=8.11, p=0.00$. Statistically significant associations were identified between parents 
meeting with school counselor and attending the transition planning meeting, $\chi^{2}(1, N=780)=$ $8.11, p=0.00$. Significance was also noted when students received information about life after high school, $\chi^{2}(1, N=780)=8.11, p=0.00$. The residual significance was found for parents who were trained but reported not attending the transition planning meeting. Moreover, parents who did not meet with the school counselor and reported non-attendance at the transition planning meeting were associated in the analysis. Residual analysis for youth receiving information did not meet the 1.96 threshold of significance.

\section{Post Hoc Findings between Parent Expectations and Parent Involvement}

The following outlines the post hoc analyses conducted on parent expectations and involvement. Table 26 summarizes the findings of significant and non-significant relationships between involvement and expectations.

\section{Homework}

Post hoc analysis found a statistical significance with employment, $\chi^{2}(1, N=780)=$ $32.66, p=0.00$, education, $\chi^{2}(2, N=780)=33.23, p=0.00$, and independent living, $\chi^{2}(1, N=$ $780)=14.16, p=0.00$ and homework support with their youth. Residual significance was found within all categories of employment expectations. High school/GED and tech/college categories were associated with parents never assisting with homework. Parent belief about independent living across both categories was associated with no assistance with homework from family members.

\section{School Discussion}

Post hoc analysis showed statistical significance between school discussion and employment, $\chi^{2}(1, N=780)=15.07, p=0.00$, education, $\chi^{2}(1, N=780)=40.66, p=0.00$, and 
independent living, $\chi^{2}(1, N=780)=24.88, p=0.00$. Related to employment, the residual showed significance between parents who did not discuss school at all, and parents who did and did not expect their youth to be employed by age 30 . Residuals for parents who believed their youth would attain a post-secondary degree and not discussing school was significant. Lastly, a significant relationship between parents who reported expecting and not expecting their youth to live independently and not discussing school was found during the residual analysis.

\section{IEP Attendance}

Post hoc analysis found a statistical significance with employment, $\chi^{2}(1, N=780)=$ $6.05, p=0.01$, however, no residual significance was noted. No statistical significance was found between independent living and parent attendance, $\chi^{2}(1, N=780)=2.63, p=0.11$.

\section{Transition Planning Meeting Attendance}

Post hoc analysis found no statistical significance between employment expectations and parent attendance at the transition planning meeting, $\chi^{2}(1, N=780)=1.20, p=0.27$. 


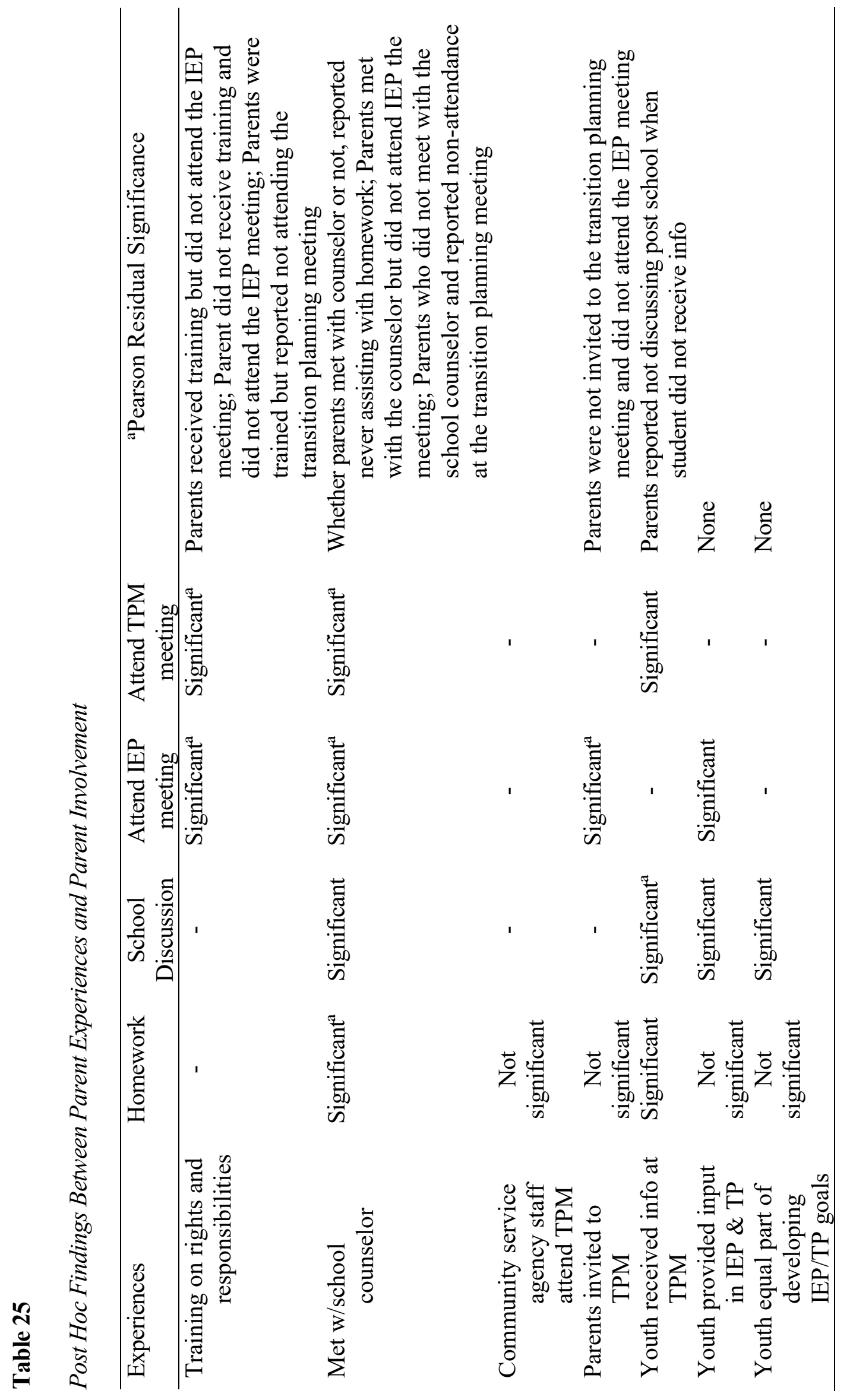




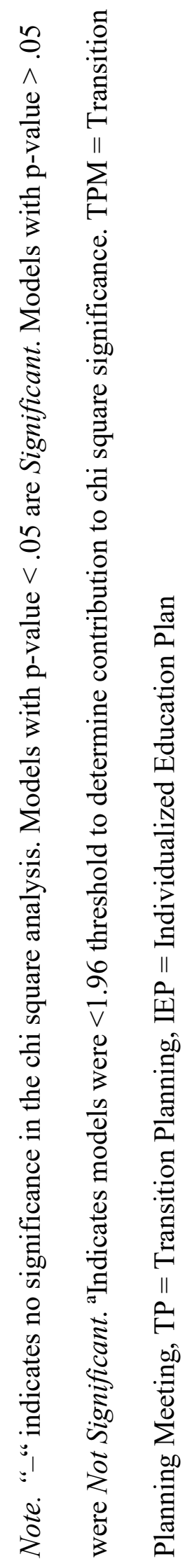




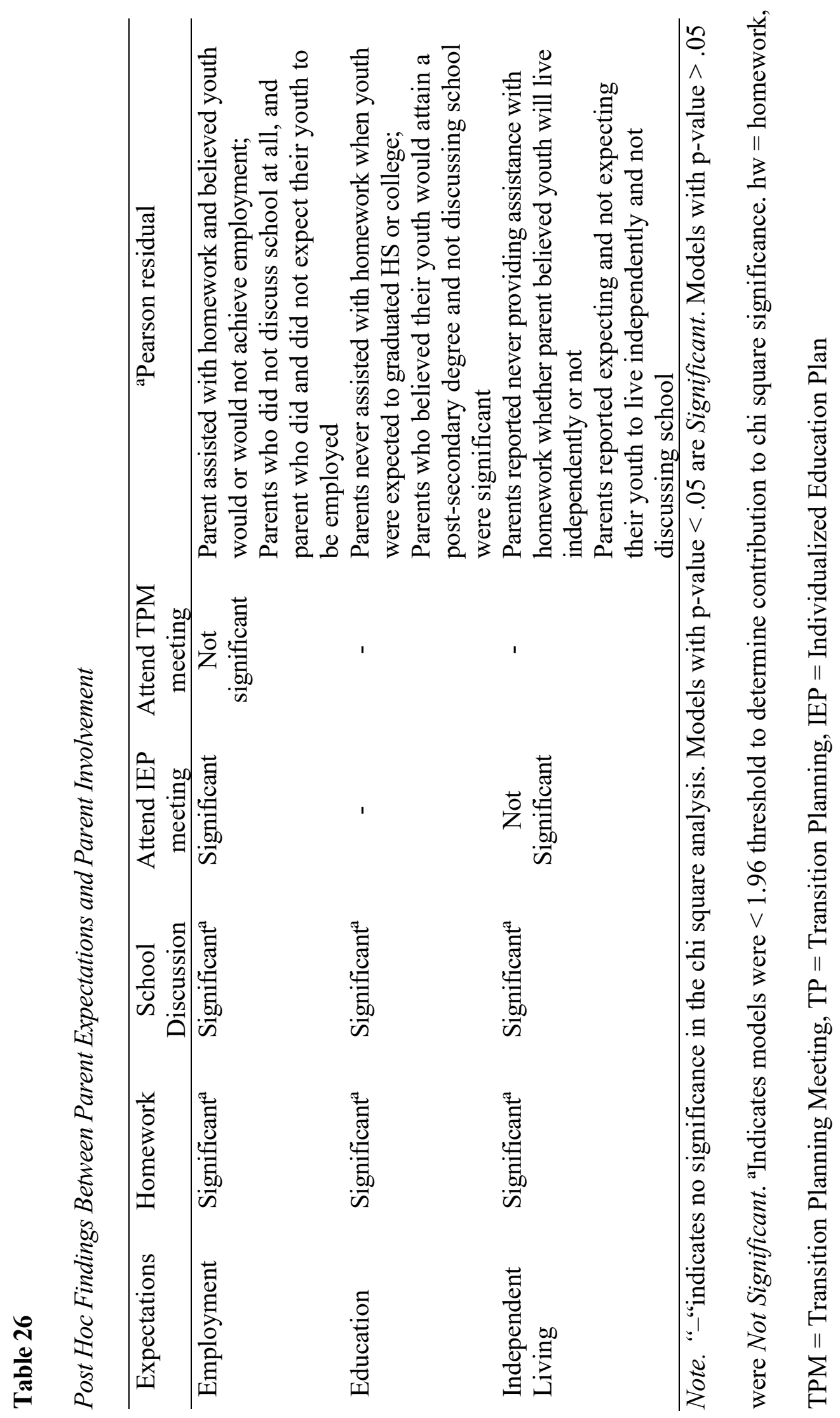




\section{CHAPTER V: DISCUSSION}

Quite often a family is the most consistent member of an IEP team for a student with a disability across educational years, whether present or not at school-based meetings. The role of most parents in their youth's educational career and beyond is lasting, though other team members and support staff change due to life's natural transitions. Parents supporting African American youth with IDD in this study overwhelmingly reported involvement in assisting with homework, discussing school experiences, attending IEP meetings, and attending the transition planning meeting. However, limited research exists on the factors associated with promoting their involvement. Thus, understanding factors associated with involvement of parents of African American youth with IDD could influence partnerships with school staff, leading to increased student success. The NLTS 2012 parent survey responses offered an opportunity to examine relations between parent involvement and factors associated with the secondary transition when considering families supporting African American students with IDD.

In this chapter, I examine how the findings from the association between parent involvement and parent demographics, experiences, and expectations align with existing research. Further, I will discuss the implication for future research, implications for practice, and limitation of this study.

\section{Parent Demographics}

Previous research investigated parental demographics such as parent income and education attainment on youth attending post-school education programs (Chiang et al., 2012). Attributes of parents supporting African American youth with IDD and their involvement in the educational process indicated some interesting associations. In this study, the socioeconomic factors showed that 
families with higher income tended not to discuss post-school options with their student. Also, the educational achievement of parents was related to their discussion about postschool options and parent attendance at the IEP meeting. Parents with higher educational achievement occasionally engaged in conversations with their youth about school.

In my study, attendance at the IEP meeting was noted for parents with higher education. One reason for this finding could be related to the availability of social and economic capital which allows for the recruitment of professionals in the field to have these conversations with the youth. Along with findings in previous studies, this study shows how access to social and economic capital allow for families to negotiate systems to gain services for their youth (Rehm et al., 2013).

Another consideration for parent report of limited discussion with their youth could be the parent's perception of the youth's ability to participate in the process. In prior studies, some parents reported the need to advocate for their youth when they believe the youth could not effectively participate in the process (Francis et al., 2019; Rabren \& Evans, 2016). Exploration of the interrelatedness of the youth's ability and parent involvement was noteworthy, but beyond the scope of this study.

Interestingly, many parents reporting income of less than $\$ 40,000$ showed an emphasis on parent involvement at home. This was especially evident in reports of homework assistance and involvement. The finding supports prior research that found parents with limited income supporting African American students participate in their youth's academic success and are actively involved in the educational process (Abel, 2012; Trotman, 2001). 


\section{Parent Experiences}

The involvement of families supporting African American students with IDD was associated with many experiences through the educational process. Parent actions related to school-based involvement specifically were associated with behaviors initiated by professionals, such as attending district facilitated training, receiving an invitation to attend meetings, and meeting with school counselors.

The findings in this study confirmed findings from prior research that the association between low parent participation when the invitation was not extended by professionals and when training was not provided (Francis et al., 2015). When considering race, Hernandez and colleagues' (2008) exploration of parent involvement found that African American families expressed an overall dissatisfaction with their involvement related to participation in the process. Further, these families reported limited knowledge of their rights in the educational process preventing engagement in advocacy or dispute resolution options when compared with White parents. These factors led to parents questioning if their youth were receiving the services needed to promote success (Hernandez et al., 2008). The association between family involvement and these two factors, invitation from professionals and parent training, show the critical role played by teachers and other educational professionals to stimulate the partnership between home and school confirming previous findings (Anderson \& Minke, 2007; Baker et al., 2016; Francis et al., 2019). Establishing and nurturing relationships is key to increasing involvement in school-based activities (Getzel, 2019).

The focus on connecting families with community agencies through training and contact with professionals most times consists of providing families with information that requires systems 
knowledge to navigate. Specifically, African American families report difficulty locating and accessing services for their youth (Levine et al., 2004). In this study, I found that parents did not attend transition planning meeting even when they received training and met with the counselor. Thus, the efforts to increase parent involvement through training and meetings with school personnel must go beyond just creating a space for families. A call for professionals to intentionally connect families with culturally relevant services and supports that extend passed the educational age is desperately needed to facilitate a meaningful change in the outcomes for African American youth with IDD.

Examination of a parent's perception of inclusiveness in the educational process for parents is important. As shown in this study, parents who were not formally invited to the transition planning meeting did not attend. The clash between parent perception of inclusiveness and experiences with professionals tends to leave parents disengaged in the decision-making process of transition planning at school and prevents the collaboration between all stakeholder (Lalvani, 2012; Wagner et al. 2012).

In this study, the overall findings of experiences with parents supporting African American youth with IDD suggests that parent involvement is present at home, but much work must be done to promote a model of inclusiveness and consideration of African American family's transition activities outside of school.

\section{Parent Expectations}

Parent expectations are consistently associated with successful post-school outcomes (Carter et al., 2012; Chiang et al., 2012; Papay \& Bambara, 2016). Previous examination of parent expectations for their youth with disabilities are linked to parent socioeconomics, educational level, and employment status sounding the alarm to engage parents with lower socioeconomic status (Qian 
et al., 2020). This study adds to the research by examining the association of parent involvement in homebased involvement factors such as homework assistance and discussions about school and parent expectations. Parents supporting youth with IDD were shown to have expectations for successful post-school outcomes and assist with tasks at home which has shown to lead to employment opportunities after high school (Carter et al., 2012). Yet, findings in this study showed their expectations for postschool outcomes did not influence their participation in school-based involvement factor. These findings show high family expectations are related to involvement at home and question the notion that family expectations based on other factors, such as family demographics, influence their desire to participate in school-based activities for this population (e.g., attending meeting; Wagner et al., 2012) as indicated in other studies (Qian et al., 2020).

\section{Implications for Research}

Parent involvement defined in the NLTS 2012 provided insight to parents supporting African American youth with IDD with transition planning. The findings here indicate that parents reported high levels of participation in the measured factors that were identified as predictors or mandated by law. Yet, these youth continue to experience less than successful post school outcomes in all transition measures. The disconnect between parent reports of promoting and implementing transition focused activities and student achievement of successful outcomes illuminates many areas to explore in future studies. In this study, I found many associations between parent involvement and demographic, experiences, and expectations of parents supporting African American youth with IDD. Based on the findings from this study, next steps are to conduct causal analyses for this data set. Using logistic regression, models could determine which factors can predict parent involvement for families 
supporting African American youth with IDD. The results of these analyses could affirm or introduce those practices and activities engaged by families of color that redefine how parent involvement is measured in mainstream research to professionals. Further, a spotlight could be shown on inequitable practices and perceptions inherent in our current systems related to parent involvement of parents supporting African American students.

The findings of this study were limited to the factors identified in the survey for analyses which failed to consider other parent involvement factors specific to youth and families from CLD backgrounds. As with the other longitudinal studies on transition, the NLTS 2012 is used to inform policy at the school, state, and federal level to promote postschool outcomes. With this, future studies of this magnitude must consider frameworks that are culturally sensitive and capture activities valued by the youth, the family, and community overall. One such example of a framework to consider is Yosso's (2005) work on Community Cultural Wealth (CCW). The CCW framework highlights communities of color use of six types of capital to navigate systems, beyond economics. Understanding the use and influence of types of cultural capital employed by families of color through investigations of lived experiences could provide professionals with additional means of access and engagement to include families in the transition process. Again, we must transform the methods used to define and evaluate parent involvement activities in research to truly develop systems of support designed to prepare these youth for adult life.

Another area of opportunity for improving future longitudinal studies on transition centers on parent voice, or advocacy in the transition planning process. While parents reported attending the IEP and transition planning meeting, the national survey did not allow for the exploration of their 
participation in the meeting. Also, the NLTS 2012 parent survey did not include the race of the parent which precluded analyses of parent involvement by African American parents. This missing variable is incredibly important to examine potential differences that may exist between experiences with professionals based on explicit and implicit racial biases because of the race of the parent. As found in previous studies, parents continue to report feelings of being unheard in the educational settings (Hernandez et al., 2008; Lalvani, 2012; Wagner et al., 2012). However, I was unable to examine this perspective in relation to their experiences with the formal transition planning, specifically, analyzing the question of parent versus professional expectations that influence home-school collaboration, student placement, and transition focused activities. A study pairing family values and expectations with staff in-school and post-school expectations for youth with IDD to identify and capitalize on commonalities can be a critical step in developing meaningful strategies which support families and are functional in the school setting.

Finally, the findings in this study were limited in the exploration of CLD family collaboration as defined by family engagement frameworks ( Getzel et al., 2019). Family engagement frameworks theorize that family involvement would increase when professionals intentionally create spaces for the family's voice that promote the integration of what is shared in the planning meeting and implementation of activities and instruction. A study examining the level of family involvement of parents of transition-aged African American students with IDD when staff purposefully seek to hear the family's vision based on their experience with the youth, identify resources using a culturally responsive lens, use cultural mapping strategies to identify 
other resources, and actively embed these assets into the school and classroom daily activities will enhance our understanding of culturally responsive transition planning practices.

\section{Implications for Practices}

Partnerships between home and school are poised to have a significant impact on transition planning for African American students with IDD. Lazar and Slostad (1999) asserted that student achievement is increased when the parent-teacher relationship is intentionally cultivated. My findings suggest several key implications for professionals. First, parent involvement is an untapped asset significant to facilitating transition instruction and activities in school for students of color (Abel, 2012). The trajectory for youth of color is influenced more by family and community over school experiences (Geenan, 2005). Parents in this study overwhelmingly reported having high post-school expectations. Leveraging the positive influence of family participation beyond the development of the IEP should be a priority for professionals to facilitate the students' global self-determination and employment opportunities, exploration of post-school opportunities, and culturally focused quality of life factors. To accomplish this feat, parents should consistently be positioned as a resource for school professionals, beyond infrequent meetings, to understand and culturally embed responsiveness (Baker et al., 2016; Getzel et al., 2019).

Second, research posits the critical benefits of effective communication between team members to maximize support across settings for youth with disabilities (Epstein, 2001; Gerzel-Short et al., 2019). Parent involvement can be influenced by opportunities to engage professionals on a consistent basis as shown with family engagement associations with meetings with school staff. Moreover, systems to capture transition-focused activities and instruction conducted in the home, or 
outside the school setting should be identified and integrated into daily school experiences (Achola, 2019). One impactful strategy in developing these partnerships is implementing two-way, familycentered communications systems. A family-centered communication system is a collaborative tool used to allow families to access school-based instruction and activities experienced by their youth. Further, the system provides an opportunity for families to provide information to schools through secure platforms. Many of these tools exist in the current structure but are not leveraged or maximized. For example, many schools have family portals that interface with teachers and student portals. Training staff on the features of these tools would facilitate the use of an existing communication vehicle to promote dialogue which increases continuity across settings.

Along with effective communication, a third strategy to engage parents is professional development on accessing culturally responsive transition related resources in the community. Although they may have received training and met with counselors, some of the parents in this study did not attend the IEP or transition planning meeting. While culturally responsive transition planning was not a focus in the NLTS 2012 study, understanding the influence of cultural factors on operationally defining successful post-school outcomes could change the narrative for youth of color. As special educators are typically the lead in facilitating the mapping of community resources, it is critical that a shared understanding of diversity-informed resource mapping is conducted during the transition planning process. Diversity informed mapping is an intentional focus on relevant resources for CLD youth (Achola, 2019). The mapping includes linking youth and families with services, support, and other resources in the community that align with individualized needs of the diverse youth (Achola, 2019). A benefit to parent partnership is lived experiences and knowledge of 
community through social, familial, and navigational capital (Yosso, 2005). Using an asset-based lens when leveraging these community resources will provide professionals an opportunity to assist the team with developing an effective, student focused transition plan.

Finally, and perhaps most important, culturally responsive partnerships with parents supporting African American youth with IDD must be the vision for schools and professionals serving youth of color with IDD. Many parents report feelings of being unwelcomed, disrespected, and unheard in the transition process (deFur, 2001). Implementing strategies and policies specifically focused on engaging and respecting families of color could have a tremendous effect on parent relationships and involvement leading to more favorable post-school outcomes for the youth. GerzelShort and colleagues (2019) offered strategies for professionals to assist with increasing family engagement such as (a) asking families how they prefer to be contacted; (b) developing a space which embraces cultural difference among families from diverse backgrounds; (c) seeking information from parents pertaining to relevant family traditions and culture; and (d) acknowledging logistical barriers and challenges, beyond school, which affect families.

\section{Limitations}

The contribution of the findings of this study has the potential to impact research and practices for teachers, administrators, and other stakeholders in promoting parent involvement for families supporting African American youth with IDD in the transition planning process. However, there were limitations that should be noted from the study. The findings reported in this study may be influenced by the collapsing and recoding of the data for analyses. For example, results may have been different if the marital category included "in married-like relationships" in the married category. 
In the findings of this study, significantly less parents reported attending the transition planning meeting versus the IEP meeting due to the skip logic function. However, the parent survey did not ask if the transition planning meeting was conducted at the before the IEP meeting. Many school districts integrate or plan transition meeting before or during the IEP meeting. Hence, parent responses to attending the transition planning meeting would have been different if the survey were designed to investigate the school's system of scheduling meetings.

As mentioned earlier, I was unable to analyze the involvement of African American parents as race was not measured in this study. Thus, I was unable to explore analyses of the influence of factors influencing involvement based on the race of the parent which could have affirmed, or disconfirmed assertions related to experiences and expectations of African American parents and their involvement in transition planning.

\section{Conclusion}

Cultural considerations are oft-times non-existent in traditional transition planning and are sometimes contrary to the families' vision for youths of color (Trainor, 2017). For example, families of color tend to rely on familial and social networks (Yosso, 2005), but traditional transition planning focuses on linkages to social services agencies as mandated by law. The findings of this study showed that parents supporting African American youth with IDD are present and engaged in post-secondary transition planning, especially with home activities.

As an African American parent, researcher, and educator supporting persons with IDD, I often

find myself floating between all the worlds I occupy through my roles. I spend my time advocating for opportunities for those I support because I filter through multiple lenses. Many times, the angst or 
struggle to meet all needs for all stakeholders lie in the need to focus on the end goal for successful post-secondary adult life, which many times is not operationally defined for those with IDD.

Moreover, the question begging to be asked is who operationalizes said goals? The question of "who" leads to the inequalities, I believe, exist in our current systems. These inequalities are both overt and covert, intentional and unintentional. They lie in the space of well-meaning people, ableist, and racist individuals alike, many times leading to families being left to struggle with the results of post-school planning and the youth missing opportunities to thrive in adult life.

In my experiences in these spaces, I have observed parents' efforts being dismissed and disrespected by professionals. Parents are discouraged from pursuing practices and strategies readily accepted by the field of special education that promote post-school success. As a result, parents give up because they feel they are not heard nor is their input valued.

The other side of the pendulum desperately requires exploration. Professionals in the educational systems must understand the balance families supporting youth with IDD engage on a regular basis. Many assume the lack of response from parents, especially parents of color, are willful. Without context, the perspective could be validated using school-based data (e.g., non-participation in school events, meeting attendance, etc.). Issues not considered are the unspoken emotions experienced by the family, other family demands, financial expectations, and navigation of systems outside of school (e.g., medical, social services, etc.) directly related to supporting their youth with disabilities. These measures are typically not considered by school systems lending to the negative narratives of parent involvement. 
We see that parent participation is present, especially outside of the school. School districts, along with other stakeholders, can redefine parent involvement through a culturally responsive lens. Instead of the traditional expectations of parents, the system can truly individualize the experiences of transition planning based on youth and family needs through professional development of transition professionals and administrative staff. Finally, schools must urgently develop actionable goals and objectives with intentionality to support families of youth with IDD to increase access to community in an authentic way. 


\section{REFERENCES}

Abel, Y. (2012). African American fathers' involvement in their children's school-based lives. The Journal of Negro Education, 81(2), 162-172. https://doi.org/10.7709/jnegroeducation.81.2.0162

Achola, E. O. (2019). Practicing what we preach: Reclaiming the promise of multicultural transition programing. Career Development and Transition for Exceptional Individuals, 42(3), 188-193. doi: $10.1177 / 2165143418766498$

Anderson, K., \& Minke, K. (2007). Parent involvement in education: Toward an understanding of parents' decision making. The Journal of Educational Research, 100(5), 311-323. https://doi.org/10.3200/joer.100.5.311-323

Anderson, R. C., Graham, M., Kennedy, P., Nelson, N., Stoolmiller, M., Baker, S. K., \& Fine, H. (2019). Student agency at the crux: Mitigating disengagement in middle and high school. Contemporary Educational Psychology, 56, 205-217.

http://doi.org/10.1016/j.cedpsych.2018.12.005

Baker, T. L., Wise, J., Kelley, G., \& Skiba, R. J. (2016). Identifying barriers: Creating solutions to improve family engagement. School Community Journal, 26, 161-184.

Bloomenthal, A., Haimson, J., Lipscomb, S., Liu, A. Y., Potter, F., \& Waits, T. (2017). National Longitudinal Transition Study 2012 Restricted-use Data File: Sampling and 2012-2013 Survey Data. U. S. Department of Education. 
Burghardt, J., Haimson, J., Lipscomb, S., Liu, A. Y., Potter, F., Waits, T., \& Wang, S. (2017). National Longitudinal Transition Study 2012 Design Documentation. U. S. Department of Education. https://files.eric.ed.gov/fulltext/ED573342.pdf

Carter, E. W., Austin, D., \& Trainor, A. A. (2011). Factors associated with the early work experiences of adolescents with severe disabilities. Intellectual and Developmental Disabilities, 49(4), 233-247. https://doi.org/10.1352/1934-9556-49.4.233

Carter, E. W., Austin, D., \& Trainor, A. A. (2012). Predictors of postschool employment outcomes for young adults with severe disabilities. Journal of Disability Policy Studies, 23(1), 50-63. doi: 10.1177/1044207311414680

Carter, E. W., Bendetson, S., Guiden, C. H., \& Wehman, P. (2018). Family perspectives on the appeals of and alternatives to sheltered employment for individuals with severe disabilities. Research and Practice for Persons with Severe Disabilities, 43 (3), 145-164. doi: $10.1177 / 1540796918778293$

Cawthon, S. W., Garberoglio, C. L., Caemmerer, J. M., Bond, M., \& Wendel, E. (2015). Effect of parent involvement and parent expectations on postsecondary outcomes for individuals who are d/Deaf or Hard of Hearing, Exceptionality, 23:2, 73-99. doi: $10.1080 / 09362835.2013 .865537$

Chiang, H., Cheung, Y., Hickson, L., Xiang, R., \& Tsai, L. Y. (2012). Predictive factors of participation in postsecondary education for high school leavers with autism. Journal of Autism and Developmental Disorders, 42, 685-696. doi:10.1007/s10803-011-1297-7 
Connor, D. J., Ferri, B. A., \& Annamma, S. A. (2016). DisCrit: Disabilities studies and critical race theory in education. Teachers College Press: New York, NY.

Crowson, H. M. (2020). Chi-square test of association (independence) using SPSS: Analysis of GSS data. [Powerpoint slides] Retrieved from https://drive.google.com/open?id=1OmC2vHxcbXVh89bmD3acQtZywyoYQZGq

deFur, S. H., Todd-Allen, M., \& Getzel, E. E. (2001). Parent participation in the transition planningprocess. Career Development for Exceptional Individuals, 24(1), 19-36. doi: https://doi.org/10.1177/088572880102400103

Doren, B., Gau, J. M., \& Lindstrom, L. E. (2012). The relationship between parent expectations and postschool outcomes of adolescents with disabilities. Exceptional Children, 79, 7-23. doi: https://doi.org/10.1177/001440291207900101

Education for All Handicapped Children Act, 20 U.S.C. $§ 1400$ et seq. (1975).

Epstein, J. (1992). Schools and family partnerships. Center on Families, Communities, Schools, and Children's Learning, 1-17. https://files.eric.ed.gov/fulltext/ED343715.pdf

Epstein, J. L. (1995). School/Family/Community partnerships: Caring for the children we share. Phi Delta Kappan, 76(9), 701-712.

Epstein, J. L. (2001). School, family, and community partnerships: Preparing educators and improving schools. Boulder, CO: Westview Press.

Epstein, J. (2005). Attainable Goals? The spirit and letter of the no child left behind act on parental involvement. Sociology of Education, 78(2), 179-182. doi:

https://doi.org/10.1177/003804070507800207 
Fourqurean, J. M., Meisgeier, C., Swank, P. R., \& Williams, R. E. (1991). Correlates of postsecondary employment outcomes for young adults with learning disabilities. Journal of Learning Disabilities, 24(7), 400-405. doi: 10.1177/002221949102400704

*Francis, G. L., Gross, J. M. S., Turnbull, A. P., \& Turnbull, H. R. (2015). An exploratory investigation into family perspectives after the family employment awareness training. Career Development and Transition for Exceptional Individuals, 38(2), 68-77. https://doi.org/10.1177/2165143414528241

*Francis, G. L., Regester, A., \& Reed, A. S. (2019). Barriers and supports to parent involvement and collaboration during transition to adulthood. Career Development and Transition for Exceptional Individuals, 42(4), 235-245. https://doi.org/10.1177/2165143418813912

Galvan, J. L., \& Galvan, M. C. (2017). Writing Literature Reviews: A Guide for Students of Social and Behavioral Sciences. New York, NY: Taylor \& Francis.

Geenen, S., Powers, L. E., \& Lopez-Vasquez, A. (2001). Multicultural aspects of parent involvement in transition planning. The Council for Exceptional Children, 67(2), 265282. https://doi.org/10.1177/001440290106700209

Geenen, S., Powers, L. E., \& Lopez-Vasquez, A. (2005). Barriers against and strategies for promoting involvement of culturally diverse parents in school-based transition planning. Journal for Vocational Special Needs Education, 27(3), 4-14. 
Geenen, S., Powers, L. E., Lopez-Vasquez, A., \& Bersani, H. (2003). Understanding and promoting the transition of minority adolescents. Career Development and Transition for Exceptional Individuals, 26(1), 27-46. doi:

https://doi.org/10.1177\%2F088572880302600103

Gerzel-Short, L., Kiru, E. W., Hsiao, Y.-U., Hovey, K. A., Wei, Y., \& Miller, R. D. (2019). Engaging culturally and linguistically diverse families of children with disabilities. Intervention in School and Clinic, 55(2), 120-126. doi: 10.1177/1053451219837637

Gothberg, J. E., Greene, G., \& Kohler, P. D. (2019). District implementation of research-based practices for transition planning with culturally and linguistically diverse youth with disabilities and their families. Career Development and Transition for Exceptional Individuals, 26(1), 27-46. doi: https://doi.org/10.1177/2165143418762794

Grigal, M., Hart, D., \& Migliore, A. (2011). Comparing the transition planning, postsecondary education, and employment outcomes of students with intellectual and other disabilities. Career Development for Exceptional Individuals, 34(4), 4-17. doi: $10.1177 / 0885728811399091$

Griffin, M. M., McMillan, E. D., \& Hodapp, R. M. (2010). Family perspectives on post-secondary education for students with intellectual disabilities. Education and Training in Autism and Developmental Disabilities, 45(3), 339-346. https://www.jstor.org/stable/23880108

Harry, B., \& Klingner, J. (2006). Why are so many minority students in special education? Understanding race and disability in schools. New York, NY: Teachers College Press. 
*Hetherington, S. A., Durant-Jones, L., Johnson, K., Nolan, K., Smith, E., Taylor-Brown, S., \& Tuttle, J. (2010). The lived experiences of adolescents with disabilities and their parents in transition planning. Focus on Autism and Other Developmental Disabilities, 25(3), 163-172. https://doi.org/10.1177/1088357610373760

Hernandez, J. E., Harry, B., Newman, L., \& Cameto, R. (2008). Survey of family involvement in and satisfaction with the Los Angeles Unified School District special education processes. Journal of Special Education Leadership, 21(2), 84-93.

Hirano, K. A., Rowe, D., Lindstrom, L., \& Chan, P. (2018). Systemic barriers to family involvement in transition planning for youth with disabilities: A qualitative metasynthesis. Journal of Child and Family Studies, 27(11), 3440-3456. https://doi.org/10.1007/s10826-018-1189-y

Howell, D. C. (2011). Chi-square test: Analysis of contingency tables. Retrieved from https://www.uvm.edu/ statdhtx/StatPages/R/Chi-SquareFolder/Chi\%20square $\% 20$ test $\% 20$ analysis $\% 20$ of $\% 20$ contingency $\% 20$ tables_David_How ell\%20.pdf

Individuals with Disabilities Education Act Amendments of 1997, 20 U.S.C. $\S 1415$ et seq. (1997).

Individuals with Disabilities Education Improvement Act of 2004, 20 U.S.C. $§ 1400$ et seq. (2004). 
Jasper, A. D., \& Bouck, E. C. (2013). Disproportionality among African American students at the secondary level: Examining the MID disability category. Education and Training Autism and Developmental Disabilities, 48(1), 31-40.

Jeynes, W. H. (2007). The Relationship Between Parental Involvement and Urban Secondary School Student Academic Achievement. Urban Education, 42(1), 82-110. doi:10.1177/0042085906293818

Johnson, D. R. (2012). Policy and adolescent transition education. In M. L. Wehmeyer \& K. W. Webb (Eds.), Handbook of Adolescent Transition Education for Youth with Disabilities. (1st ed., pp. 11-31). New York, NY: Routledge.

Johnson, D. R., Thurlow, M. L., Wu, Y-C., LaVelle, J. M., \& Davenport, E. C. (2020). IEP/transition planning participation among students with the most significant cognitive disabilities: Findings from NLTS 2012. Career Development and Transition for Exceptional Individuals, 43(4) 226-239. doi: 10.1177/2165143420952050

Ju, S., Zhang, D., \& Landmark, L. J. (2018). Culturally and linguistically diverse family involvement in transition planning: A research synthesis. Journal of Special Education Leadership, 31(1), 16-26.

Katsiyannis, A., Yell, M. L., \& Bradley, R. (2001). Reflections on the $25^{\text {th }}$ anniversary of the individuals with disabilities education act. Remedial and Special Education, 22(6), 324334. https://doi.org/10.1177\%2F074193250102200602 
Kim, K.-H., \& Morningstar, M. E. (2005). Transition planning involving culturally and linguistically diverse families. Career Development for Exceptional Individuals, 28(2), 92-103. doi: https://doi.org/10.1177/08857288050280020601

Knapp, H. (2018). Intermediate Statistics Using SPSS. Thousand Oaks, CA: Sage Publication Inc.

Kohler, P. D. (1996). Taxonomy for transition programming: Linking research and practice. Champaign: University of Illinois at Urbana-Champaign, Transition Research Institute.

Kohler, P. D., Gothberg, J. E., Fowler, C., \& Coyle, J. (2016). Taxonomy for transition programming 2.0: A model for planning, organizing, and evaluating transition education, services, and programs. Western Michigan University. Available at www.transitionta.org.

Landmark, L. J., Zhang, D., \& Montoya, L. (2007). Culturally diverse parents' experiences in their children's transition: Knowledge and involvement. Career Development and Transition for Exceptional Individuals, 30(2), 68-79. doi:

https://doi.org/10.1177/08857288070300020401

Landmark, L. J., Roberts, E. L., \& Zhang, D. (2012). Educators' beliefs and practices about parent involvement in transition planning. Career Development and Transition for Exceptional Individuals, 36(2), 114-123. doi:

https://doi.org/10.1177\%2F2165143412463047 
Lalvani, P. (2012). Parents' participation in special education in the context of implicit educational ideologies and socioeconomic status. Education and Training in Autism and Developmental Disabilities, 47(4), 474-486.

Lazar, A., \& Slostad, F. (1999). How to overcome obstacles to parent-teacher partnerships. The Clearing House, 72(4), 206-210. doi: 10.1080/00098659909599393

Levine, P., Marder, C., \& Wagner, M. (2004). Services and supports for secondary school students with disabilities: A special topic report of findings from the National Longitudinal Transition Study-2 (SRI project P11182). Office of Special Education Programs, U. S. Department of Education. https://files.eric.ed.gov/fulltext/ED496552.pdf

Lipscomb, S., Haimson, J., Liu, A. Y., Burghardt, J., Johnson, D. R., \& Thurlow. (2017). Preparing for life after high school: The characteristics and experiences of youth in special education. Findings from the National Longitudinal Transition Study 2012. Volume 1: Comparisons with other youth (Full report) (NCEE 20174016). Department of Education, Institute of Education Sciences, National Center for Education Evaluation and Regional Assistance. https://ies.ed.gov/ncee/pubs/20174016/pdf/20174016.pdf 
Lipscomb, S., Haimson, J., Liu, A. Y., Burghardt, J., Johnson, D. R., \& Thurlow. (2017). Preparing for life after high school: The characteristics and experiences of youth in special education. Findings from the National Longitudinal Transition Study 2012.

Volume 2: Comparisons across disability groups (Full report) (NCEE 20174018).

Department of Education, Institute of Education Sciences, National Center for Education Evaluation and Regional Assistance.

https://ies.ed.gov/ncee/pubs/20174016/pdf/20174018.pdf

Liu, A. Y., Lacoe, J., Lipscomb, S., Haimson, J., Johnson, D. R., \& Thurlow, M. L. (2018). Preparing for life after high school: The characteristics and experiences of youth in special education. Findings from the National Longitudinal Transition Study 2012. Volume 3: Comparisons over time (Full report) (NCEE 20184007). Department of Education, Institute of Education Sciences, National Center for Education Evaluation and Regional Assistance. https://ies.ed.gov/ncee/projects/evaluation/disabilities_nlts2012.asp.

*Lo, L., \& Bui, O. (2020). Transition planning: Voices of Chinese and Vietnamese parents of youth with autism and intellectual disabilities. Career Development and Transition for Exceptional Individuals, 43(2), 89-100. https://doi.org/10.1177/2165143419899938

Martinez, D. C., Conroy, J. W., \& Cerreto, M. C. (2012). Parent involvement in the transition process of children with intellectual disabilities: The influence of inclusion on parent desires and expectations for postsecondary education. Journal of Policy and Practice in Intellectual Disabilities, 9(4), 279-288. doi: https://doi.org/10.1111/jppi.12000 
Mazzotti, V. L., Rowe, D. A., Kelly, K. R., Test, D. W., Fowler, C. H., Kohler, P. D., \& Kotering, L. J. (2009). Linking transition assessment and postsecondary goals. Teaching Exceptional Children, 42(2), 44-51. doi: https://doi.org/10.1177/004005990904200205

Mazzotti, V. L., Rowe, D. A., Kwiatek, S., Voggt, A., Chang, W.-H., Fowler, C. H., Poppen, M., Sinclair, J., \& Test, D. W. (2021). Secondary transition predictors of postschool success: An update to the research base. Career Development and Transition for Exceptional Individuals, 44(1) 47-64. https://doi.org/10.1177/21651434209597

Mazzotti, V. L., Rowe, D. A., Sinclair, J., Poppen, M., Woods, W. E., \& Shearer, M. L. (2016). Predictors of Post-school Success: A Systematic Review of NLTS2 Secondary Analyses. Career Development and Transition for Exceptional Individuals, 39(4), 196-215. doi: $10.1177 / 2165143415588047$

National Institutes of Health. (2016). Intellectual and developmental disabilities (IDDs): Condition information. https://www.nichd.nih.gov/health/topics/idds/conditioninfo/default

Newman, L. (2005). Family involvement in the educational development of youth with Disabilities. A special topic report of findings from the national longitudinal transition study-2 (NLTS2). Menlo Park, CA: SRI International.

Newman, L., Wagner, M., Cameto, R., Knokey, A.-M., \& Shaver, D. (2010). Comparison across time of the outcomes of youth with disabilities up to 4 years after high school. A report of findings from the National Longitudinal Transition Study (NLTS) and the National Longitudinal Transition Study-2 (NLTS2). Menlo Park, CA: SRI International. 
No Child Left Behind Act of 2001. P.L.107-110, 115 stat. 1425. (2001).

Papay, C. K., \& Bambara, L. M. (2014). Best practices in transition to adult life for youth with intellectual disability. Career Development and Transition for Exceptional Individuals, 37,136-148. doi:10.1177/2165143413486693

Qian, X., Johnson, D. R., Wu, Y. C., LaVelle, J., Thurlow, M. L., \& Davenport, E. (2020). Parents' postsecondary education expectations for students with autism, intellectual disability, and multiple disabilities: Findings from NLTS 2012. Research and Practice for Persons with Severe Disabilities, 45(4), 256-270. doi: 10.1199/1540796920962423

*Rabren, K., \& Evans, A. M. (2016). A Consensual Qualitative analysis of parental concerns and strategies for transition. Journal of Vocational Rehabilitation, 44(3), 307-321. https://doi.org/10.3233/JVR-160801

*Rehm, R. S., Fisher, L. T., Fuentes-Afflick, E., \& Chesla, C. A. (2013). Parental advocacy styles for special education students during the transition to adulthood. Qualitative Health Research, 23(10), 1377-1387. https://doi.org/10.1177/1049732313505915

Rowe, D. A., Alverson, C. Y., Unruh, D. K., Fowler, C. H., Kellems, R., \& Test, D. W. (2015). A Delphi study to operationalize evidence-based predictors in secondary transition. Career Development and Transition for Exceptional Individuals, 38(2), 113-126. https://doi.org/10.1177/2165143414526429

Saldaña, J. (2016). The Coding Manual for Qualitative Researchers. Thousand Oaks, CA: Sage. 
Test, D. W., Mazzotti, V. L., Mustian, A. L., Fowler, C. H., Kortering, L., \& Kohler, P. (2009). Evidence-based secondary transition predictors for improving postschool outcomes for students with disabilities. Career Development for Exceptional Individuals, 32(3), 160181. doi: $10.1177 / 0885728809346960$

Trainor, A. A. (2008). Using cultural and social capital to improve postsecondary outcomes and expand transition models for youth with disabilities. The Journal of Special Education, $42(3), 148-162$

Trainor, A. A. (2017). Transition by Design. New York, NY: Teacher College Press.

Trotman, M. F. (2001). Involving the African American parent: Recommendations to increase level of parent involvement within African American Families. Journal of Negro Education, 275-285. http://www.jstor.org/stable/3211280

Wagner, M., Newman, L., Cameto, R., Javitz, H., \& Valdes, K. (2012). A national picture of parent and youth participation in IEP and transition planning meetings. Journal of Disability Policy Studies, 23(3) 140 - 155. doi: 10.1177/1044207311425384

Wagner, M. M., Newman, L. A., \& Javitz, H. S. (2014). The influence of family socioeconomic status on the post-high school outcomes of youth with disabilities. Career Development and Transition for Exceptional Individuals, 37(1), 5-17. doi: 10.1177/2165143414523980 Williams, T. T., \& Sanchez, B. (2011). Identifying and decreasing barriers to parent involvement for inner-city parents. Youth \& Society, $X X(X), 1-21$. doi: 10.1177/0044118X11409066 
Yell, M. L., Rogers, D., \& Rogers, E. L. (1998). The legal history of special education: What a long, strange trip it's been! Remedial and Special Education, 19(4), 219-228. https://doi.org/10.1177/074193259801900405

*Young, J., Morgan, R. L., Callow-Heusser, C. A., \& Lindstrom, L. (2016). The effects of parent training on knowledge of transition services for students with disabilities. Career Development and Transition for Exceptional Individuals, 39(2), 79-87. https://doi.org/10.1177/2165143414549207

Yosso, T. J. (2005). Whose culture has capital? A critical race theory discussion of community cultural wealth. Race Ethnicity and Education, 8, 69-91. doi:10.1080/1361332052000341006

Zionts, L. T., Zionts, P., Harrison, S., \& Bellinger, O. (2003). Urban African American families' perceptions of cultural sensitivity within the special education system. Focus on Autism and Other Developmental Disabilities, 18, 41-50. doi:10.1605/01.301-0006628826.2009 


\section{APPENDIX: QUESTIONS SELECTED FROM THE NLTS 2012 PARENT SURVEY}

\section{Parent involvement at home}

During this school year, how often did you or another adult in the household help $\{$ YOUTH $\}$ with $\{$ his/her $\}$ homework? Would you say...

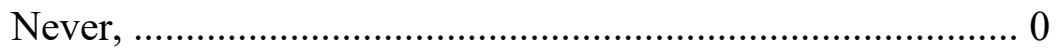

Less than once a week, ....................................................... 1

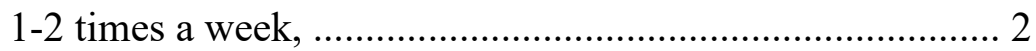

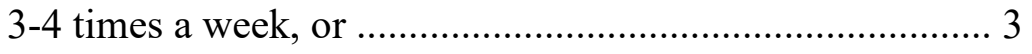

5 or more times a week? ............................................... 4

Adults differ in how much they talk to children about school. During this school year, did you or another adult in the household talk with $\{$ YOUTH $\}$ about $\{$ his/her $\}$ experiences in school?

Would you say...

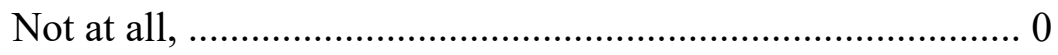

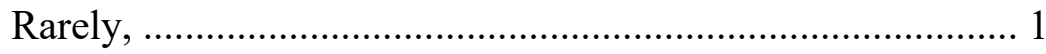

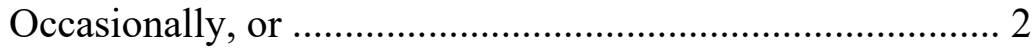

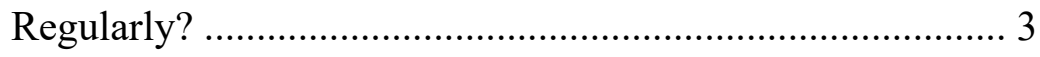




\section{Parent involvement at school}

During this or last school year, did you or another adult in the household go to a meeting about an Individualized Education Program, or IEP, for \{YOUTH'S\} special education pro-gram or services?

IF NEEDED: That is, during the 2011-2012 or the 2012-2013 school years.

YES 1

$\mathrm{NO}$ 0

Did \{you/NAME of youth $\}$ meet with adults at school to set goals for what $\{$ you/he/she $\}$ will do after high school and make a plan for how to achieve them? Sometimes this is called a transition plan. YES 1

$\mathrm{NO}$ 0

\section{Parent Demographics}

What was your total household income from all sources before taxes and deductions in calendar year $\{2011 / 2012\}$ ? Please include all income such as income from work, investments, money from public assistance, retirement, and alimony for all household members, before taxes.

$\$ 20,000$ or less, or 1

$\$ 20,001$ to $\$ 40,000$, 2

$\$ 40,001$ to $\$ 60,000, \ldots \ldots \ldots \ldots \ldots \ldots \ldots \ldots \ldots \ldots \ldots \ldots \ldots \ldots \ldots \ldots \ldots \ldots \ldots \ldots \ldots \ldots . . .3$

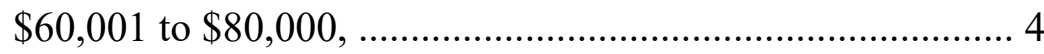


$\$ 80,001$ to $\$ 100,000$, 5

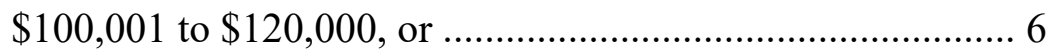

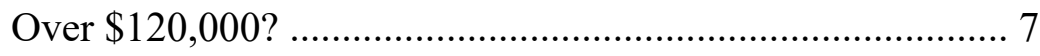

Are you...

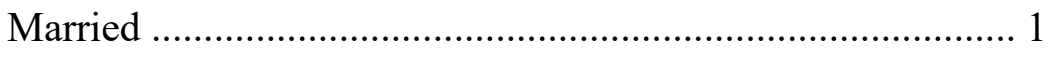

In a marriage-like relationship........................................... 2

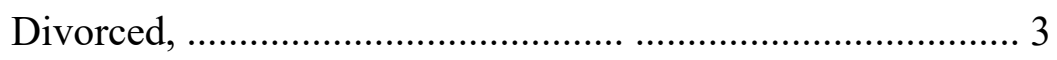

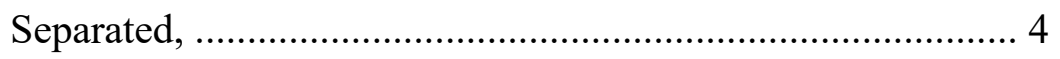

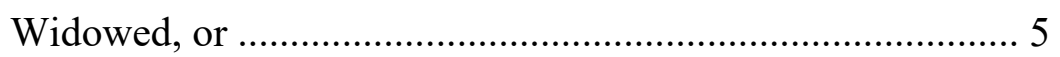

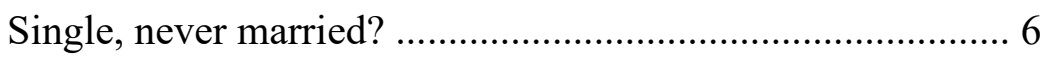

What is the highest year or grade you finished in school?

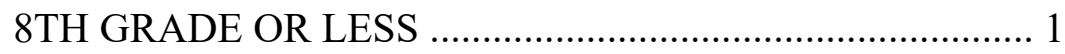

9TH GRADE OR ABOVE, NOT A HIGH SCHOOL GRADUATE......... 2

HIGH SCHOOL GRADUATE OR GED …………………..... 3

POST HIGH SCHOOL EDUCATION, NO COLLEGE DEGREE...................... 4

VOCATIONAL-TECHNICAL (VOC-TECH) DEGREE OR CERTIFICATE ......... 5

2-YEAR COLLEGE DEGREE/AA DEGREE ............................ 6

4-YEAR COLLEGE DEGREE/BA, BS DEGREE ………….... 7

SOME POST BA, BS WORK, NO GRADUATE DE-GREE ........................ 8 
MASTER'S DEGREE, E.G. MSW, MA, MFA, MPH, MBA 9

PHD, MD, JD, LLB, OR OTHER PROFESSIONAL GRADUATE DEGREE ..........10

OTHER (SPECIFY) 99

Do you have a paid job now?

YES

1

$\mathrm{NO}$ 0

\section{Parent/Youth Experiences}

As $\{$ YOUTH $\}$ 's parent or guardian, did you receive any classes or counseling on [YOUTH]'s rights and responsibilities under disability-related laws during this school year?

YES 1

NO 0

Have you talked with a school counselor or someone else at school about what $\{$ YOUTH $\}$ might do after high school, including education or career options?

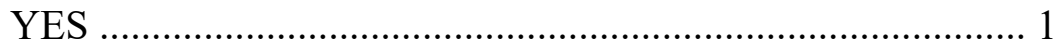

NO

Did staff from any community service agency, such as vocational rehabilitation services, take part in that meeting?

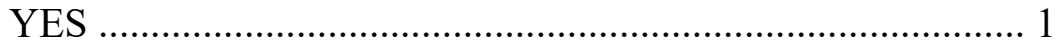


Were you invited to the transition meeting:

YES 1

$\mathrm{NO}$ 0

Was [YOUTH] given information on education, careers, or community living options for when $\{$ he/she $\}$ leaves high school?

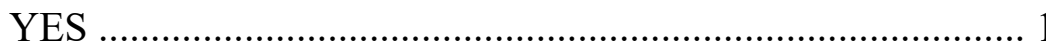

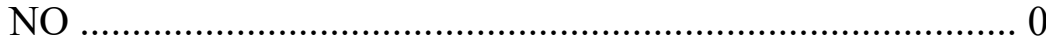

Which of the following best describes $\{$ YOUTH'S $\}$ role in $\{$ his/her $\}$ IIEP and transition planning/IEP planning\}?

$\{\mathrm{He} / \mathrm{She}\}$ did not participate 1

$\{\mathrm{He} / \mathrm{She}\}$ was present in discussions but participated very little or not at all 2

$\{$ He/She $\}$ provided some input ..................................... 3

$\{\mathrm{He} / \mathrm{She}\}$ took a leadership role (helping set the direction of the discussions, goals, and plans) .... 4

DOESN'T KNOW ABOUT ANY GOALS 5 
Did the school mostly come up with the goals on $\{$ his/her IEP \{and transition plan $\}$ or was it mostly you or $\{$ YOUTH $\}$ who came up with the goals?

MOSTLY SCHOOL 1

MOSTLY RESPONDENT OR OTHER ADULT 2

MOSTLY YOUTH 3

SCHOOL AND YOUTH EQUALLY.... 4

SCHOOL AND RESPONDENT OR OTHER ADULT EQUALLY 5

YOUTH AND RESPONDENT OR OTHER ADULT EQUALLY

6

SCHOOL, RESPONDENT OR OTHER ADULT, AND YOUTH EQUALLY

\section{Parent Expectations}

By the time $\{$ YOUTH $\}$ is 30 years old, how likely do you think it is that $\{$ YOUTH $\}$ will earn enough to support $\{$ himself/herself $\}$ without financial help from $\{$ his/her $\}$ family or government benefit programs? Do you think $\{$ he/she $\} \ldots$

Definitely will, .............................................................. 1

Probably will, ............................................................ 2

Probably won't, or ................................................... 3

Definitely won't? ...................................................... 4 
As things stand now, how far do you think $\{$ YOUTH $\}$ will get in school?

IF NEEDED: What is the highest level of schooling you think \{he/she\} will complete?

Select high school diploma or GED for a certificate of completion or attendance.

LESS THAN HIGH SCHOOL (WILL NOT GRADUATE OR GET GED............................... 1

HIGH SCHOOL DIPLOMA OR GED …………………….... 2

TECHNICAL OR TRADE SCHOOL ……………………..... 3

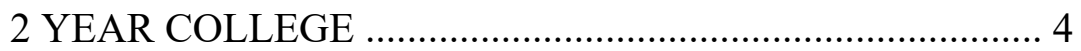

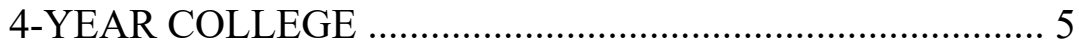

MASTER'S, PHD, OR OTHER ADVANCED DEGREE ............. 6

When $\{$ YOUTH $\}$ is 30 years old, do you think $\{$ he/she $\}$ will be living:

On (his/ her) own - without friends or family, .................... 1

At home with parents, ................................................. 2

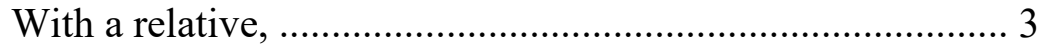

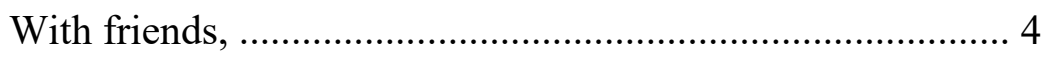

With a spouse or partner, ................................................ 5

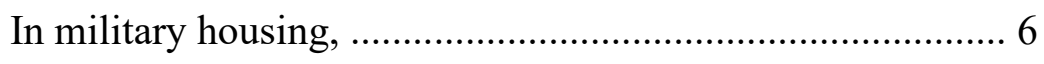

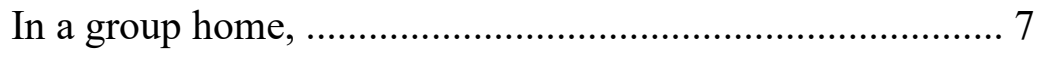

In an institution, or .............................................................. 8

Some other place? (SPECIFY) ............................................ 99

*Assisted living facility .................................................. 9

*Living on his/her own in housing with professional assistance ................. 10 